Florida International University FIU Digital Commons

\title{
A Confluence of Invasion, Behavioral, and Theoretical Ecology: What Drives Ephemeral Metacommunity Re-assembly?
}

Jesse Ryan Blanchard

Florida International University, blanchje@fiu.edu

DOI: $10.25148 /$ etd.FIDC006532

Follow this and additional works at: https:// digitalcommons.fiu.edu/etd

Part of the Behavior and Ethology Commons, Biology Commons, and the Other Animal Sciences Commons

\section{Recommended Citation}

Blanchard, Jesse Ryan, "A Confluence of Invasion, Behavioral, and Theoretical Ecology: What Drives Ephemeral Metacommunity Reassembly?" (2018). FIU Electronic Theses and Dissertations. 3651.

https://digitalcommons.fiu.edu/etd/3651 


\title{
FLORIDA INTERNATIONAL UNIVERSITY
}

\author{
Miami, Florida
}

A CONFLUENCE OF INVASION, BEHAVIORAL

AND THEORETICAL ECOLOGY:

\section{WHAT DRIVES EPHEMERAL METACOMMUNITY RE-ASSEMBLY?}

\author{
A dissertation submitted in partial fulfillment of the \\ requirements for the degree of \\ DOCTOR OF PHILOSOPHY
}

In

EARTH SYSTEMS SCIENCE

by

Jesse Ryan Blanchard

2018 
To: Dean Michael R. Heithaus

College of Arts, Sciences and Education

This dissertation, written by Jesse Ryan Blanchard, and entitled A Confluence of Invasion, Behavioral and Theoretical Ecology: What Drives Ephemeral Metacommunity Re-assembly? having been approved in respect to style and intellectual content, is referred to you for judgement.

We have read this dissertation and recommend that it be approved.

John Kominoski

$\begin{array}{r}\hline \text { Hong Liu } \\ \hline \text { Phillip Stoddard } \\ \hline \text { Michael Ross } \\ \hline \text { Jennifer Rehage, Major Professor }\end{array}$

Date of defense: March 30, 2018

The dissertation of Jesse Ryan Blanchard is approved.

Dean Michael R. Heithaus
College of Arts, Sciences and Education

Florida International University 2018 
(C) Copyright 2018 by Jesse Ryan Blanchard

All rights reserved. 


\section{DEDICATION}

I would like to dedicate this dissertation to my parents, Jeffery and Theresa Blanchard, who gave me the work ethics needed and the support necessary to accomplish my goals. Without their lifelong support of my decision to pursue this degree, I never would have gotten this far. I owe all past, present, and future accomplishments to them. 


\section{ACKNOWLEDGMENTS}

I wish to thank the members of my dissertation committee who, through their support, patience and advice, facilitated the work detailed in this dissertation. In particular, I need to thank Dr. Jennifer Rehage for giving me the intellectual freedom to develop this work in a way that diverged from the typical focus of her lab, thereby allowing me to develop my unique niche within ecology. Also, none of this work would have been possible without the support of the department of the Earth and Environment. Through my teaching assistantship, Seema Sah's efforts to minimize the impact of teaching requirements on my dissertation schedule removed many potential impediments and allowed me to accomplish more than I would have been able to otherwise. Similarly, Gail Excell provided essential and timely logistical support throughout the process. Additionally, the historic data used in Chapter II graciously provided by Dr. W. Loftus and Dr. M. Kobza were critical contributions toward that component of the research, as was the advice and assistance of Jeff Kline with the National Park Service and Pam Schofield with the United States Geological Survey. The field component of this dissertation relied heavily on the time, sweat and good nature of over twenty incredible field volunteers, without whom the scope of those data would have been severely reduced. Finally, Alejandra Blanchard's moral and logistical support of my dissertation from conception to completion was an invaluable resource which cannot be overstated. 


\begin{abstract}
OF THE DISSERTATION
A CONFLUENCE OF INVASION, BEHAVIORAL, AND THEORETICAL ECOLOGY:

WHAT DRIVES EPHEMERAL METACOMMUNITY RE-ASSEMBLY?
\end{abstract}

by

Jesse Ryan Blanchard

Florida International University, 2018

Miami, Florida

\title{
Professor Jennifer S. Rehage, Major Professor
}

Metacommunity theory has been particularly useful in understanding the way spatially structured communities assemble. Both niche and neutral processes are known to influence metacommunity assembly, and the relative influence of each depends on the level of dispersal-limitation. Contemporary trait-based analyses of metacommunity assembly have enhanced our understanding of these processes. Of the traits investigated, individual personalities have received the least attention, but have been suggested to be drivers of metacommunity assembly model parameters, such as dispersal tendencies and patch density. I address this topic from three angles, three chapters, in this dissertation. First, I used a three-year field survey of fish metacommunity assembly in Everglades National Park to investigate the influence of dispersal-limitation on trait-based metacommunity assembly, asking which traits were important under different levels of dispersal-limitation. I found that the relative influence of traits and local environmental factors decreased, and the influence of regional factors increased with increasing 
dispersal-limitation. The Rocky Glades has recently been invaded by a micropiscivore with many novel traits, the African Jewelfish. In the second chapter I used my field data to ask what influence this invader has on metacommunity assembly. Overall, African Jewelfish abundance was the third most influential factor in driving assembly. I also used data, which were previously collected by collaborators, from three years prior and two years following the invasion to observe shifts in assembly rules. Assembly became significantly more aggregative immediately following the invasion, a condition which persisted more than a decade later. All previous studies asking the same question, found the same result: invasive introductions correspond with increased species aggregation. This may be a consistent, taxa-independent signal of truly invasive species that can be detected early in the invasion process, making it a potentially useful management tool after further empirical review. In the final chapter, I investigate the potential influence of individual personalities on a metapopulation's structure. To do this, I used a behavioral individual-based model to explore the influence of sociability, an individual's propensity to associate with conspecifics, on metapopulation structure at ecologically relevant spatiotemporal scales. I found that individual sociability can significant influence key metapopulation parameters such as dispersal distance and patch density but may not influence landscape occupation. Chapter three concludes with new hypothesis to be evaluated by future field studies. Overall, this dissertation demonstrates the relative roles of invasions, species traits, and individual personalities on metacommunity assembly processes. 


\section{TABLE OF CONTENTS}

CHAPTER

PAGE

INTRODUCTION

1

I. TRAIT BASED RE-ASSEMBLY: WHAT DRIVES

EPHEMERAL METACOMMUNITY RE-ASSEMBLY?.................. 6

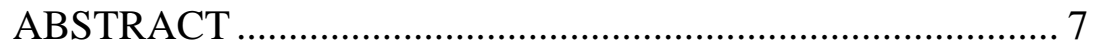

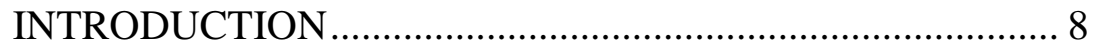

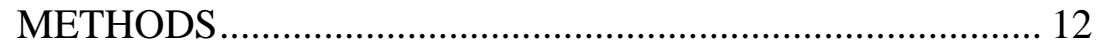

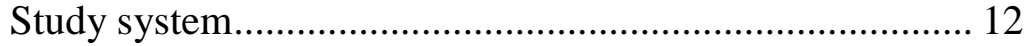

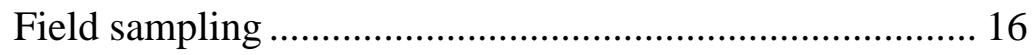

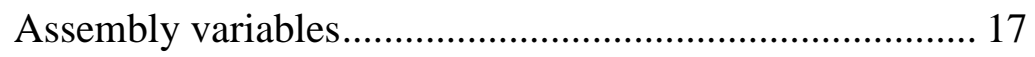

Statistical Analyses...................................................... 23

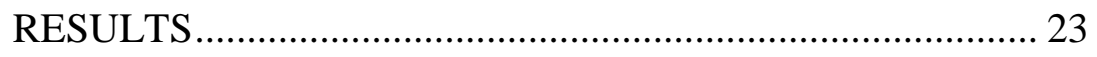

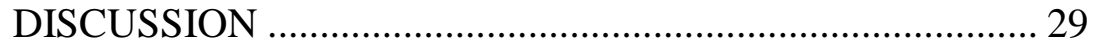

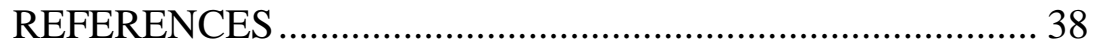

II. INVASIVE SPECIES AGGREGATE ASSEMBLING

METACOMMUNITIES ............................................................ 45

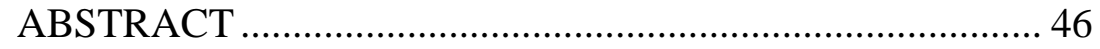

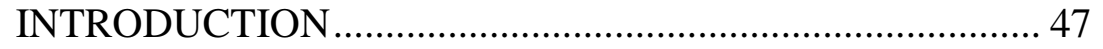

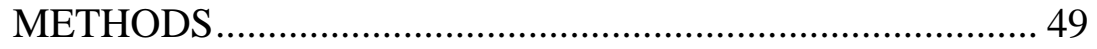

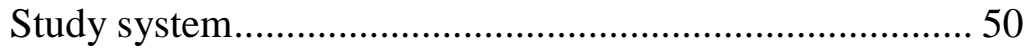

Community sampling ............................................... 51

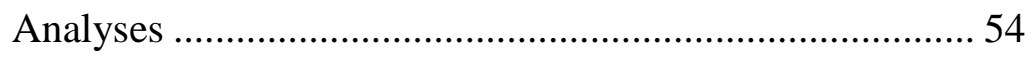

Literature-review ....................................................... 56

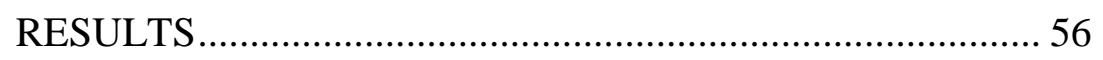

African Jewelfish invasion .............................................. 56

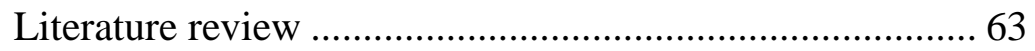

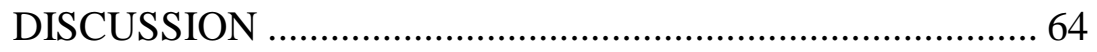

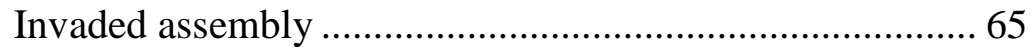

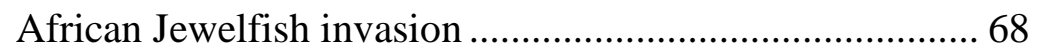

Conclusion............................................................... 70 
III. CAN INDIVIDUAL PERSONALITIES STRUCTURE DISPERSAL LIMITED METAPOPULATIONS AT ECOLOGICALLY RELEVANT SPATIOTEMPORAL SCALES? . 77

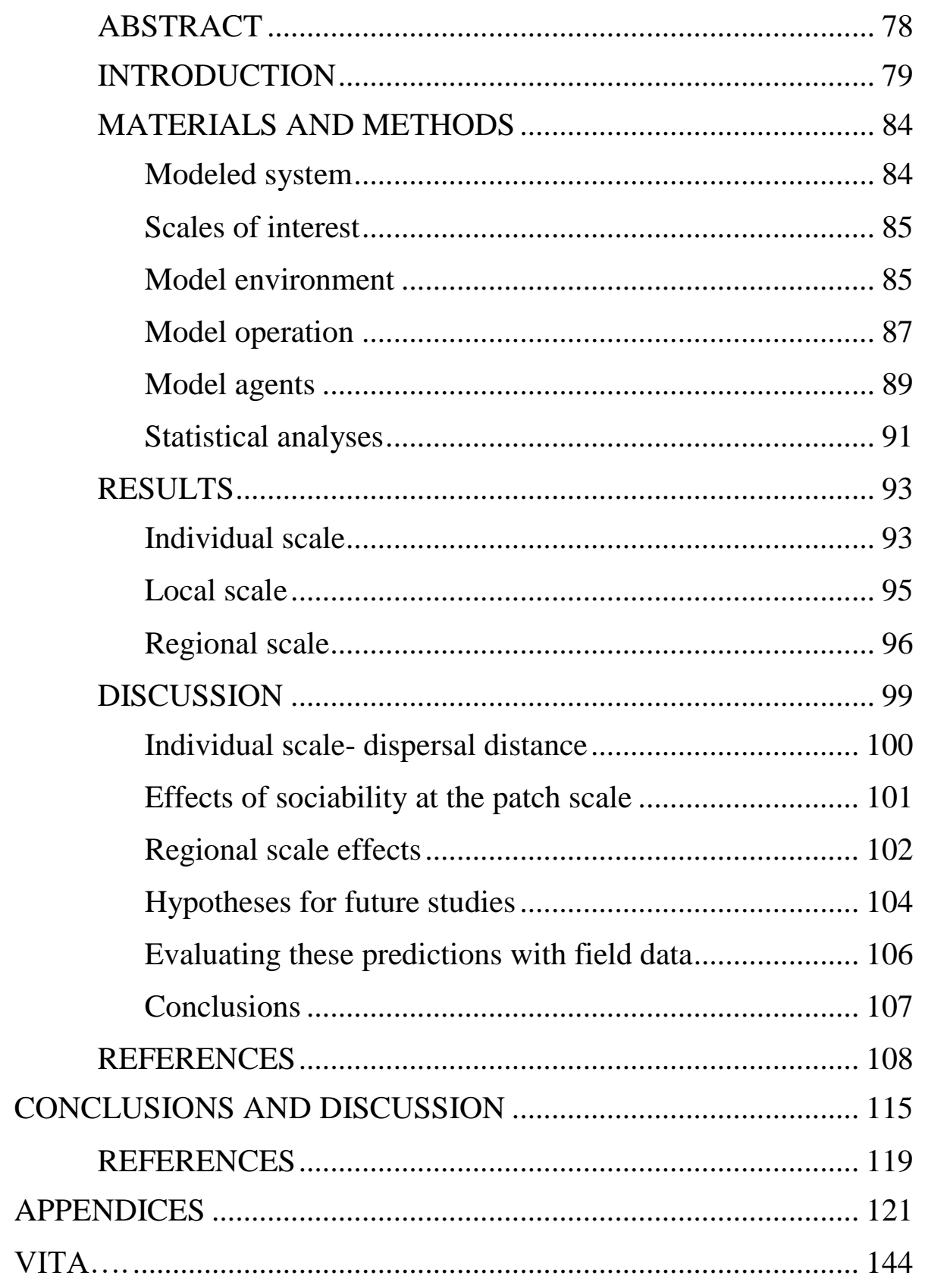




\section{LIST OF TABLES}

TABLE

PAGE

Table 1 Descriptive statistics (mean, standard error and range) for solution holes sampled in the study. 16

Table 2. Summary of the 1) species traits, 2) local scale factors and 3) regional scale factors examined in analyses of metacommunity assembly.

Table 3 RDA biplot scores of the top three factors driving assembly on each RDA axis for each level of limitation.

Table 4 AIC summary table for models with significant explanatory power for each level of inferred dispersal-limitation. The adjusted $\mathrm{R}^{2}$ is also shown for supported models. ... 27

Table 5 Biplot scores for RDAs 1 and 2. Higher absolute values denote higher relative influence on the metacommunity assembly process. The top three driving factors along each axis are shaded. Global $\mathrm{R}_{\text {adj }}^{2}=0.170$

Table 6 The ANOSIM R and P values are shown at the top of the table, demonstrating that there are negligible but significant differences between the communities. The table shows the results of the SIMPER analysis which describes the differences between communities where Jewelfish were present versus absent in terms of the species which explain a cumulative $80 \%$ of the variance in the differences. Species with significant variation between the two categories are denoted with an asterisk adjacent to the P-value, and the direction of the change in density $(\Delta \mathrm{D})$ of the species when Jewelfish are present. Non-natives are noted by ${ }^{\mathrm{NN}}$. 62

Table 7 Hypotheses to be tested at each scale of interest. N.P. represents a no personality (control) treatment.

Table 8 Mean sociability values used for each treatment in statistical analyses.

Table 9 Parameters used to generate random beta distributions from which sociability scores were drawn for the population. Note that neutral populations had no personality. 


\section{LIST OF FIGURES}

\section{FIGURE}

PAGE

Figure 1. Hypothesized relative importance of factors contributing to metacommunity assembly. Unlimited dispersal tends to overwhelm observable gradients, resulting in neutrality. As limitation becomes increasingly limited, local factors should be most influential when dispersal limitation is lowest, but not unlimited. Conversely, regional factors should become more influential as dispersal-limitation is induced largely by regional environmental forces. Life-history traits are determinants of propagule pressure and dispersal features, allowing them to be influential on assembly without necessarily interacting with dispersal-limitation. Competitive traits were hypothesized to have the greatest influence when local selectivity was possible, while dispersal traits were hypothesized to increase in influence as dispersal overall became more limited.

Figure 2. Map of the Rocky Glades region (shown in red in inset), located in the northeast corner of ENP. Blue regions are Shark River Slough to the west, Taylor Slough and canals to the east. Sampled solution holes are denoted by white diamonds. Sample size is displayed for each of four solution hole regions with similar topographic and hydrological features and proximity to a nearby hydrological station. Boxes represent the sampling regions used in this study. The hydrograph (middle) shows the Rocky Glades mean weekly NAVD88 water level (black line in $\mathrm{cm}$ ), and the mean weekly rainfall (grey line). Gray boxes represent the length of the wet season determining the dispersal window and thus degree of dispersal-limitation for fishes. Boxplot at the bottom shows the distribution of Rocky Glades wet seasons (dispersal windows) from 2002-2017, in the unit of days wet, with our three sampled years marked by vertical lines. Stage and rainfall data are averages from four hydrological stations in the regions, shown by the black circles.

Figure 3 Wet (top left) and early dry season (bottom left) images of the Rocky Glades marsh showing hydrologically-connected and isolated solution holes. During the wet season, solution holes are connected by surface water allowing for dispersal of fishes and colonization of holes. Sampling of assembled communities in each hole took place at the start of the dry season (when holes became first disconnected from surface water, bottom left). The right three images show surface area with varying solution hole types: small, shallow, low-rugosity and no vegetative cover hole (top), a deep 
hole with high rugosity and no vegetative cover (middle), and a shallow high-rugosity hole with high vegetative cover (bottom).

Figure 4 Percent of explained variance contributed by each factor during each assembly event with the associated global $\mathrm{R}^{2}$ above each bar, and the proportion of the variance explained by traits, local and regional factors in each year are shown within the bars.

Figure 5 RDA1 vs RDA2 plots for the first through third assembly years respectively. Vector shades correspond to the legend in Figure 4. Dots represent individual species in multivariate space.

Figure 6 Map of the Rocky Glades region (shown in red in insert), top, located in the northeast corner of Everglades National Park. Blue regions are Shark River Slough to the west, Taylor Slough and canals to the east. Sampled solution holes are denoted by white diamonds. Sample size is displayed over each hole cluster, and the nearest hydrological stations are represented by black circles. Boxes represent sampling regions used in this study. The bottom three panels show examples of the RG environment in the wet, left, and dry, middle, seasons as well as an example of the photographs used to determine solution hole surface area.

Figure 7 Standardized effect sizes of all fish assembly data available (Kobza et al 2004, Loftus et al 2004 and this study's electrofishing data) over time. White points are pre-invasion and black are post-invasion data, showing a decline in the standardized effect size of following the African Jewelfish invasion of the Rocky Glades (black vertical line). Bars mark the cumulative diversity of non-native fish in the Rocky Glades, per Kline et al. (2014), horizontal dashed lines denote approximate significance boundaries for deviations from "random" assembly.

Figure 8 Mean abundance, and standard errors of the mean, of each species in modern (2013-2015) solution hole communities across all years. Black bars are natives, gray bars are non-natives and the focal species of this study, the African Jewelfish, is highlighted with the arrow. This species was the second most abundant fish, and was the most abundant non-native, encountered.

Figure 9 Bi-plot of RDA scores describing Rocky Glades 2013-2015 fish metacommunity assembly. Vector colors reflect descriptor category (local=dark gray, regional=light gray and African Jewelfish=black), with the relative importance of each factor signified by the relative length of the vector and the direction of its influences 
signified by the direction. Gray points show where individual species sort along these gradients. Distance to source, regional hydroperiod and African Jewelfish abundance were the most influential factors overall

Figure 10 Significant differences in the mean total abundance (top) and diversity (bottom) of solution hole communities where African Jewelfish were present versus absent in the electrofishing data are shown. For diversity, the native only (circle), nonnative only (square) and total (triangle) diversity are shown. Error bars represent standard errors of the mean.

Figure 11 NMDS of solution hole communities where African Jewelfish were present (dark gray) versus absent (white), across all three years of electrofishing data showing little dissimilarity between the two types of communities. The relatively low two dimensional stress suggests that the large amount of overlap shown is representative of reality.

Figure 12. Standardized effect sizes, derived via comparable null model analyses, presented in papers assessing pre-invasion/uninvaded (black) and invaded (white) communities, showing consistent reductions in the standardized effect size upon invasion. Dashed lines represent approximate boundaries (1.96 standard deviations from 0 ) for significant deviations from random assembly to aggregation (lower standardized effect sizes) or segregation (higher standardized effect sizes).

Figure 13 The top panel shows the model landscape based on a random allocation of habitat patches (solution holes) in a 20 by $10 \mathrm{~km}$ matrix. Dots represent patches, gray is the dispersal matrix and the black band to the left is the source area. Panels below show example distributions of the four source population sociability treatments.

Figure 14 The distance individuals traveled, in the unit of $100 \mathrm{~m}^{2}$ cells, was negatively related to individual sociability and varied with dispersal window length. Panel a shows the raw distance traveled by all socially informed individuals, with the line of best fits for each dispersal window (black= long, gray=short), as well as boxplots of the distances no-personality (N.P.) individuals traveled. Note sociability ranges from $0=$ extremely asocial to $1=$ extremely social. Panel $b$ shows the means and standard errors of individual travel distances for each of the treatments, demonstrating that asocials move further, socials move the least the normal distribution resembles the N.P. control, and longer dispersal windows result in longer dispersal distances. 
Figure 15 Median patch density from the four sociability treatments in the low (dark) and high (light) dispersal window treatments positively associated with mean population sociability, and the normal treatment was not significantly different from the no personality control. Circles denote outliers

Figure 16 Boxplots showing the proportion of the patches which were occupied during each of the four sociability treatments under low (dark) and high (light) dispersal treatments. Circles are outliers.

Figure 17 The top panel shows a linear model of the mean sociability of patches as a function of distance from the source, in the unit of patches, and associated standard errors for each level of dispersal. The bottom panel shows the mean patch density as a function of distance from the source, and associated standard errors, for the with and without personality treatments under each dispersal window treatment. Note that the with personality treatment shown here is only the normal distribution treatment as other sociability treatments violated parametric assumptions.

Figure 18 Proposed hypotheses to be evaluated in natural metasystems. The left panel shows relationships which our data suggest should emerge because of sociability dependent dispersal. The right panel shows the two hypothesized population sociability distributions for dynamic (top) and stable (bottom) landscapes. 106

Figure 19 Map of Everglades national park (outlined in white) with the model system, the Rocky Glades, shown in red and the longest hydroperiod regions (Shark River Slough, west, and Taylor Slough east) shown in blue. Previous work suggests that Shark River Slough is the primary source community for fishes entering the Rocky Glades. Main Park Road, shown in black likely inhibits most southerly dispersal. The shaded black box approximates the area simulated in this model.

Figure 20 The top panel shows the model landscape with black patches representing pools, the dark western bar shows the source area and the gray area is the dispersal matrix. Example distributions of sociability for each of the populations which contain intraspecific variability.

Figure 21 Conceptual flow diagram of the model. Grey represents user interface buttons, green shows initialization procedures, orange shows patch processes yellow represents fish (turtle) processes. Lighter colors indicate features of the preceding process. Words in all capitals are model parameters. 


\section{INTRODUCTION}

The rules of community assembly have been at the forefront of ecology for several decades (Diamond 1975, Cadotte et al. 2013). In particular, the metacommunity concept has been a major driver of recent advances through its explicit consideration of regional heterogeneity, local factors and dispersal (Leibold et al. 2004, Holyoak et al. 2005, Jacobson and Peres-Neto 2010, Logue et al. 2011). Much of the metacommunity assembly work to date has focused on understanding the varying contribution of local vs. regional forces to assembly processes at various taxonomic (e.g., Zheng et al. 2015), and spatial scales (e.g., Mouquet and Loreau 2003). Two key insights from this literature are that 1) the relative importance of these regional vs. local forces varies along dispersallimitation gradients (Winegardner et al. 2012, Padial et al. 2014), and 2) inter- and intraspecific trait variation are highly influential during assembly (Violle et al. 2007, Dolbeth et al. 2013, Kittelson et al. 2015).

The observed shift of assembly drivers in response to changing dispersallimitation has been the net result of many individual studies (see Winegardner et al. 2012 for a more thorough discussion). Strong limitation tends to result in competitive structuring (Winegardner et al. 2012, Leibold et al. 2016), while moderately limited metacommunities assemble along environmental gradients (Winegardner et al. 2012, Sarremejane et al. 2017), and a lack of limitation tends to result in neutrality, essentially stochasticity (Hubbell 2001a, Muneepeerakul et al. 2008, Winegardner et al. 2012). Despite this insight, ecologists still lack a complete understanding of assembly mechanisms. The way species are influenced by the environment, and therefore the underlying reasons for the influences of local and regional factors, is determined by their 
traits (Petchey and Gaston 2006, Loughnan and Gilbert 2017). Recent works have suggested that interspecific trait variation can be the most influential drivers of assembly, explaining more variance in biodiversity data than any environmental factors (Gianuca et al. 2016). For example, body size is an important driver of zooplankton $\alpha$-diversity, with traits explaining $22.8 \%$ more of the variance than traditional environmental factors (Gianuca et al. 2016). However, how the relative influence of these traits shifts along the dispersal-limitation gradient is currently unknown. The influence of interspecific trait variation may also explain the high relative influence of certain individual species on assembly mechanisms.

The high influence of individual species on the spatiotemporal distribution of species has been well documented. For example, some predators can shift prey distributions resulting in patchy prey aggregations (Mouquet et al. 2005), while others prevent emigration without inhibiting immigration at local patches, increasing local abundances and diversities (e.g., Stier et al. 2013). However, if individual species can be drivers of assembly mechanisms, then this leads us to ask: what influence does the introduction of a new species have on assembly? The answer to this question is currently unknown, but potentially important. Invasion impacts can range from non-significant to catastrophic (Cucherousset and Olden 2011), with the most damaging invasions resulting in multi-species extirpations (e.g., Nile Perch; Goudswaard et al. 2006), yet few commonalities have been described to allow prediction of these impacts (see Simberloff et al. 2013 for discussion on this). Given the ever increasing global rate of biological invasions, and increasing stresses of climatic changes on native communities (Huang et al. 2011, Rehage and Blanchard 2016), understanding which invaders will impact 
metacommunity assembly, and how, is essential for the proper management of spatially structured populations in the Anthropocene. In addition to this high relative influence of interspecific trait-variation, intraspecific variation has also been shown to be highly influential.

It has been demonstrated that differences within a species can restructure individual metapopulations within metacommunities, in both space and time, via dispersal mediation (e.g., Hawkes, 2009; Sutherland et al., 2014). Of the types of individual traits investigated, among the most poorly understood are individual personalities. These physically cryptic traits have been shown to influence propagule dispersal tendencies (Duckworth and Badyaev 2007, Cote et al. 2010a, Myles-Gonzalez et al. 2015), dispersal speeds (Maes et al. 2013), dispersal distances (Cote et al. 2010b), competitive abilities (Groen et al. 2012, Capelle et al. 2015), physiological states (MylesGonzalez et al. 2015), parental abilities (Duckworth and Badyaev 2007), and colonization behaviors (Duckworth 2008, Groen et al. 2012). However, few studies describe the impact of personalities on metapopulation structure. Those that do, tend to focus on boldness (e.g., Myles-Gonzalez et al. 2015) and aggression (e.g., Duckworth and Badyaev 2007). Sociability has received comparatively little attention, despite empirical support for its importance. Sociability, the propensity to associate with conspecifics, has been demonstrated to influence the spatiotemporal structure of metapopulations by altering the likelihood of an individual to disperse, and how they perceive the quality of patches (Cote and Clobert 2007, Cote et al. 2010b, 2010a). Previous works suggest asocial individuals travel further, and that sociability is negatively associated with patch density in mesocosms (Cote and Clobert 2007, Cote et al. 2010b, 2010a), but no large 
scale (10's-100's of km) studies considering dispersal-limitation have been performed. Given these three gaps in ecological understanding of assembly processes, I address the following questions in this dissertation:

1) How do the relative influences, on metacommunity assembly, of species traits, local and regional factors shift along a dispersal-limitation gradient?

2) What influence, if any, do invasive species have on metacommunity assembly?

3) Can intraspecific sociability variation influence the spatiotemporal distribution of a species at ecologically relevant spatiotemporal scales?

Chapter I describes the observation of three consecutive assembly events in the Rocky Glades fish metacommunity. This ephemeral marsh, in Everglades National Park, floods and desiccates annually (Loftus et al. 1992, McVoy et al. 2011). The duration of these flooding events presumably dictates the level of dispersal-limitation for fish in this system, and annual desiccation results in a functional extirpation of all but the longest hydroperiod source habitats (Rehage et al. 2014). Each observed assembly event had distinct hydrological patterns resulting in a gradient of low-high dispersal-limitation. Along with traditional local and regional scale environmental factors, I also evaluate the influence of five species traits on the assembling patch communities. Each assembly event is described in terms of the shifting relative importance of these traits, as well as local and regional environmental factors.

In Chapter II I focus on understanding the relative influence of invasive species on metacommunity assembly. Using historic data, I investigate how the African Jewelfish 
(Hemichromis letourneuxi), a recent invader to the Rocky Glades, influenced metacommunity assembly. I also evaluate their role in contemporary invasions, relative to environmental factors, using the field data obtained in Chapter I. Chapter I concludes with a comprehensive literature review to determine if invasions have a repeatable influence on assembly. I finish with the discussion of a hypothesized taxa-independent signal of invasive species introductions that can be quickly detected using standard biodiversity data, which could be a useful management tool.

In the closing chapter, I built and analyzed an empirically parameterized behavioral individual based model. Using this model, I investigate how population sociability can influence metapopulation assembly in a Rocky Glades-like environment, and how the length of the dispersal window (dispersal-limitation) mediates this structuring. I conclude by posing a series of hypothesized relationships which can be directly evaluated with field-data and suggest methodologies for doing so. 


\section{CHAPTER I}

TRAIT BASED RE-ASSEMBLY: WHAT DRIVES EPHEMERAL

METACOMMUNITY

RE-ASSEMBLY? 


\begin{abstract}
Recent literature suggests that the relative influence of local and regional factors on metacommunity assembly shifts along a dispersal-limitation gradient. Interspecific variation in the traits which interact with these factors has also been shown to be a primary driver of assembly. I hypothesized that the relative influence of five species traits (each related to life-history, competitive, or dispersal abilities) along with local and regional environmental factors, would shift along a dispersal-limitation gradient. The hypothesis was tested in the Rocky Glades region of Everglades National Park, an ephemeral karstic marsh, by observing assembly in aquatic refugia at the onset of three consecutive dry seasons (2013-2015), each following natural extirpation events, with differing levels of dispersal-limitation. I find broad support for my hypothesis, with individual traits contributing $85 \%$ of the explainable variance in the least dispersal limited assembly event, to $60 \%$ under moderate limitation and $51 \%$ with the highest dispersal-limitation. The decreasing influence of traits corresponded with an increasing influence of regional factors as dispersal-limitation became more severe, from less than $1 \%$ to $39 \%$, and a decrease in the influence of local factors, from $15 \%$ to $10 \%$, as dispersal-limitation was increased. Of the traits that we investigated, life history and competitive traits were the most useful in deriving explanatory models. Dispersal traits had relatively high influences on assembly regardless of dispersal-limitation. The inclusion of these traits resulted in substantially more variance in metacommunity assembly events being explainable, and their relative influence shifted along a dispersallimitation gradient. In agreement with previous works, we suggest metacommunity
\end{abstract}


assembly be considered a trait-based process which responds directly to dispersallimitation gradients.

\section{INTRODUCTION}

The rules of community assembly have been at the forefront of ecology for several decades (Diamond 1975, Cadotte et al. 2013). In particular, the metacommunity concept has been a major driver of recent advances through its explicit consideration of regional heterogeneity, local factors, and dispersal (Leibold et al. 2004, Holyoak et al. 2005, Jacobson and Peres-Neto 2010, Logue et al. 2011). Much of the metacommunity assembly work to date has focused on understanding the varying contribution of local vs. regional forces to assembly processes at various taxonomic (e.g., Zheng et al. 2015), and spatial scales (e.g., Mouquet and Loreau 2003). One key insight from the literature is that the relative importance of these regional vs. local forces varies along dispersal gradients (Winegardner et al. 2012, Padial et al. 2014). Specifically, assembling metacommunities with high dispersal tend to have weak associations with the environment, while those with moderate to low dispersal (or high dispersal-limitation), show strong effects of environmental factors (Winegardner et al. 2012, Sarremejane et al. 2017). Heavily limiting dispersal typically results in intensified interspecific interactions, with a reduced influence of environmental factors (Winegardner et al. 2012, Leibold et al. 2016).

While these insights have contributed greatly to our understanding of assembly processes, environmental factors, whether local or regional, typically explain a limited amount of the variance in metacommunity assembly (Soininen 2014). In particular, recent efforts have demonstrated the need to consider functional traits, as they underlie 
the mechanisms driving environmental and interspecific interactions (Petchey and Gaston 2006, Loughnan and Gilbert 2017). For example, life-history traits were useful for describing a butterfly metacommunity's assembly (Pavoine et al. 2014), and the dispersal abilities of aquatic macroinvertebrates interacted with environmental factors to drive stream-riffle assemblages (Sarremejane et al. 2017). Competition-related traits, such as body size, can be important drivers of zooplankton $\alpha$ diversity, while microhabitat use patterns explain $\beta$ diversity (Gianuca et al. 2016). In the same zooplankton metacommunity, Gianuca et al. (2016) also showed the added value of traits to the study of assembly dynamics. Accounting only for typical environmental and spatial variables, they could explain approximately $18 \%$ of the variance in assembly. However, through trait-based analyses they could explain an additional $22.8 \%$ of the variance in $\alpha$ diversity, and $30.8 \%$ of the variance in $\beta$ diversity.

These examples highlight how the inclusion of traits in describing metacommunity assembly is informative, but they also show that understanding which traits are important under what conditions remains unresolved. The variability in the importance and type of traits influencing assembly likely reflects the context dependency of the metacommunity assembly process itself. As traits influence the way species interact with environmental factors (Violle et al. 2007), and the relative influence of these factors change along a dispersal-limitation gradient (Winegardner et al. 2012), we expect the relative importance of different types of traits to also shift along this gradient. Yet, few studies quantify assembly repeatedly across varying environmental conditions, while accounting for the role of various traits. Those that have, have typically observed significant relationships between functional traits and key environmental gradients. For 
example, Spasojevic et al. (2014) found that trait variation among species tended to be lowest in patches with the greatest dispersal-limitation, isolation, and lowest temperatures at the highest elevations in their 'alpine sky island' metacommunity.

In the present study, we examined the varying importance of local factors, regional factors and species traits in driving metacommunity assembly as a function of a dispersal-limitation gradient. That is, a gradient in environmental conditions that could affect dispersal or colonization of habitat patches and thus the overall assembly of the metacommunity. We focused on an ephemeral fish metacommunity in the Rocky Glades region of Everglades National Park. In this karstic environment, limestone is exposed on the surface and the region is peppered with solution holes, or depressions in the limestone matrix, which function as dry-season refugia for freshwater fishes (Kobza et al. 2004). The fish metacommunity in this short-hydroperiod wetland re-assembles annually during the wet season, when these holes are connected by standing water to more permanent regional habitats (Loftus et al. 1992, Kobza et al. 2004, Rehage et al. 2014). We expect that the length of the wet season determines connectivity to the regional species pool, and thus the degree of dispersal-limitation. We examined fish metacommunity assembly across three consecutive years, with varying wet season lengths, resulting in a dispersallimitation gradient for fishes.

When dispersal is functionally unlimited, metacommunity theory predicts neutrality to prevail, as high stochastic interpatch movement overwhelms other structuring forces (Hubbell 2001a, Winegardner et al. 2012). During high water levels, when dispersal-limitation should be low for Everglades fishes, we hypothesized assembly 
to be reliant largely on propagule pressure, and competitive interactions. As life-history traits directly influence propagule pressure (the number of available propagules is partly determined reproductive behavior and fecundity; Duckworth 2008, Bonte et al. 2012), we hypothesized that under this low dispersal-limitation scenario, life history traits should partially drive assembly. Under moderate dispersal-limitation, we expect an increasing influence of local factors to coincide with a reduction of competitive structuring, and an increasing influence of regional factors. As dispersal-limitation becomes more severe, the influences of the regional factors and dispersal traits should increase, especially so in ephemeral environments as the relative ability to overcome dispersal-limitation affords a dispersal advantage (Figure 1).

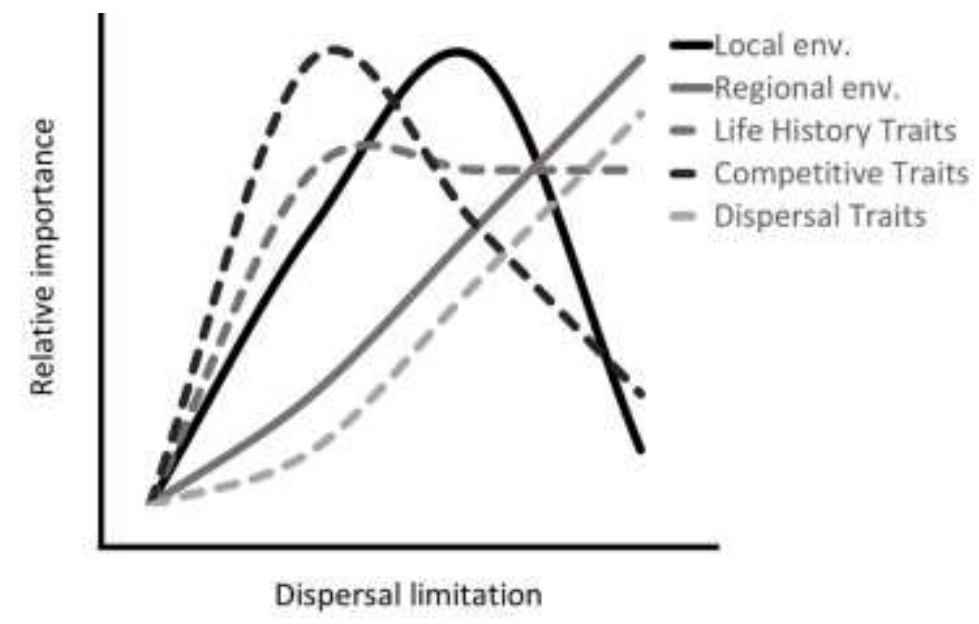

Figure 1. Hypothesized relative importance of factors contributing to metacommunity assembly. Unlimited dispersal tends to overwhelm observable gradients, resulting in neutrality. As limitation becomes increasingly limited, local factors should be most influential when dispersal limitation is lowest, but not unlimited. Conversely, regional factors should become more influential as dispersal-limitation is induced largely by regional environmental forces. Life-history traits are determinants of propagule pressure and dispersal features, allowing them to be influential on assembly without necessarily interacting with dispersal-limitation. Competitive traits were hypothesized to have the greatest influence when local selectivity was possible, while dispersal traits were hypothesized to increase in influence as dispersal overall became more limited. 


\section{METHODS}

\section{Study system}

We assessed first assembly of the fish metacommunity inhabiting solution holes in the Rocky Glades region of Everglades National Park (ENP) in 2013, 2014 and 2015 (Figure 2). By first assembly, we are referring to the initial formation of a metacommunity in a previously uninhabited or extirpated habitat (i.e., upon colonization but before in situ reproduction or local species interactions alter patch diversity and densities-effectively $\mathrm{T}=0$ ). At the onset of the wet season, solution holes in the Rocky Glades become connected via surface water to other solution holes and to deeper, more permanent habitats forming a complex matrix of habitat patches and population sources (Kobza et al. 2004; Figure 2). During this high water period, fish disperse out of deeper sources to colonize solution holes (Kobza et al. 2004, Loftus et al. 2005, Rehage et al. 2014, Goss et al. 2014). In the dry season, these solution holes become disconnected from the surface as waters recede, limiting aquatic habitat to only the deepest solutions holes in the landscape as the dry season progresses (Kobza et al. 2004; Figure 2). Under current post-drainage hydrological conditions, most fishes are annually extirpated by a combination of abiotic stress, predation from both native and non-native species, and premature desiccation (Loftus et al. 1992, Kobza et al. 2004, Rehage et al. 2014), such that the metacommunity re-assembles annually. Previous works have shown that these communities tend to have high non-native diversity, averaging $45 \%$ non-native abundance (Rehage et al. 2014, Kline et al. 2014).

In this study, each observed year had distinct the wet season durations (Davis et al. 2005, Kotun and Renshaw 2014), resulting in different levels of dispersal-limitation 
for fishes, and allowing for the comparison of the relative role of structuring factors on the metacommunity (Figure 2, Table 1). This form of environmentally mediated dispersal-limitation has been used in similar previous studies, such as the dispersallimitation induced by elevation and distance between patches in the sky-island plant communities observed by Spasojevic et al. (2014). To quantify dispersal-limitation here, we defined the start of the wet season as the first week when rainfall resulted in a significant increase in mean water levels in the Rocky Glades, as determined using data from the nearest Everglades Depth Estimation Network stations (Figure 1; Telis and Henkel 2009). The first sample was in an exceptionally prolonged wet season, resulting in a dispersal window of 273 days, which is substantially longer than a typical wet season duration (median duration=206.5 days,). The second year's dispersal window was intermediate with an estimated 154 days of flooding. The third dispersal window was much shorter, only 98 days, falling in the low end of the distribution of wet season durations (Figure 2). 

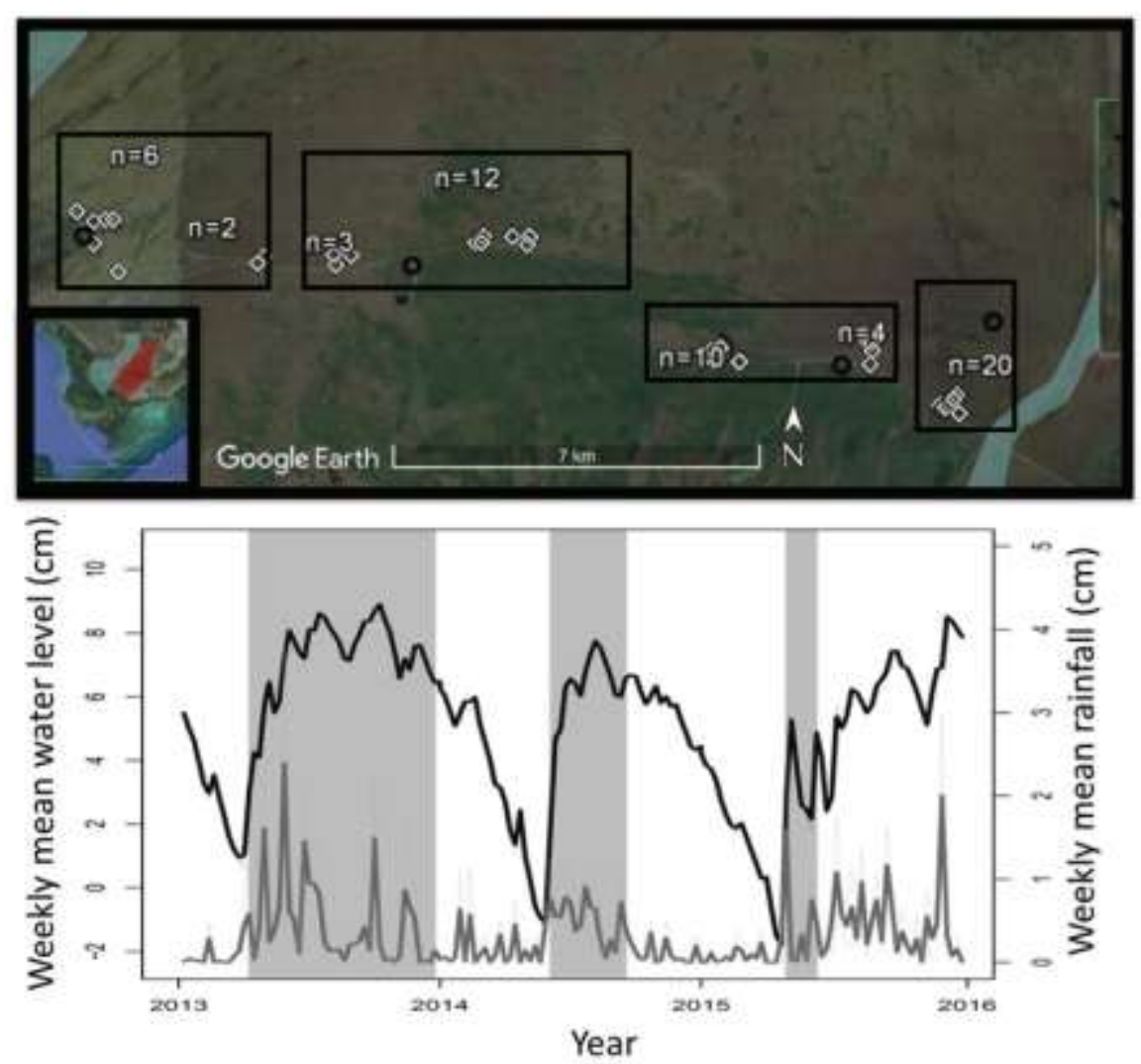

2002-2017 Dispersal windows

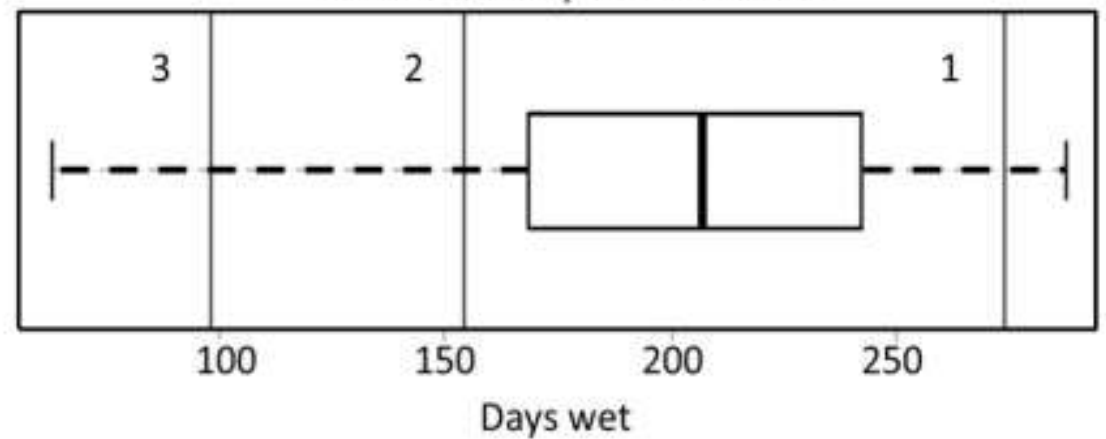

Figure 2. Map of the Rocky Glades region (shown in red in inset), located in the northeast corner of ENP. Blue regions are Shark River Slough to the west, Taylor Slough and canals to the east. Sampled solution holes are denoted by white diamonds. Sample size is displayed for each of four solution hole regions with similar topographic and hydrological features and proximity to a nearby hydrological station. Boxes represent the sampling regions used in this study. The hydrograph (middle) shows the Rocky Glades mean weekly NAVD88 water level (black line in $\mathrm{cm}$ ), and the mean weekly rainfall (grey line). Gray boxes represent the length of the wet season determining the dispersal window and thus degree of dispersal-limitation for fishes. Boxplot at the bottom shows the distribution of Rocky Glades wet seasons (dispersal windows) from 2002-2017, in the unit of days wet, with our three sampled years marked by vertical lines. Stage and rainfall 
data are averages from four hydrological stations in the regions, shown by the black circles.

Sampling sites covered a $20 \mathrm{~km}$ east to west swath of the Rocky Glades and were located between two potential source populations for fishes, Shark River Slough to the west, and Taylor Slough and man-made canals to the east, along ENP's boundary (Figure 2). Both are semi to permanently flooded habitants and have been shown to act as a source for colonists of the Rocky Glades region during the wet season (Goss and Trexler 2014). Individual solution holes were selected to be representative of solution holes in the region, covering a range of surface areas, depths and rugosities along this east to west gradient (Table 1). Prior to sampling, local patch characteristics of solution holes were surveyed by measuring surface area, rugosity, maximum depth, and percent vegetative cover. Surface area was measured from photographs taken from above the hole during the dry season and analyzed using Image J (Schneider et al. 2012; Figure 3). Maximum depth was measured as the distance from the top of the hole to the top of the sediment at the deepest point on the bottom of each hole. Rugosity, an index of the solution hole's internal complexity, was measured as $\frac{\left(\frac{\alpha_{1}}{\beta_{1}}+\frac{\alpha_{2}}{\beta_{2}}\right)}{2}$ where $\alpha_{1}$ and $\alpha_{2}$ represent the lengths of crossing chains laid out in perpendicular lines across the surface of the hole, tracking the complex surfaces of the sides and bottom, and $\beta_{1}$ and $\beta_{2}$ represent the shortest linear distances across the surface (Alvarez-Filip et al. 2009). Finally, the percent vegetative cover was visually estimated as the proportion of the hole surface area covered by either emergent or submerged vegetation, including floating periphyton. 
Table 1 Descriptive statistics (mean, standard error and range) for solution holes sampled in the study.

\begin{tabular}{l|ccc}
\multicolumn{1}{c|}{ Attribute } & Mean & S.E.M. & Range \\
\hline \hline Surface area $\left(\mathrm{m}^{2}\right)$ & 1.44 & 0.89 & $0.90-8.63$ \\
Vegetation cover $(\%)$ & 31.96 & 4.29 & $0-100$ \\
Depth $(\mathrm{cm})$ & 66.12 & 4.82 & $11.43-172.50$ \\
Rugosity & 1.97 & 0.11 & $1.12-4.46$
\end{tabular}

\section{Field sampling}

All holes were sampled during the wet season, when they first became isolated from surface water (i.e., when they become a single habitat patch). For standardization purposes, sampling was conducted within seven days of the hole community becoming disconnected from surface water. This was considered the point when no further immigration or emigration was possible, but before within-patch interactions (i.e., predation, competition or in situ reproduction) played a major role. The complex solution hole environment itself is not conducive to many forms of non-lethal sampling. Fish-traps have been used in the past (see Kobza et al. 2004 and Kline et al. 2014), but can be subject to behavioral and size biases (Kneib and Craig 2001) and have poor capture rates on some species (particularly with synbranchiform eels, Jeff Kline personal communication). Thus, we sampled study sites with backpack electrofishing, known to be effective in confined environments (Thompson and Rahel 1996). Each site was electrofished to depletion in two sequential sampling events, using a Smith-Root L-24 with 100-250 volts and a duty cycle of 12-18\% (Thompson and Rahel 1996, Panek and Densmore 2013). In each sampling event, we sampled in 10 second bouts that covered the entire area of the hole up and down the water column, in and out of any vegetation present. When five consecutive bouts yielded no additional fish, the hole was 'rested' for 
a minimum of ten minutes; after which, the hole was sampled again until five consecutive bouts yielded no signs of additional animals. Upon capture, all fishes were placed in an aerated bucket for identification and enumeration (Appendix 1). All fishes were counted, their standard lengths were measured and all natives were released. All non-natives were humanely euthanized per scientific permit requirements. Total sample sizes were 46, 51 and 40 sites sampled in the early dry seasons of 2013, 2014 and 2015, respectively. Most solution holes were sampled repeatedly, with 32 sampled in all years, 16 sampled twice, and 9 were sampled only once.

Assembly variables

We examined the assembly of the solution hole fish metacommunity as a function of three types of factors: 1) species traits (five traits), 2) regional factors (three), and 3) local scale factors (four; Table 2). The species traits we examined were standard length, trophic level, relative fecundity, colonization tendency and parental care (i.e., the number of parents that typically care for the brood). Standard length, the length of a fish from the tip of its snout to the hypural joint, is a standard metric of fish body size. Body size can influence both consumptive and non-consumptive (competitive) interactions (Mills et al. 2004), dispersal abilities and tendencies, and relates to a species' life history (e.g., reproductive output, van Noordwijk et al. 2015). Lengths were obtained at the time of sampling and averaged across all individuals to obtain a species mean value for each sample. Trophic level, a metric for where a species falls within the food web, has direct implications for interspecific interactions (Martin et al. 2010, Liew et al. 2016) and was obtained from Froese and Pauly (2017). The fecundity of each species (i.e., the number of eggs or offspring produced in the case of live-bearers) was obtained from published 
studies and used to develop a five-category scoring system, representing increasing orders of fecundity (following Pavoine et al. 2014, Appendix 2). This life-history trait was included as for many Everglades fishes' reproduction is year-round or precedes the reflood, such that the number of dispersing propagules should be related, in part, to the reproductive output of each species.

Colonization tendency was obtained from previous work in the Rocky Glades and was calculated as the mean week of arrival of each species on the marsh surface during re-flooding (Loftus et al. 2005, Goss et al. 2014, Appendix 2). The tendency to colonize new patches should be an important dispersal-related trait. Earlier dispersers may detect patches and settle sooner than slower dispersing species, potentially imposing priority effects on later colonists (Fukami 2004, Urban and De Meester 2009). Parental care was obtained from available literature, and each species was ranked as single parent, biparental or no brood care (Appendix 2). This trait was included because, species in the species pool vary in their brood strategies, including many nonnative species (Kline et al. 2014), and may affect colonization strategies. To use these trait values as community descriptors, we applied a weighted means (WM) approach (see Pavoine et al. 2014, Gianuca et al. 2016, Michelson et al. 2016). The WM approach involved multiplying the relative abundance of each species by their trait value to obtain a weighted mean for each species. We then averaged across species to obtain a trait value for each solution hole. WMs were calculated for all five traits considered in the analyses for each sample taken.

For regional factors, we quantified: a) the number of days the marsh surface was inundated prior to assembly (hereafter days wet), b) the recession rate, and c) the distance 
of each sampled solution hole to Shark River Slough, a potential source of colonists (located west of all solution holes, Figure 2, Table 2). For distance to source, since the other potential sources of colonists are located east of our study area, Taylor Slough and the L31 canal, the distance metric also captures distance to these sources (inverse of distance to Shark slough). Because of small-scale topographical variation, days wet and the recession rate were calculated at smaller regional scales across four regions with similar topographic and hydrological features (Figure 2). Each region has slight differences in elevation and soil profiles, resulting in variation in recession rates and stage at this smaller regional scale, which were obtain from the closest hydrological station to the region (Everglades Depth Estimation Network hydrostations E112, NPS44, NPS62 and NTS14, see Figure 2 for locations). Days wet was calculated separately for each of the four regions as the number of days between the start of the wet season and our first sampleable day (i.e., when we observed patch isolation). Regional recession rates were calculated as the mean rate of change in water level from one day to the next at the nearest hydrostation. For local scale factors, we included traits of the solution hole or habitat patches: surface area, percent vegetative cover, maximum depth (henceforth referred to as depth), and rugosity (Table 1 and Table 2). 


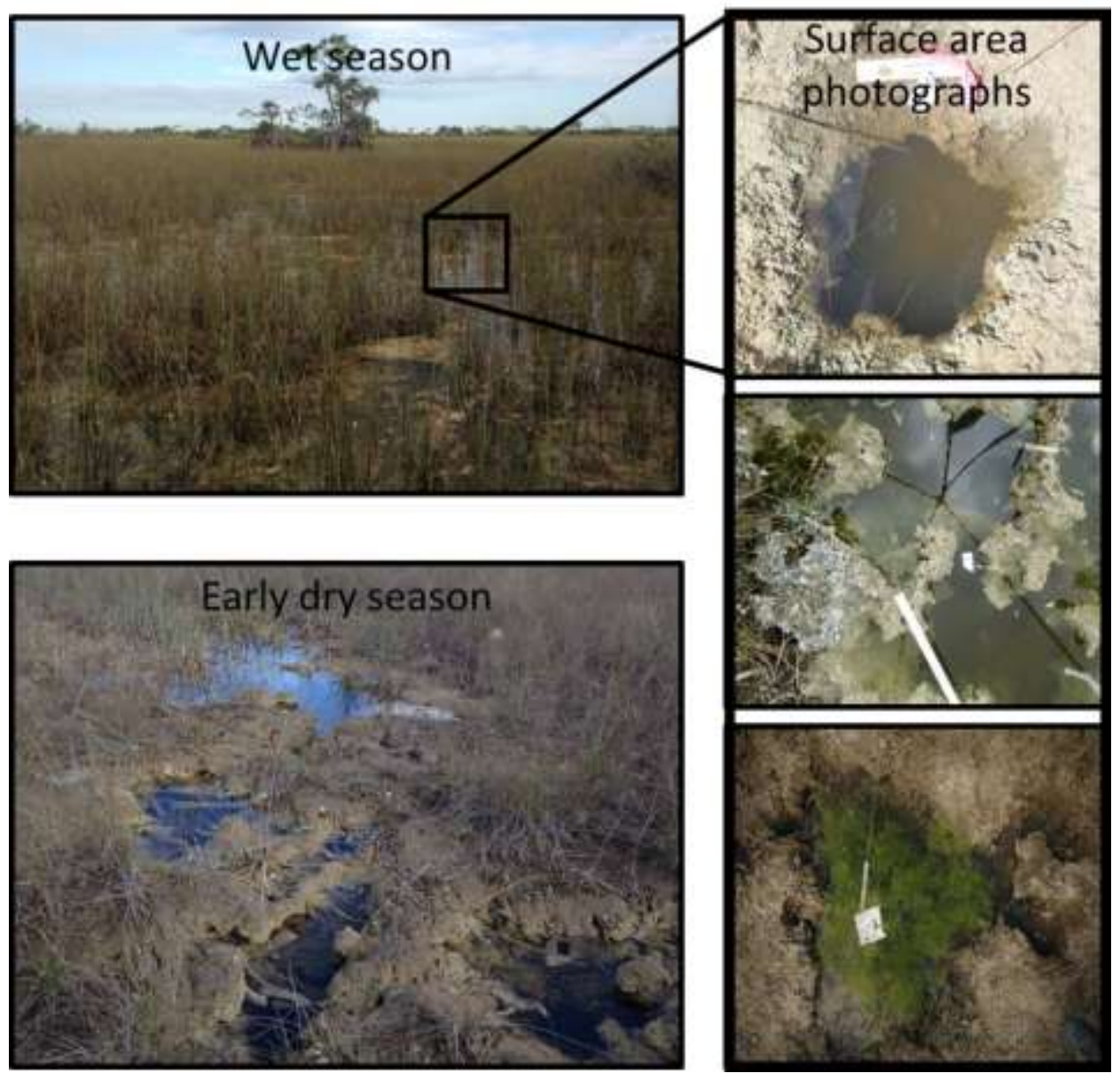

Figure 3 Wet (top left) and early dry season (bottom left) images of the Rocky Glades marsh showing hydrologically-connected and isolated solution holes. During the wet season, solution holes are connected by surface water allowing for dispersal of fishes and colonization of holes. Sampling of assembled communities in each hole took place at the start of the dry season (when holes became first disconnected from surface water, bottom left). The right three images show surface area with varying solution hole types: small, shallow, low-rugosity and no vegetative cover hole (top), a deep hole with high rugosity and no vegetative cover (middle), and a shallow high-rugosity hole with high vegetative cover (bottom). 
Table 2. Summary of the 1) species traits, 2) local scale factors and 3) regional scale factors examined in analyses of metacommunity assembly.

\begin{tabular}{|c|c|c|c|c|}
\hline Category & Variable & Type & Description & \\
\hline Species traits & & & & Scoring scheme \\
\hline & $\begin{array}{l}\text { Colonization } \\
\text { tendency }\end{array}$ & Continuous & Timing of arrival to the Rocky Glades & $\begin{array}{l}1.1 \text { to } 8.2 \text { weeks } \\
\text { since reflood }\end{array}$ \\
\hline & $\begin{array}{l}\text { Standard } \\
\text { length }\end{array}$ & Continuous & Distance from snout to hypural joint & $0.1-389.0 \mathrm{~mm}$ \\
\hline & Trophic level & Continuous & $\begin{array}{l}\text { Functional level in the food web, with higher scores } \\
\text { representing higher degrees of omnivory. }\end{array}$ & 2-4 (unitless) \\
\hline & Parental care & Categorical & Number of parents caring for the brood. & $\begin{array}{l}1=1 \text { parent } \\
2=2 \text { parents } \\
3=\text { none }\end{array}$ \\
\hline & $\begin{array}{l}\text { Relative } \\
\text { fecundity }\end{array}$ & Categorical & $\begin{array}{l}\text { Relative number of offspring produced by a single } \\
\text { female in a single reproductive event. }\end{array}$ & $\begin{array}{l}1=<100 \\
2=100-199 \\
3=1000-1999 \\
4=10000-99999 \\
5=>99999 \\
\text { Potential offspring }\end{array}$ \\
\hline \multirow[t]{3}{*}{ Local factors } & & & & Unit \\
\hline & Surface area & Continuous & Area of solution hole opening. & $\mathrm{m}^{2}$ \\
\hline & Rugosity & Continuous & Internal complexity of the solution hole. & Unitless \\
\hline
\end{tabular}




\begin{tabular}{l|llll} 
Regional factors & $\begin{array}{l}\text { Depth } \\
\text { Percent } \\
\text { vegetative } \\
\text { cover }\end{array}$ & Continuous & $\begin{array}{l}\text { Maximum depth from the top of the solution hole to the } \\
\text { top of the sediment in the deepest area. } \\
\text { Amount of area covered by vegetation. }\end{array}$ & $\mathrm{cm}$ \\
\hline $\begin{array}{l}\text { Distance to } \\
\text { source }\end{array}$ & Continuous & $\begin{array}{l}\text { Distance from the hole to the closest edge of Shark River } \\
\text { Slough }\end{array}$ & $\mathrm{m}$ & Unit \\
\hline $\begin{array}{l}\text { Days wet } \\
\text { Continuous }\end{array}$ & $\begin{array}{l}\text { Number of days between reflood and isolation from } \\
\text { surface water in the region (regional dispersal window) }\end{array}$ & Days \\
$\begin{array}{l}\text { Recession } \\
\text { rate }\end{array}$ & Continuous & $\begin{array}{l}\text { Mean regional rate of daily reduction in water level from } \\
\text { the start of the recession in water levels until isolation. }\end{array}$ & $\mathrm{cm} / \mathrm{day}$
\end{tabular}




\section{Statistical Analyses}

In order to quantify the relative importance of the three factor categories (species traits, local and regional factors) on the assembly of the Rocky Glades fish metacommunity, we conducted redundancy analyses (RDA; Gianuca et al. 2016) for each year independently and compared these. Redundancy analyses are an ordination technique that calculates the relative relationship of explanatory variables in driving the overall variance in multivariate community data. We then used variance partitioning analyses, based on the RDAs, to determine the individual contribution of each individual variable group (trait, local or regional factor) to explaining the variance in each year's community data (Gianuca et al. 2016, Rodríguez and Kouki 2017).

Third, we performed model selection to evaluate the contribution of the top three individual variables within a group to determine the most useful model for describing assembly in each year. We evaluated models containing every possible combination of the top three ranked variables from each year using an AIC-like multivariate permutational stepwise forward selection approach (described in detail in Blanchet et al. 2008). All analyses followed Hellinger transformations of abundance and mean-centered descriptor data (Legendre and Gallagher 2001). All analyses were performed in R ( R Core 2012). The RDAs, variance partitioning analyses and model selection procedures were performed using the $r d a$, varpart and ordistep functions, from the 'vegan' package, respectively.

\section{RESULTS}

In total, we were able to explain a substantial portion of the variance in the metacommunity's assembly for each year, with $43.1 \%, 49.9 \%$ and $62.0 \%$ variance 
explained in years 1-3 respectively. Across years, species traits consistently explained the largest portion of the variance. When comparing years, in year 1, traits accounted for $85 \%$ of the explained variance, while $15 \%$ was held by local factors and less than $1 \%$ for regional factors. For years 2 and 3, the drier years with more dispersal-limitation, regional factors accounted for a larger proportion of the explained variance, $31.62 \%$ in year 2 and $39.47 \%$ in year 3, while trait contributions decreased to $60.31 \%$ in year 2 and $51.02 \%$ in year 3 (Figure 4). Of the traits tested, parental care (a life-history and competitive trait) and trophic level (a competitive trait) were most influential in assembly year 1 when the wet season was prolonged, and dispersal was less limited. In contrast, in years 2 and 3, colonization tendency (a dispersal trait) consistently explained a larger proportion of the variation among the traits tested. The influence of fecundity and trophic level diminished with increasing dispersal-limitation. 


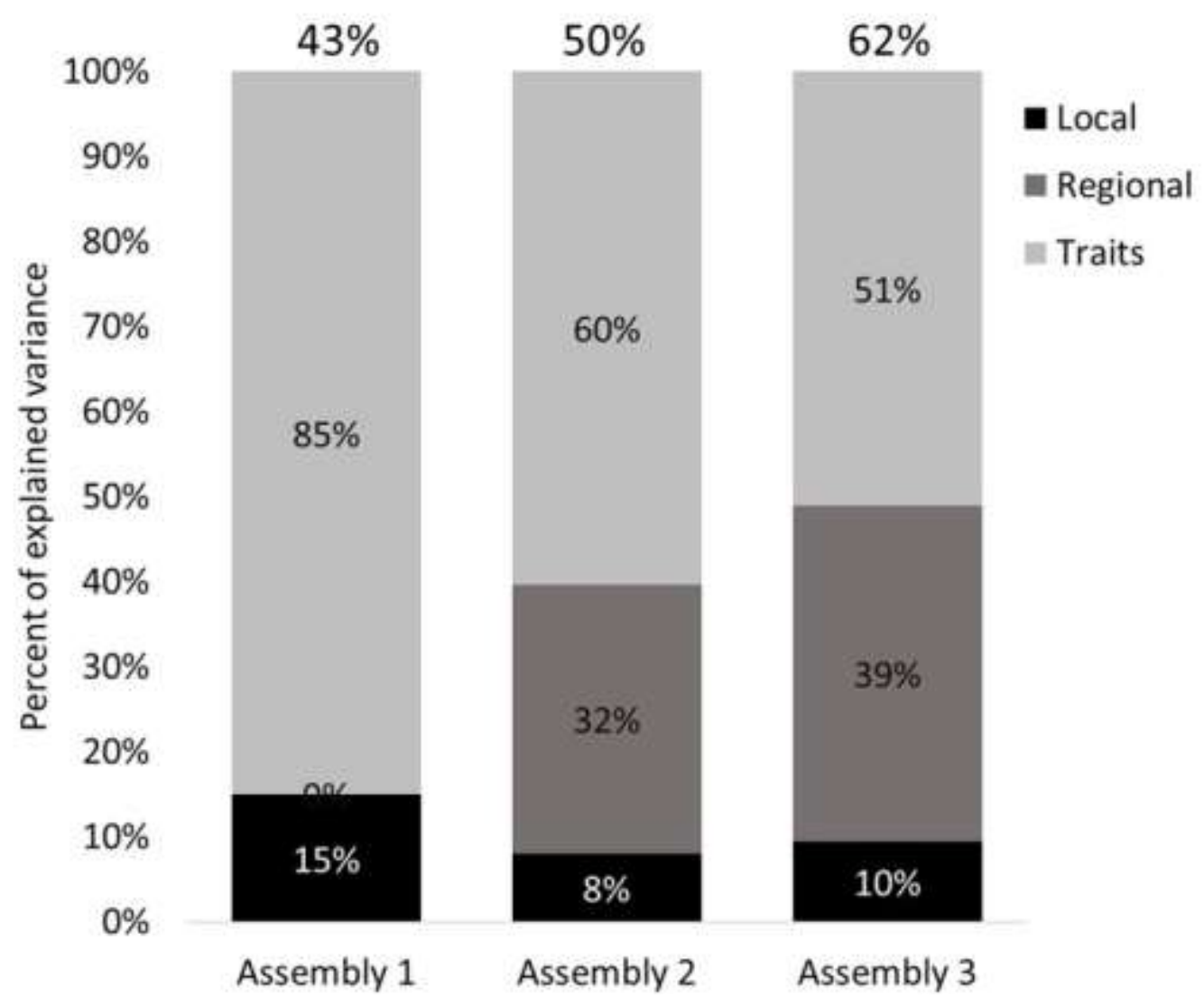

Figure 4 Percent of explained variance contributed by each factor during each assembly event with the associated global $\mathrm{R}^{2}$ above each bar, and the proportion of the variance explained by traits, local and regional factors in each year are shown within the bars.

Overall, the first year's assembly was driven by parental care, trophic level and rugosity $\left(\mathrm{F}=3.84\right.$, D.F.=12, $\mathrm{P}<0.001$, global $\mathrm{R}_{\text {adj }}=0.43$; Table 3 , Figure 5). The best model was a full three-way interaction of these traits and rugosity, explaining $26.3 \%$ of the variance (Table 4). Assembly in year two was driven largely by regional factors, distance to the source and days wet, interacting with parental care $(\mathrm{F}=5.15, \mathrm{D} . \mathrm{F} .=12$, $\mathrm{P}<0.001$, global $\mathrm{R}^{2}$ adj $=0.50$; Table 3, Figure 5). 
Table 3 RDA biplot scores of the top three factors driving assembly on each RDA axis for each level of limitation.

\begin{tabular}{cl||lcc} 
Year & Limitation & RDA1 factor & RDA1 score & Individual R ${ }^{2}$ \\
\hline \hline 1 & Low & Parental care & 0.620 & 0.140 \\
1 & Low & Rugosity & -0.517 & 0.028 \\
1 & Low & Trophic level & 0.477 & 0.110 \\
& & & 0.723 & 0.059 \\
2 & Moderate & Distance to source & 0.669 & 0.034 \\
2 & Moderate & Days wet before assembly & 0.450 & 0.036 \\
2 & Moderate & Parental care & & \\
& & & 0.811 & 0.117 \\
3 & High & Distance to source & 0.551 & 0.091 \\
3 & High & Parental care & 0.476 & 0.082 \\
3 & High & Trophic level &
\end{tabular}

There were two models with equal support for describing year 2: an interaction between distance to the source and parental care, as well as an interaction between distance to the source and days wet, which explained $18.5 \%$ and $18.4 \%$ of the variance respectively (Table 4). In the final year, with the highest dispersal-limitation, assembly was driven by a regional factor, distance to the source, parental care and trophic level $(\mathrm{F}=6.31$, D.F. $=12$, $\mathrm{P}<0.001$, global $\mathrm{R}^{2}$ adj $=0.62$; Table 3, Figure 5). The two models with equal support for year 3 both involved distance to the source interacting with either trophic level or parental care, explaining $28.86 \%$ and $29.68 \%$ of the variance respectively (Table 4). 
Table 4 AIC summary table for models with significant explanatory power for each level of inferred dispersal-limitation. The adjusted $\mathrm{R}^{2}$ is also shown for supported models.

\begin{tabular}{|c|c|c|c|c|c|c|c|c|c|}
\hline Year & Limitation & Best model & & & D.F. & $\mathrm{F}$ & $\mathrm{P}$ & $\begin{array}{c}\Delta \\
\mathrm{AIC} \\
\end{array}$ & $\mathrm{R}^{2}$ \\
\hline 1 & Low & $\begin{array}{l}\text { Parental } \\
\text { care }\end{array}$ & $*$ & $\begin{array}{l}\text { Rugosity } \\
* \text { Trophic } \\
\text { level }\end{array}$ & 1 & 2.06 & 0.05 & 0 & 0.26 \\
\hline 2 & Moderate & $\begin{array}{l}\text { Parental } \\
\text { care }\end{array}$ & * & $\begin{array}{l}\text { Dist. to } \\
\text { source }\end{array}$ & 1 & 2.32 & 0.04 & 0 & 0.19 \\
\hline 2 & Moderate & Days wet & $*$ & $\begin{array}{l}\text { Dist. to } \\
\text { source }\end{array}$ & 1 & 2.71 & 0.02 & 0.42 & 0.18 \\
\hline 3 & High & $\begin{array}{l}\text { Trophic } \\
\text { level }\end{array}$ & $*$ & $\begin{array}{l}\text { Dist. to } \\
\text { source }\end{array}$ & 1 & 3.70 & 0.01 & 0 & 0.29 \\
\hline 3 & High & $\begin{array}{l}\text { Parental } \\
\text { care }\end{array}$ & $*$ & $\begin{array}{l}\text { Dist. to } \\
\text { source }\end{array}$ & 1 & 3.99 & 0.01 & 0.31 & 0.30 \\
\hline
\end{tabular}




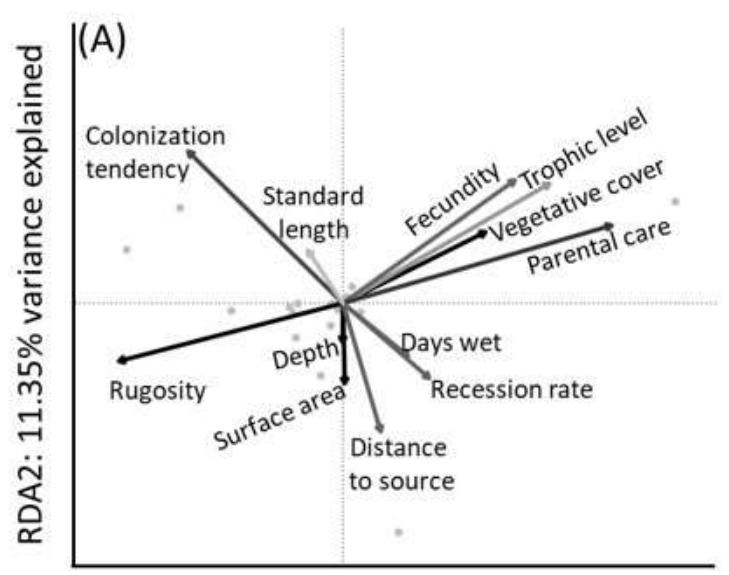

RDA1: $28.83 \%$ variance explained

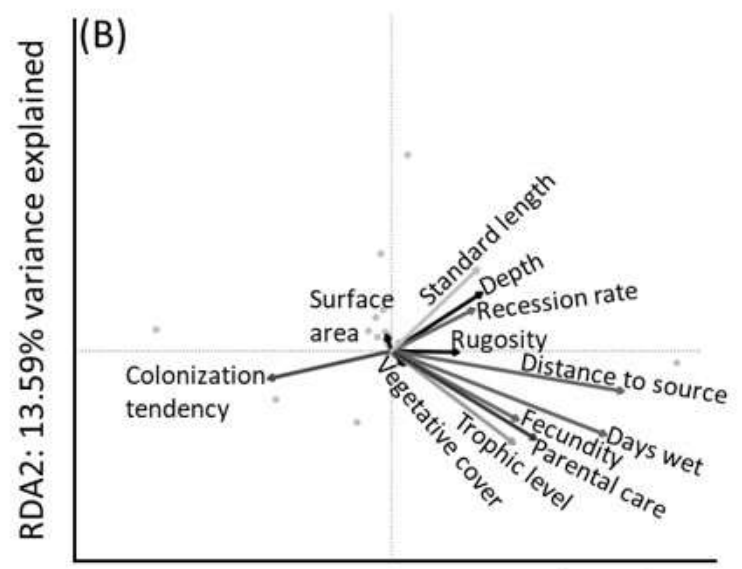

RDA1: $38.87 \%$ variance explained

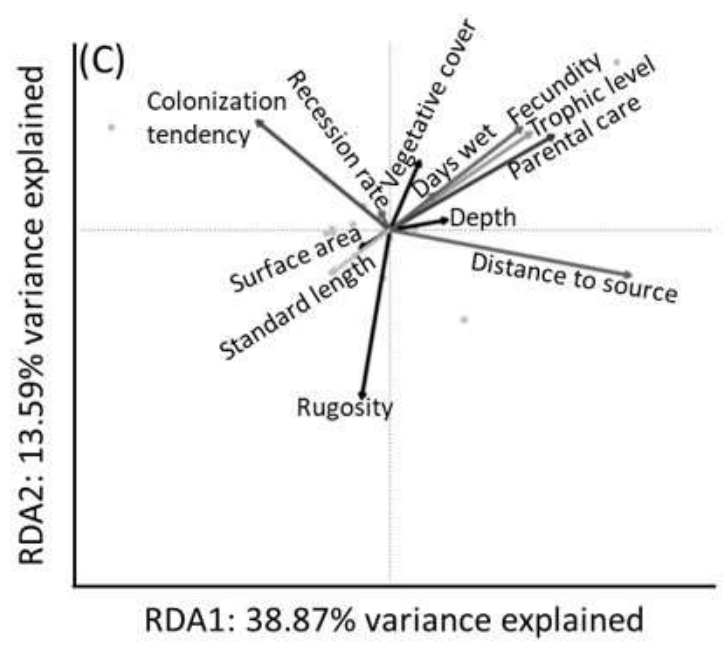

Figure 5 RDA1 vs RDA2 plots for the first through third assembly years respectively. Vector shades correspond to the legend in Figure 4. Dots represent individual species in multivariate space. 


\section{DISCUSSION}

The relative contribution of individual traits, local and regional environmental factors is of growing interest to metacommunity ecology (e.g., Kneitel and Chase 2004, Pavoine et al. 2014, Castillo-Escriva et al. 2017). Despite a historic focus on environmental factors, evidence to date suggests species traits can be more useful in describing assembly mechanisms (e.g., Gianuca et al. 2016). Here we also found that individual traits have an overriding influence on metacommunity assembly. While the relative importance of these traits diminishes as the degree of dispersal-limitation increases, traits still contributed approximately half of the explained variance, even in the most limited assembly event we observed. As dispersal-limitation increased, we saw a decreasing role for traits (from 85-51\% of the explained variance), and an increasing role of regional factors, while local factors played a comparatively lesser role in community structure. Our original hypothesis, that the relative importance of species traits, local and regional factors structuring metacommunity-assembly shift along an environmentallymediated dispersal-limitation gradient, was supported.

\section{Which traits matter when?}

Broadly speaking, those traits which facilitate environmental filtering will tend to be the most influential (Pavoine et al. 2014). For instance, life history traits can directly interact with the environment as organisms seek preferable nesting habitats and follow phenological cues for their behavior. For example, Pavoine et al. (2014) found that their butterfly metacommunity was structured largely in response to the presence of plant species which similar butterfly species utilized for reproduction. Similarly, competitive 
traits can directly influence which species are capable of persisting in an otherwise equal environment. Accordingly, body size has been a major factor in driving zooplankton metacommunities, such as in Michelson et al. (2016). In line with these previous findings, we report that both life history traits (i.e. parental care) and competitive traits (i.e. trophic level) were driving factors of assembly in our study system. However, the relative importance of these, or other, traits with respect to dispersal-limitation is largely understudied. Here we will discuss the role each trait type played in our study system, and how that changed under differing levels of dispersal-limitation.

Parental care, primarily a life history trait, was of paramount importance to the assembly of this ephemeral metacommunity, structuring this fish community across all observed years. Despite previous studies' suggestions that life history traits are drivers of assembly (Pavoine et al. 2014, Harvey \& MacDougall 2014), this is somewhat perplexing. Little reproduction occurs in the solution hole environment. All observed cichlids and live-bearers (members of the Cichlidae and Poeciliidae families respectively) were seen reproducing in solution holes during this study, but this was not common (personal observation). The influence of parental care on assembly may stem from two possible pathways. First, higher parental investment typically translates to increased offspring survival and quality (McGinley et al. 1987), and therefore is likely related to propagule pressure from source habitats. First assembly of any metacommunity is necessarily dependent on propagules from source habitats, and therefore, the number and quality of offspring produced prior to, or during, assembly will influence resultant patterns (Gotelli 1991, Holyoak et al. 2005). However, if this was the primary mechanism at work then we might also expect fecundity to have a large structuring force, which was 
not the case. While it was of moderate influence in the low and moderately dispersallimited years, it had a negligible influence in the most extreme year.

The second possible pathway is that parental care may correlate with other important structuring traits not included in our analysis. All species in this study which exhibit bi-parental brood care, a strategy novel to the native community, were non-native cichlids (members of the Cichlidae family; Appendix 1), several of which were numerically dominant (Appendix 2). Cichlids are typified by high inter- and intraspecific aggression, particularly during reproduction (Kullander 2003, Lorenz et al. 2010). Aggressive behavior has been noted to have particularly strong influences on dispersal (Duckworth and Badyaev 2007, Groen et al. 2012, Sih et al. 2012), and plays a role in priority effects (Gotelli 1991, Almany 2003, Stier et al. 2013). High patch complexity can provide structural refugia for poor competitors and prey (Stunz et al. 2001), if the dispersal-window is of sufficient length to permit local selectivity. Unfortunately, comparable aggression data were not universally available for Rocky Glades fishes, so the trait could not be included in this study. Regardless, our observations are in line with this hypothesized pathway. The lowest amount of dispersal-limitation saw a high influence of local complexity, coupled with trophic interactions and parental-care structuring. Higher levels of dispersal-limitation saw a loss of this local selectivity in favor of regional gradients, while retaining the influence of parental-care. These observations suggest life-history information is always important, and it interacts with dispersal-limitation to influence the relative importance of local and regional environmental factors during assembly. Interestingly, this type of trait has also been noted to be highly convergent among species at the patch scale suggesting an interaction 
between life-history and environmental factors playing a role in the assembly process (Pavoine et al. 2014). This agrees with previous works, which have found overwhelming influences of life-history traits as compared to environmental filtering (Lepš et al. 1982, Pavoine et al. 2014).

Trophic level was also important to assembly in all years, although it was only ranked fourth in the second year (Figure 5). This competitive trait is a useful proxy for interspecific competitive ability, with upper trophic level species likely to be more competitive overall (e.g., Dayton 2013). Poor competitors, such as prey, are also known to avoid superior competitors when selecting local patches (Capone and Kushlan 1991, Almany 2003, Stier et al. 2013), often favoring the ability to colonize a variety of patches over competitive abilities (Cadotte 2007, Kadowaki et al. 2011), or colonizing poorer quality patches (Kobza et al. 2004, Rehage et al. 2014). Predator avoidance should result in patchy local mean trophic levels, with some holes being more dominated by predators and others dominated by prey, regardless of local factors. Such local selectivity would also preserve the influence of regional environmental gradients. We observed a high influence of trophic level interacting with a regional distance gradient in our most dispersal-limited year, suggesting this may have been the case. High complexity can offset this pattern by providing local structural refugia (Amarasekare 2003) where local selectivity is made viable by low dispersal-limitation scenarios. Like parental care, trophic level appears to be influential regardless of dispersal-limitation, but the way it alters interactions with local and regional factors' importance varies considerably. Specifically, given low enough dispersal-limitation, trophic level as a structuring force encourages poor competitors to seek local conditions that permit coexistence, such as 
local complexity. Higher levels of dispersal-limitation appear to remove this possible method for coexistence, with regional factors being more influential and the prevention of local selectivity. Similar interactions of trophic level and metacommunity structure have been noted to encourage competitive co-existence of lower trophic level species while differentially influencing the way individual species utilize patches and the dispersal matrix (Orrock et al. 2008). This appears to not be the case in non-competitively structured metacommunities however, where environmental heterogeneity has been suggested to have little influence on metacommunity structure (Heino and Grönroos 2013).

Standard length, body-size, was expected to be important as both a dispersal related and competitive trait, as it influences movement and interspecific interactions. Small fish may move faster in shallow areas but be less competitive. Conversely, larger fish can typically move faster or further when unimpeded (Drucker 1996, Drucker and Lauder 1999), and body-size tends to positively correlate with home range size (Wootton and Emmerson 2005). Regardless, body-size was consistently the least influential trait, suggesting the benefits of differing body sizes were not important here. The lack of influence of body-size conflicts with previous studies which have found that, when measured, it is a primary factor in structuring metacommunities (e.g., Ingimarsdóttir et al. 2012, Michelson et al. 2016). Body-size's influence may have an effect in source habitats, which were not considered here, as environmental filtering may have precluded larger fish from the shallow matrix of our sampling universe. Few large fish were observed in solution holes, possibly limiting the potential influence of body size on these data. An alternative hypothesis as to the lack of influence by body size is that both small 
and large bodied fishes are influencing assembly in the Rocky Glades. African Jewelfish (Hemichromis letourneuxi) was the second most abundant species observed (Appendix 1), and is an aggressive micropiscivore (Rehage et al. 2014), a novel trait combination in the Rocky Glades. As the only small bodied piscivore, this highly predatory fish has been documented predating on a large number of native fishes (Rehage et al. 2014), potentially overwhelming the influence of larger fishes such as Belonesox belizanus or Clarius batrachus. Direct manipulative studies are necessary to differentiate between these potential causes for the lack of effect by standard length.

The other dispersal-related trait, the timing of marsh colonization by each species, was relatively influential alone, consistently accounting for approximately $20 \%$ of the explained variance. We hypothesized some species would being able to reach further patches than others under high dispersal-limitation by starting sooner. It was overshadowed by other interactions however and did not rank in the top three most factors in any of the observed assembly events. There are two possibilities to explain the lower influence of the dispersal-trait relative to other interactions. First, the importance of dispersal traits is unaffected by dispersal-limitation. While we cannot refute this possibility, we consider it unlikely. For example, Castillo-Escriva et al. (2017) discuss how dispersal-limitation influences passive dispersing organisms more heavily than active dispersers, with active dispersers, such as in this study, overwhelming the effects of environmental filtering through high movement despite dispersal-limitation. More likely is that the level of the dispersal-limitation was never high enough to induce severe dispersal-limitation. While the third year's hydroperiod was exceptionally short by Rocky Glades standards (Figure 2), it may have been possible for all species to disperse and 
colonize the entire system. We hypothesize that more extreme dispersal-limitation would enhance the influence of dispersal related traits in future studies and suggest that its influence would be highest under the highest degrees of dispersal-limitation.

\section{Which environmental factors matter when?}

In this study, the relative amount of dispersal-limitation was directly induced by differing levels of two regional factors: the number of days a region was wet before assembly, and regional recession rate. From the perspective of a propagule, these two factors interact with distance to impose limits on aquatic dispersers. In other marshes within the Everglades ecosystem the regional hydroperiod is a driving factor in aquatic invertebrate assembly, along with chemical gradients (Sokol et al. 2014). Considering this, it is not surprising that the two more dispersal-limited years were largely driven by regional factors interacting with species traits, primarily distance to a source community, Shark River Slough, as is often the case in fish metacommunities (Logue et al. 2011, Fernandes et al. 2013). The relative influence of these regional factors increased rapidly, from negligible under low dispersal-limitation to nearly $40 \%$ of the explainable variance, more so than any other two factors combined, in the most dispersal-limited year. Interestingly, this was almost purely a function of space as neither hydrological factor was of any particular importance under high dispersal-limitation. Local patch selectivity was consistently less influential than these regional factors, with only rugosity having a strong influence under the lowest level of dispersal-limitation. In summary, in the ephemeral metacommunity we studied, local factors matter when dispersal-limitation is low enough to allow patch selectivity but at moderate and high levels of dispersal- 
limitation, regional hydrological gradients and spatial factors overwhelm local influences. Modern metacommunity theory agrees with these results: moderately dispersal-limited systems tend to be driven by environmental gradients (Holyoak et al. 2005, Logue et al. 2011, Winegardner et al. 2012). However, environmental factors overall pale in comparison to the influences of interspecific trait differences.

\section{Implications}

While trait-based metacommunity assembly is becoming increasingly common in the literature (e.g., Pavoine et al. 2014, Spasojevic et al. 2014, Gianuca et al. 2016, Sarremejane et al. 2017), there has been little integration with metacommunity theory. In particular, the core paradigms of metacommunity ecology (neutral, mass effects, species sorting and patch dynamics) rely primarily on environmental factors, with the exception of patch dynamics (Leibold et al. 2004, Holyoak et al. 2005, Logue et al. 2011). This study has demonstrated that interspecific trait variation explains more variance in metacommunity assembly data than environmental factors. Specifically, standard theory would suggest that low dispersal-limitation should be driven largely by high inter-patch dispersal such that environmental signals are overwhelmed and even sinks persist (Holyoak et al. 2005, Logue et al. 2011, Winegardner et al. 2012). We add the suggestion that, in competitively structured metacommunities, competitive and life-history trait variation will be the greater structuring forces. As dispersal-limitation increases, standard theory states that environmental gradients will be driving forces of assembly (Holyoak et al. 2005, Winegardner et al. 2012). Our findings agree and add the hypothesis that 
environmental gradients will interact with competitive trait variation to drive assemblages.

Interestingly, the species-sorting style (along environmental gradients) assembly we observed in years two and three was still competitively structured according to traitbased analyses, which would suggest a more patch-dynamical (competitive) assemblage. Winegardner et al. (2012) discussed how the four core paradigms can be collapsed in to two: species sorting and neutral, with the three types of species sorting differentiating along a dispersal gradient and neutrality predominating with unlimited dispersal. We support this notion and provide evidence for such differentiation within a single metacommunity as it naturally re-assembles under various levels of dispersal-limitation. Our results also suggest that the lines between these discrete classifications are blurrier than typically discussed. Our second and third years represent moderately dispersallimited scenarios, which appear to be both competitively and environmentally structured. In other words, they align with both the species sorting and patch dynamics perspectives, likely because the level of dispersal-limitation is in between the levels necessary to fully adhere to either. We suggest metacommunity assembly be considered along a dispersallimitation gradient, in agreement with previous works (Ellis et al. 2006, Winegardner et al. 2012, Kuglerová et al. 2014, Gianuca et al. 2016), but also that greater thought be given to the mechanisms driving observed patterns. Species traits interact with the local and regional environment, as well as other species, to produce observed patterns. The details of these interactions are the true driving forces of assembly. We suggest that only through integration of trait-based and standard metacommunity assembly theory will we 
better understand the intricacies of metacommunity ecology, improve our understanding

and eventually management of spatially structured communities overall.

\section{REFERENCES}

Almany, G. R. 2003. Priority effects in coral reef fish communities. Ecology 84:19201935.

Alvarez-Filip, L., N. K. Dulvy, J. a Gill, I. M. Côté, and A. R. Watkinson. 2009. Flattening of Caribbean coral reefs: region-wide declines in architectural complexity. Proceedings of the Royal Society/ Biological sciences 276:3019-25.

Amarasekare, P. 2003. Competitive coexistence in spatially structured environments: a synthesis. Ecology Letters 6:1109-1122.

Blanchet, G., P. Legendre, and D. Borcard. 2008. Forward selection of spatial explanatory variables. Ecology 89:2623-2632.

Bonte, D., H. Van Dyck, J. M. Bullock, A. Coulon, M. Delgado, M. Gibbs, V. Lehouck, E. Matthysen, K. Mustin, M. Saastamoinen, N. Schtickzelle, V. M. Stevens, S. Vandewoestijne, M. Baguette, K. Barton, T. G. Benton, A. Chaput-Bardy, J. Clobert, C. Dytham, T. Hovestadt, C. M. Meier, S. C. F. Palmer, C. Turlure, and J. M. J. Travis. 2012. Costs of dispersal. Biological Reviews 87:290-312.

Cadotte, M., C. H. Albert, and S. C. Walker. 2013. The ecology of differences: Assessing community assembly with trait and evolutionary distances. Ecology Letters 16:1234-1244.

Cadotte, M. W. 2007. Competition-Colonization Trade-offs and Disturbance Effects at Multiple Scales. Ecology 88:823-829.

Capone, T. A., and J. A. Kushlan. 1991. Fish community structure in dry-season stream pools. Ecology 72:983-992.

Castillo-Escriva, A., J. A. Aguilar-Alberola, and F. Mesquita-Joanes. 2017. Spatial and environmental effects on a rock-pool metacommunity depend on landscape setting and dispersal mode. Freshwater Biology 62:1004-1011.

Davis, S. M., E. E. Gaiser, W. F. Loftus, and A. E. Huffman. 2005. Southern marl prairies conceptual ecological model. Wetlands 25:821-831.

Dayton, P. K. 2013. Competition, Disturbance, and Community Organization: The Provision and Subsequent Utilization of Space in a Rocky Intertidal Community. Ecological Monographs 41:351-389. 
Diamond, J. 1975. Assembly of species communities. Pages 342-444in M. Cody and J. Diamond, editors. Ecology and evolution of communities. Harvard University Press, Cambridge.

Drucker, E. G. 1996. The use of gait transition speed in comparative studies of fish locomotion. American Zoologist 36:555-566.

Drucker, E., and G. Lauder. 1999. Locomotor forces on a swimming fish: threedimensional vortex wake dynamics quantified using digital particle image velocimetry. The Journal of Experimental Biology 202:2393-2412.

Duckworth, R. A. 2008. Adaptive dispersal strategies and the dynamics of a range expansion. The American Naturalist 172: S4-S17.

Duckworth, R. a., and A. V Badyaev. 2007. Coupling of dispersal and aggression facilitates the rapid range expansion of a passerine bird. Proceedings of the National Academy of Sciences of the United States of America 104:15017-22.

Ellis, A. M., L. P. Lounibos, and M. Holyoak. 2006. Evaluating the long-term metacommunity dynamics of tree hole mosquitoes. Ecology 87:2582-2590.

Fernandes, I. M., R. Henriques-Silva, J. Penha, J. Zuanon, and P. R. Peres-Neto. 2013. Spatiotemporal dynamics in a seasonal metacommunity structure is predictable: the case of floodplain-fish communities. Ecography

Froese, R., and D. Pauly. 2017. FishBase. www.fishbase.org.

Fukami, T. 2004. Assembly history interacts with ecosystem size to influence species diversity. Ecology 85:3234-3242.

Gianuca, A. T., S. A. J. Declerck, M. W. Cadotte, C. Souffreau, T. De Bie, and L. De Meester. 2016. Integrating trait and phylogenetic distances to assess scaledependent community assembly processes. Ecography:1-11.

Goss, C. W., W. F. Loftus, and J. C. Trexler. 2014. Seasonal Fish Dispersal in Ephemeral Wetlands of the Florida Everglades. Wetlands January:1-11.

Gotelli, N. J. 1991. Metapopulation models: the rescue effect, the propagule rain, and the core-satellite hypothesis. The American naturalist 138:768-776.

Groen, M., N. M. Sopinka, J. R. Marentette, A. R. Reddon, J. W. Brownscombe, M. G. Fox, S. E. Marsh-Rollo, and S. Balshine. 2012. Is there a role for aggression in round goby invasion fronts? Behaviour 149:685-703. 
Heino, J., and M. Grönroos. 2013. Does environmental heterogeneity affect species cooccurrence in ecological guilds across stream macroinvertebrate metacommunities? Ecography 36:926-936.

Holyoak, M., M. A. Liebold, and R. D. Holt. 2005. Metacommunities: Spatial dynamics and ecological communities. University of Chicago Press.

Hubbell, S. P. 2001. The unified neutral theory of species abundance and diversity. Pages 96-97in S. P. Hubbell (2004), editor. Quarterly Review of Biology. Princeton University Press, Princeton, N.J.

Ingimarsdóttir, M., T. Caruso, J. Ripa, O. B. Magnúsdóttir, M. Migliorini, and K. Hedlund. 2012. Primary assembly of soil communities: disentangling the effect of dispersal and local environment. Oecologia 170:745-54.

Jacobson, B., and P. R. Peres-Neto. 2010. Quantifying and disentangling dispersal in metacommunities: How close have we come? How far is there to go? Landscape Ecology 25:495-507.

Kadowaki, K., R. a. B. Leschen, and J. R. Beggs. 2011. Competition-colonization dynamics of spore-feeding beetles on the long-lived bracket fungi Ganoderma in New Zealand native forest. Oikos 120:776-786.

Kline, J. L., W. F. Loftus, K. Kotun, J. C. Trexler, J. S. Rehage, J. J. Lorenz, and M. Robinson. 2014. Recent Fish Introductions Into Everglades National Park: An Unforeseen Consequence of Water Management? Wetlands 34:175-187.

Kneib, R. T., and A. H. Craig. 2001. Efficacy of Minnow Traps for Sampling Mummichogs in Tidal Marshes. Estuaries 24:884-893.

Kneitel, J. M., and J. M. Chase. 2004. Trade-offs in community ecology: linking spatial scales and species coexistence. Ecology Letters 7:69-80.

Kobza, R. M., J. C. Trexler, W. F. Loftus, and S. A. Perry. 2004. Community structure of fishes inhabiting aquatic refuges in a threatened Karst wetland and its implications for ecosystem management. Biological Conservation 116:153-165.

Kotun, K., and A. Renshaw. 2014. Taylor Slough Hydrology. Wetlands 34:9-22.

Kuglerová, L., R. Jansson, R. A. Sponseller, H. Laudon, and B. Malm-Renöfält. 2014. Local and regional processes determine plant species richness in a river-network metacommunity. Ecology 96:140817224931000. 
Kullander, S. O. 2003. Family Cichlidae. Pages 605-654in R. E. Reis, S. O. Kullander, and C. J. Ferraris, Jr., editors. Check List of the Freshwater Fishes of South and Central America.

Legendre, P., and E. Gallagher. 2001. Ecologically meaningful transformations for ordination of species data. Oecologia 129:271-280.

Leibold, M. A., J. M. Chase, and S. K. M. Ernest. 2016. Community Assembly and the Functioning of Ecosystems: How Metacommunity Processes Alter Ecosystems Attributes. Ecology 38:42-49.

Leibold, M. a., M. Holyoak, N. Mouquet, P. Amarasekare, J. M. Chase, M. F. Hoopes, R. D. Holt, J. B. Shurin, R. Law, D. Tilman, M. Loreau, and a. Gonzalez. 2004. The metacommunity concept: a framework for multi-scale community ecology. Ecology Letters 7:601-613.

Lepš, J., J. Osbornová-Kosinová, and M. Rejmánek. 1982. Community stability, complexity and species life history strategies. Plant Ecology 50:53-63.

Liew, J. H., L. R. Carrasco, H. H. Tan, and D. C. J. Yeo. 2016. Native richness and species level trophic traits predict establishment of alien freshwater fishes. Biological Invasions 18:3495-3512.

Loftus, W. F., R. A. Johnson, and G. H. Anderson. 1992. Ecological impacts of the reduction of groundwater levels in short-hydroperiod marshes of the Everglades. Pages 199-208. Proceedings of the First International Convergence on Ground Water Ecology.

Loftus, W. F., J. C. Trexler, J. S. Rehage, S. E. Liston, and K. J. Dunker. 2005. The Role of Aquatic Refuges in the Rockland Wetland Complex of Southern Florida, in Relation to System Restoration. Final project report to the National Park Service.

Logue, J. B., N. Mouquet, H. Peter, and H. Hillebrand. 2011. Empirical approaches to metacommunities: a review and comparison with theory. Trends in Ecology \& Evolution 26:482-91.

Lorenz, O. T., M. T. O’Connell, and P. J. Schofield. 2010. Aggressive interactions between the invasive Rio Grande cichlid (Herichthys cyanoguttatus) and native bluegill (Lepomis macrochirus), with notes on red spotted sunfish (Lepomis miniatus). Journal of Ethology 29:39-46.

Loughnan, D., and B. Gilbert. 2017. Trait-mediated community assembly: distinguishing the signatures of biotic and abiotic filters. Oikos 126:1112-1122. 
Martin, C. W., M. M. Valentine, and J. F. Valentine. 2010. Competitive interactions between invasive Nile tilapia and native fish: the potential for altered trophic exchange and modification of food webs. PloS One 5:e14395.

McGinley, M. A., D. H. Temme, and M. A. Geber. 1987. Parental investment in offspring in variable environments: theoretical and empirical considerations. The American Naturalist 130:370-398.

Michelson, A. V., L. E. Park Boush, and J. J. Pan. 2016. Discerning patterns of diversity from biogeographical distributions: testing models of metacommunity dynamics using non-marine ostracodes from San Salvador Island, Bahamas. Hydrobiologia 766:305-319.

Mills, M. D., R. B. Rader, and M. C. Belk. 2004. Complex Interactions Between Native and Invasive Fish: the Simultaneous Effects of Multiple Negative Interactions. Oecologia 141:713-21.

Mouquet, N., and M. Loreau. 2003. Community patterns in source-sink metacommunities. The American Naturalist 162:544-557.

van Noordwijk, C. G. E., W. C. E. P. Verberk, H. Turin, T. Heijerman, K. Alders, W. Dekoninck, K. Hannig, E. Regan, S. McCormack, M. J. F. Brown, E. Remke, H. Siepel, M. Berg, and D. Bonte. 2015. Species - area relationships are modulated by trophic rank, habitat affinity, and dispersal ability. Ecology 96:518-531.

Orrock, J. L., J. H. Grabowski, J. H. Pantel, S. D. Peacor, B. L. Peckarsky, A. Sih, and E. E. Werner. 2008. Consumptive and nonconsumptive effects of predators on metacommunities of competing prey. Ecology 89:2426-35.

Padial, A. A., F. Ceschin, S. A. J. Declerck, L. De Meester, C. C. Bonecker, F. A. Lansac-Tôha, L. Rodrigues, L. C. Rodrigues, S. Train, L. F. M. Velho, and L. M. Bini. 2014. Dispersal ability determines the role of environmental, spatial and temporal drivers of metacommunity structure. PLoS ONE 9:1-8.

Panek, F. M., and C. L. Densmore. 2013. Frequency and severity of trauma in fishes subjected to multiple-pass depletion electrofishing. North American Journal of Fisheries Management 33:178-185.

Pavoine, S., M. Baguette, V. M. Stevens, M. A. Leibold, C. Turlure, and M. B. Bonsall. 2014. Life-history traits, but not phylogeny, drive compositional patterns in a butterfly metacommunity. Ecology 95:1939-1970.

Petchey, O. L., and K. J. Gaston. 2006. Functional diversity: Back to basics and looking forward. Ecology Letters 9:741-758. 
R Core, T. 2012. R: A language and environment for statistical computing. R Foundation for Statistical Computing, Vienna, Austria.

Rehage, J. S., S. E. Liston, K. J. Dunker, and W. F. Loftus. 2014. Fish community responses to the combined effects of decreased hydroperiod and nonnative fish invasions in a karst wetland: are Everglades solution holes sinks for native fishes? Wetlands:1-15.

Rodríguez, A., and J. Kouki. 2017. Disturbance-mediated heterogeneity drives pollinator diversity in boreal managed forest ecosystems. Ecological Applications 27:589602.

Sarremejane, R., H. Mykrä, N. Bonada, J. Aroviita, and T. Muotka. 2017. Habitat connectivity and dispersal ability drive the assembly mechanisms of macroinvertebrate communities in river networks. Freshwater Biology 62:10731082.

Schneider, C. A., W. S. Rasband, and K. W. Eliceiri. 2012. NIH Image to ImageJ: 25 years of image analysis. Nature Methods 9:671-675.

Sih, A., J. Cote, M. Evans, S. Fogarty, and J. Pruitt. 2012. Ecological implications of behavioral syndromes. Ecology Letters 15:278-89.

Soininen, J. 2014. A quantitative analysis of species sorting across organisms and ecosystems. Ecology 95:3284-3292.

Sokol, E. R., J. M. Hoch, E. Gaiser, and J. C. Trexler. 2014. Metacommunity Structure Along Resource and Disturbance Gradients in Everglades Wetlands. Wetlands 34:135-146.

Spasojevic, M. J., S. Copeland, and K. N. Suding. 2014. Using functional diversity patterns to explore metacommunity dynamics: a framework for understanding local and regional influences on community structure. Ecography 37:939-949.

Stier, A. C., S. W. Geange, K. M. Hanson, and B. M. Bolker. 2013. Predator density and timing of arrival affect reef fish community assembly. Ecology 94:1057-1068.

Stunz, G. W., P. S. Levin, and T. J. Minello. 2001. Selection of estuarine nursery habitats by wild-caught and hatchery-reared juvenile red drum in laboratory mesocosms. Environmental Biology of Fishes 61:305-313.

Telis, P. A., and H. Henkel. 2009. Everglades Depth Estimation Network (EDEN) Applications: Tools to view, extract, plot and manipulate EDEN data. 
Thompson, P. D., and F. J. Rahel. 1996. Evaluation of depletion-removal electrofishing of brook trout in small rocky mountain streams. North American Journal of Fisheries Management 16:332-339.

Urban, M. C., and L. De Meester. 2009. Community monopolization: local adaptation enhances priority effects in an evolving metacommunity. Proceedings. Biological sciences / The Royal Society 276:4129-38.

Violle, C., M. L. Navas, D. Vile, E. Kazakou, C. Fortunel, I. Hummel, and E. Garnier. 2007. Let the concept of trait be functional! Oikos 116:882-892.

Winegardner, A. K., B. K. Jones, I. S. Y. Ng, T. Siqueira, and K. Cottenie. 2012. The terminology of metacommunity ecology. Trends in Ecology \& Evolution 27:2534.

Wootton, J. T., and M. Emmerson. 2005. Measurement of Interaction Strength in Nature. Annual Review of Ecology, Evolution, and Systematics 36:419-444.

Zheng, C., O. Ovaskainen, T. Roslin, and A. J. M. Tack. 2015. Beyond metacommunity paradigms: habitat configuration, life history, and movement shape an herbivore community on oak. Ecology 96:3175-3185. 


\section{CHAPTER II}

INVASIVE SPECIES AGGREGATE ASSEMBLING METACOMMUNITIES 


\begin{abstract}
Community assembly has long been considered a function of niche or neutral processes, or a combination of the two. However, recent work has shown that individual species have an overriding influence on the assembly process. Given the ever-increasing global rate of biological invasions, it is then prudent to ask: how does the introduction of a new species influence community assembly? I addressed that question by observing assembly in a fish metacommunity before and after the introduction of, an invasive species. African Jewelfish (Hemichromis letourneuxi) expanded through the Rocky Glades region of Everglades National Park in 2002. Through collaboration with other researchers, I observed assembly in the Rocky Glades for three years prior to invasion (1999, 2000 and 2002), two years immediately following invasion (2003 and 2004), and 10+ years after the invasion (2013-2015). Pre-invasion, the fish metacommunity was neutrally assembled, while post-invasion it was significantly aggregative. The switch from neutrality to aggregation occurred immediately following the African Jewelfish invasion. This condition persisted over 10 years later. The aggregated contemporary assembly was driven by regional hydrology and variation in the African Jewelfish's local abundance. An extensive review of the limited literature asking the same core question shows that decreased segregation, or increased aggregation, has been observed immediately following invasions across multiple taxa (plants, insects, amphibians and now fish). While further work is needed to assess the repeatability and reliability of the pattern, it appears that the introduction of an invasive species decreases segregation. If true, this could be a useful tool for quickly and inexpensively screening for effects of new invaders using existing biological monitoring data.
\end{abstract}




\section{INTRODUCTION}

Community assembly is typically considered to be a function of either neutral or niche-based processes (Hubbell 2001b, Tilman 2004, Mikkelson 2005). In other words, communities can be structured in space and time by either stochastic immigration and emigration, or by species responding to environmental gradients and interspecific competition. More recently ecologists have begun to accept that both niche and neutral processes play a role in the assembly of natural communities (Tilman 2004, Adler et al. 2007, Mutshinda and O'Hara 2011), and attentions are shifting toward understanding the relative roles of species themselves in the assembly process (e.g., Giacomini et al. 2013, Mouillot et al. 2013, Loughnan and Gilbert 2017). The relative importance of individual species, and the differences among them, on the overall assembly of natural communities can be more influential than the structuring forces of the environment itself (Gianuca et al. 2016). For example, some predators can shift prey distributions resulting in patchy prey aggregations (Mouquet et al. 2005), while others prevent emigration from local patches thereby increasing local abundances and diversities (e.g., Stier et al. 2013). Given the high relative influence of individual species on assembly, and the ever increasing global rate of biological invasions (Huang et al. 2011, Rehage and Blanchard 2016), it is prudent to ask what influence does introduction of new species have on assembly.

While the impact of invasions can range from non-significant to catastrophic (Cucherousset and Olden 2011), with the most damaging invasions resulting in multispecies extirpations (e.g., Nile Perch; Goudswaard et al. 2006), few commonalities have been described to allow prediction of these impacts (but see Simberloff et al. 2013 for a discussion of some commonalities). In the context of community assembly, potential 
consequences of an invasion can be broadly categorized into three groups: no influence, segregative (reduction in the number of species co-occurrences) or aggregative (increase in the number of species co-occurrences). The most common result of new introductions is likely to be no impact, with few species becoming truly invasive (Williamson et al. 1996). If they increase aggregation, this may result in higher levels of interspecific competition, encouraging either high emigration rates or local extirpations of poorly competitive species (Amarasekare 2003, Holyoak et al. 2005). Conversely, increased segregation can serve to preserve diversity of a system by allowing the co-existence of competitive species and the persistence of poor competitors, but may also create other negative effects such as a spatiotemporal consumer-resource mismatch (Amarasekare 2003, Holyoak et al. 2005).

Both scenarios can result from spatially variable influences of the invasive species, whereby avoidance of the invader can serve to aggregate natives, or else the differential ability of native species to co-exist with the invader could segregate them (Sanders et al. 2003). Most frequently in the context of ant communities, invasions have been shown to 'disassemble' a community through decreased segregation following the introduction of an invasive species (Gotelli and Arnett 2000, Sanders et al. 2003). The same general pattern of decreasing segregation has also been noted in plant and amphibian communities (Reshi et al. 2008, Richter-Boix et al. 2013), with no studies to date demonstrating an alternative response. The consistency of this response so far, across a few taxa, lead us to hypothesize that invasive species may have a consistent effect on community assembly. 
The present study evaluates this hypothesis using a two-pronged approach. First we observed the annual re-assembly of the most heavily invaded fish community in South Florida, the Rocky Glades (RG) region of Everglades National Park (Kline et al. 2014, Schofield and Loftus 2014). This system, which has nearly 50\% non-native diversity (Kline et al. 2014), was neutrally structured in 1999 and 2000 (Kobza et al. 2004), which is typical of fish communities lacking truly invasive species (Muneepeerakul et al. 2008, Sharma et al. 2011), despite multiple non-native species already having been well established in the area for several decades (Kobza et al. 2004, Kline et al. 2014). Following Kobza et al.'s 2004 field data collection however, in late 2002, the African Jewelfish (Jewelfish, Hemichromis letourneuxi) was noted to begin expanding throughout the RG region (Kline et al. 2014). Jewelfish are now highly abundant throughout the ecosystem (Kline et al. 2014), and generally thought to be an invasive species. We asked if the Jewelfish invasion of the Rocky Glades corresponded to a shift in community assembly patterns. Second, we follow up our own findings with a review of all comparable previous studies which asked if the introduction of an invasive species corresponded to a shift in community assembly patterns. Specifically, the goals of this study were to address three key questions: 1) Did the Jewelfish invasion shift community assembly patterns? If so, then 2) is this species a driver of modern assembly? We conclude with the question: 3) have previous studies found a repeated pattern of assembly changes following the introduction of an invasive species?

\section{METHODS}

To determine if the introduction of African Jewelfish corresponded to a shift in assembly patterns in the Rocky Glades, we observed a fish metacommunity re- 
assembling following drought induced extirpations for two years before and three years following an invasion. We also observed assembly for three more recent years, with depletion sampling to examine the influence of this species on contemporary metacommunity assembly. We concluded with an extensive review of the comparable literature to determine if our observed patterns were repeated in previous works.

\section{Study system}

We observed assembly of the fish community inhabiting solution holes in the Rocky Glades (RG) region of Everglades National Park in 2013, 2014 and 2015 (Figure 6). At the onset of the wet season, solution holes in the RG fill with water and are connected via surface water to other holes, and to deeper, more permanent habitats forming a complex matrix of habitat patches and population sources (Kobza et al. 2004). As wet season water levels rise and these habitats become flooded, fish disperse out of deeper sources to colonize solution holes (Kobza et al. 2004, Loftus et al. 2005, Rehage et al. 2014, Goss et al. 2014). In the dry season, solution holes become disconnected from the surface as waters recede, limiting aquatic habitat to only the deepest solutions holes in landscape (Kobza et al. 2004). Under modern hydrological conditions, most fishes are annually extirpated by a combination of abiotic stress, predation from both native and non-native taxa, and desiccation (Loftus et al. 1992, Kobza et al. 2004, Rehage et al. 2014), such that the metacommunity re-assembles annually. Previous studies have shown that these communities tend to have high non-native diversity, with 3-75\% non-native diversity (Kline et al. 2014) trending closer to $45 \%$ in moderate hydroperiod areas (Rehage et al. 2014). Notably, the African Jewelfish which began spreading through the RG in 2002 following a high water event, is now numerically dominant in the RG and 
neighboring source habitats (Kline et al. 2014). We focus on Jewelfish as their rapid population growth and expansion in the system (Kline et al. 2014), as well as novel behavior and piscivory (Lopez 2011, Rehage et al. 2014) suggest it to likely be, or become, invasive. Therefore, we considered the 'pre-invasion' data to be those gathered before 2003, categorizing all data collected during or after 2003 as 'post-invasion.'

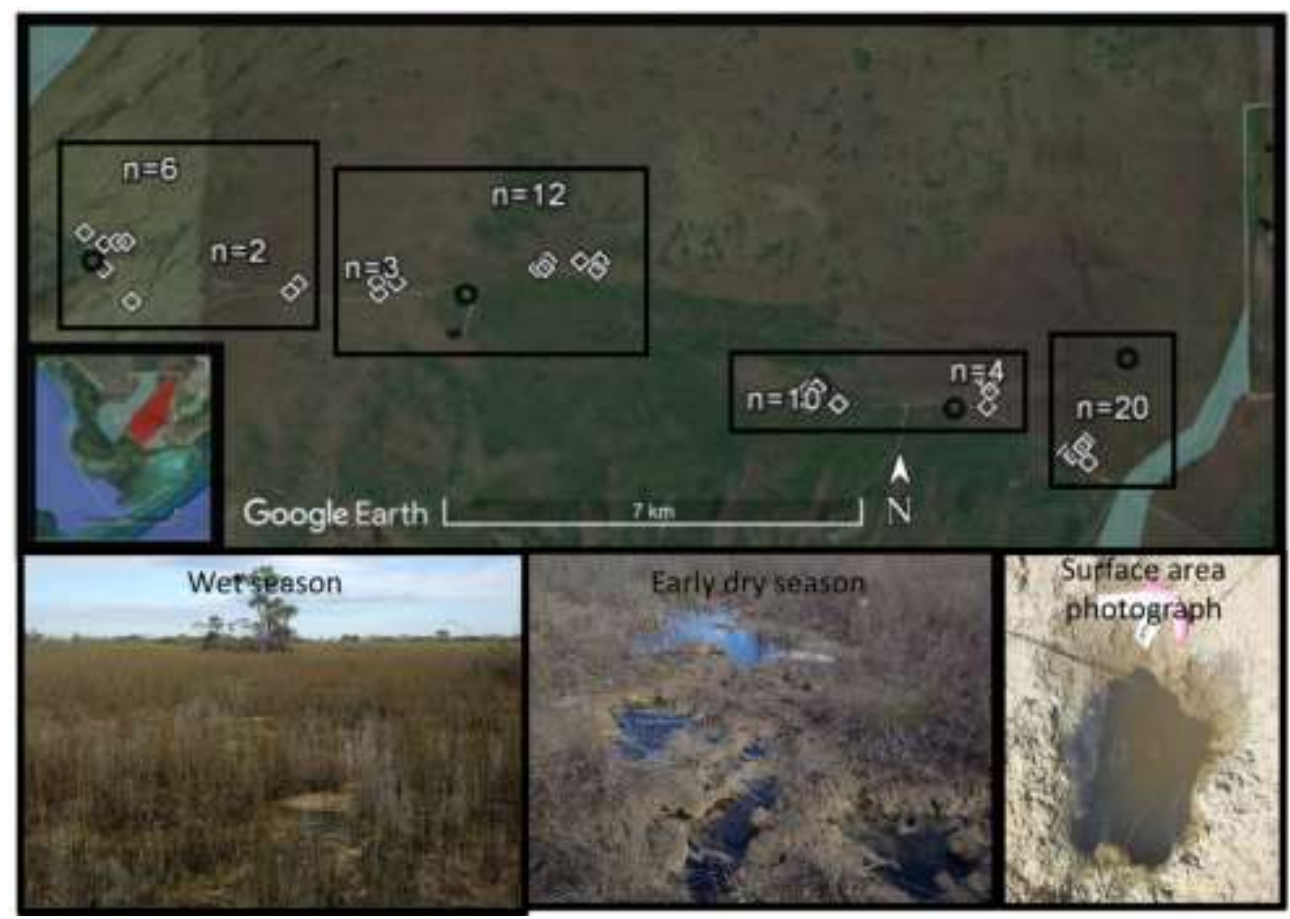

Figure 6 Map of the Rocky Glades region (shown in red in insert), top, located in the northeast corner of Everglades National Park. Blue regions are Shark River Slough to the west, Taylor Slough and canals to the east. Sampled solution holes are denoted by white diamonds. Sample size is displayed over each hole cluster, and the nearest hydrological stations are represented by black circles. Boxes represent sampling regions used in this study. The bottom three panels show examples of the RG environment in the wet, left, and dry, middle, seasons as well as an example of the photographs used to determine solution hole surface area.

\section{Community sampling}

The data used in this study come from three distinct sampling efforts. The first was originally published in Kobza et al. 2004. They used un-baited minnow traps in 21 
solution holes in 1999 and 23 in 2000 during the wet season re-assembly events. This was followed by the sampling detailed in Loftus et al. (2005), which used comparable sampling methods. From that effort, we collected data on the assembly of fishes in 30, 36 and 32 solution holes in 2002, 2003 and 2004 respectively. The 2002 samples took place before the first noted expansion of Jewelfish in to this area. For more details on these studies, see Kobza et al. (2004) and Loftus et al. (2005).

To evaluate the modern status of Jewelfish in the RG, and their role in contemporary assembly events, we also used more recent (2013-2015) assembly data. All holes were sampled during the wet season, when they first became isolated from surface water (i.e., when they become a single habitat patch). Sampling was done as water levels receded, within seven days of the hole community becoming disconnected from surface water. This was considered the point when no further immigration or emigration was possible, but before post-assembly interactions (i.e., predation, competition or in situ reproduction) cause changes in the structure of each solution hole's fish community. The complex solution hole environment itself is not conducive to many forms of non-lethal sampling. Fish-traps have been used in the past (see Kobza et al. 2004 and Kline et al. 2014), but can be subject to behavioral and size biases and have poor capture rates on some species (particularly with synbranchiform eels, Jeff Kline personal communication). Thus, we sampled study sites with depletion backpack electrofishing, shown to be effective in confined environments (Thompson and Rahel 1996), and likely more representative of the true community present. 
Each site was electrofished to depletion in two sequential sampling events, using a Smith-Root L-24 with 100-250 volts and a duty cycle of 12-18\% (Thompson and Rahel 1996, Panek and Densmore 2013). In each sampling event, we sampled in ten second bouts that covered the entire area of the hole up and down the water column, in and out of any vegetation present. When five consecutive bouts yielded no additional fish, the hole was 'rested' for a minimum of ten minutes; after which, the hole was sampled again until five consecutive bouts yielded no signs of additional animals. Upon capture, all fishes were placed in an aerated bucket for identification and enumeration. All fishes were counted, their standard lengths were measured, and all natives were released. All nonnatives were humanely euthanized per scientific permit requirements. Overall, we observed the fishes in 137 solution hole communities over the three years. No native mortality was noted.

To describe the solution hole environment, surface area, rugosity, maximum depth and percent vegetative cover were surveyed prior to sampling. Surface area was measured using photographs, taken from above the hole during the dry season, using Image J (Schneider et al. 2012). Maximum depth was measured as the distance from the top of the hole to the top of the sediment. Rugosity was measured as $\frac{\left(\frac{\alpha_{1}}{\beta_{1}}+\frac{\alpha_{2}}{\beta_{2}}\right)}{2}$ where $\alpha_{1}$ and $\alpha_{2}$ represent the lengths of chain passed along perpendicular straight lines, between two points on the surface of the hole, tracking the complex surfaces of the sides and bottoms of the solution hole, whereas $\beta_{1}$ and $\beta_{2}$ represent the shortest linear distance between the same two points (Alvarez-Filip et al. 2009). Finally, the percent vegetative 
cover was visually estimated as the proportion of area of the hole covered by either emergent or submerged vegetation, including floating periphyton.

We described the environment fish must transverse to reach solution holes or the dispersal matrix, by measuring the shortest distance from each hole to longer-hydroperiod source habitats (i.e., Shark River Slough), the regional daily water recession rate (mean difference of water depth, in $\mathrm{mm}$, from one day to the next during the annual recession in each region), and the annual regional hydroperiod in days (how long the surface was flooded before assembly events). Preliminary analyses and observations indicated four hydrologically distinct regions within the $\mathrm{RG}$, and both recession and hydroperiod were at this regional scale (Figure 6). Distance to source was measured in Google Earth. Both hydrological variables were calculated using raw water level data from the four Everglades Depth Estimation Network hydrostations located in each region (Telis and Henkel 2009).

Analyses

We used Stone and Robert's (Stone and Roberts 1990) null model analysis to test for patterns of co-occurrence before and after the African Jewelfish invasion. The technique has been used extensively to evaluate if species co-occur more or less frequently than expected by random chance. Using Gotelli and Entsminger's EcoSim v.7 software (Gotelli and Entsminger 2005), we generated 5000 random matrices via a fixedequiprobable sequential swap algorithm (the number of sites a species occurs in was fixed, but the number of species in a given site was allowed to vary randomly). From these, we tested if each year's observed presence-absence matrix deviated from these 
matrices. The mean number of co-occurrences is converted into a standardized effect size (SES), with 2 standard deviations from zero being approximated by the values of \pm 1.96 . To evaluate if pre and post invasion structures were significantly different. We used a Ttest to investigate differences in the mean SES for pre-invasion years $(1999,2000$ and 2002) and invaded years (2003 and 2004) structure.

Contemporary metacommunity assembly was described using redundancy analyses (RDAs) as a function of regional (two hydrological variables), local factors (four solution hole attributes) and the presence and abundance of jewelfish. Redundancy analyses are designed to ordinate two related matrices, a descriptor matrix and a community matrix, to determine the two dimensions (descriptors) which best explain variations in the community matrix (Legendre and Anderson 2006, Blanchet et al. 2008). To determine the influence of Jewelfish on assembly, relative to abiotic factors, we included them in the descriptor matrix and removed them from the community matrix. Non-metric multidimensional scaling (NMDS) was used to evaluate the differences in communities where Jewelfish were present versus when they were absent (Kruskal and Wish 1978). An analysis of similarities (ANOSIM) was used to evaluate whether the differences between groups were statistically significant, and a similarity of percentage analysis (SIMPER) to determine which species contributed the most to these differences, following Santos et al. (2016). We also compared the total diversity, non-native diversity and total abundance across sites where Jewelfish were present and absent using T-tests. Analyses comparing sites where Jewelfish were present and absent did not include Jewelfish as part of the community. All statistical analyses were performed in RStudio (R Core 2012). The t-tests were performed using the t.test function from the stats package, 
while the RDA, NMDS, ANOSIM and SIMPER were performed using the $r d a$, metaMDS, anosim and simper functions respectively from the vegan package (R Core 2012). The ANOSIM and SIMPER analyses were both performed with 999 permutations for the evaluation of significant differences. For all analyses relying on distance-matrices, the Bray-Curtis dissimilarity metric was used.

\section{Literature-review}

Our goal was to review all available peer reviewed literature addressing the question: do assembly rules change following the introduction of an invasive species. We searched the literature for peer-reviewed papers containing the words "invasive" or "nonnative", or containing the terms "community assembly", "invasive" or "non-native" and employed a null model analysis. Described at length in Stone and Roberts (1990), these null model analyses have been widely used to address similar questions over the past several decades as they are robust to the small matrix sizes, additions of new species (Lavender et al. 2016) and their results are comparable across taxa. From these studies, we extracted the reported standardized effect sizes (SES) for before and after invasions. For studies which presented time series data, with multiple reported SES before or after invasion, we used the mean SES. Where values were not directly reported in text, they were estimated from figures using DataThief III (Tummers 2006).

\section{RESULTS}

\section{African Jewelfish invasion}

Before the Jewelfish invasion, the Rocky Glades fish metacommunity did not significantly deviate from a random assemblage (Kobza et al. 2004; Figure 7). However, 
in the first year following the invasion, 2003, and in all subsequent years, assembly was aggregative (Figure 7). There was a significant difference between pre $(1999-2000,2002)$ and post (2003-2004) invasion SES (D.F.=3, $\mathrm{t}=3.433, \mathrm{P}=0.021$ ). Contemporary assembly events remain aggregative and were substantially lower than earlier observed events. However, the contemporary data were derived in a way which was not comparable to the older data sets and therefore statistical differences between the time periods cannot be evaluated. Jewelfish are also now the second most abundant species in RG solution hole fish communities, and the only abundant piscivorous fish (Figure 8).

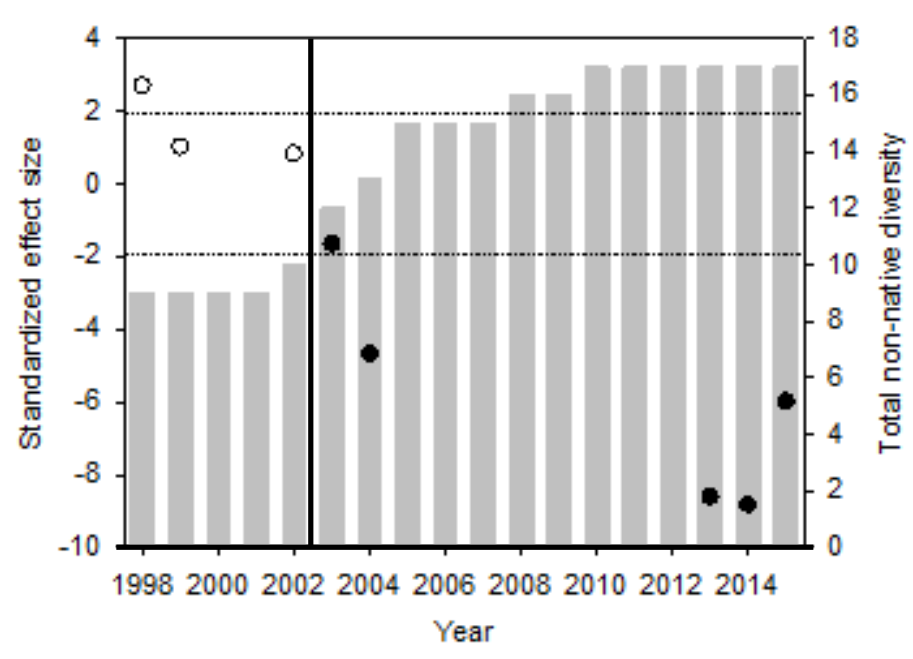

Figure 7 Standardized effect sizes of all fish assembly data available (Kobza et al 2004, Loftus et al 2004 and this study's electrofishing data) over time. White points are preinvasion and black are post-invasion data, showing a decline in the standardized effect size of following the African Jewelfish invasion of the Rocky Glades (black vertical line). Bars mark the cumulative diversity of non-native fish in the Rocky Glades, per Kline et al. (2014), horizontal dashed lines denote approximate significance boundaries for deviations from "random" assembly. 


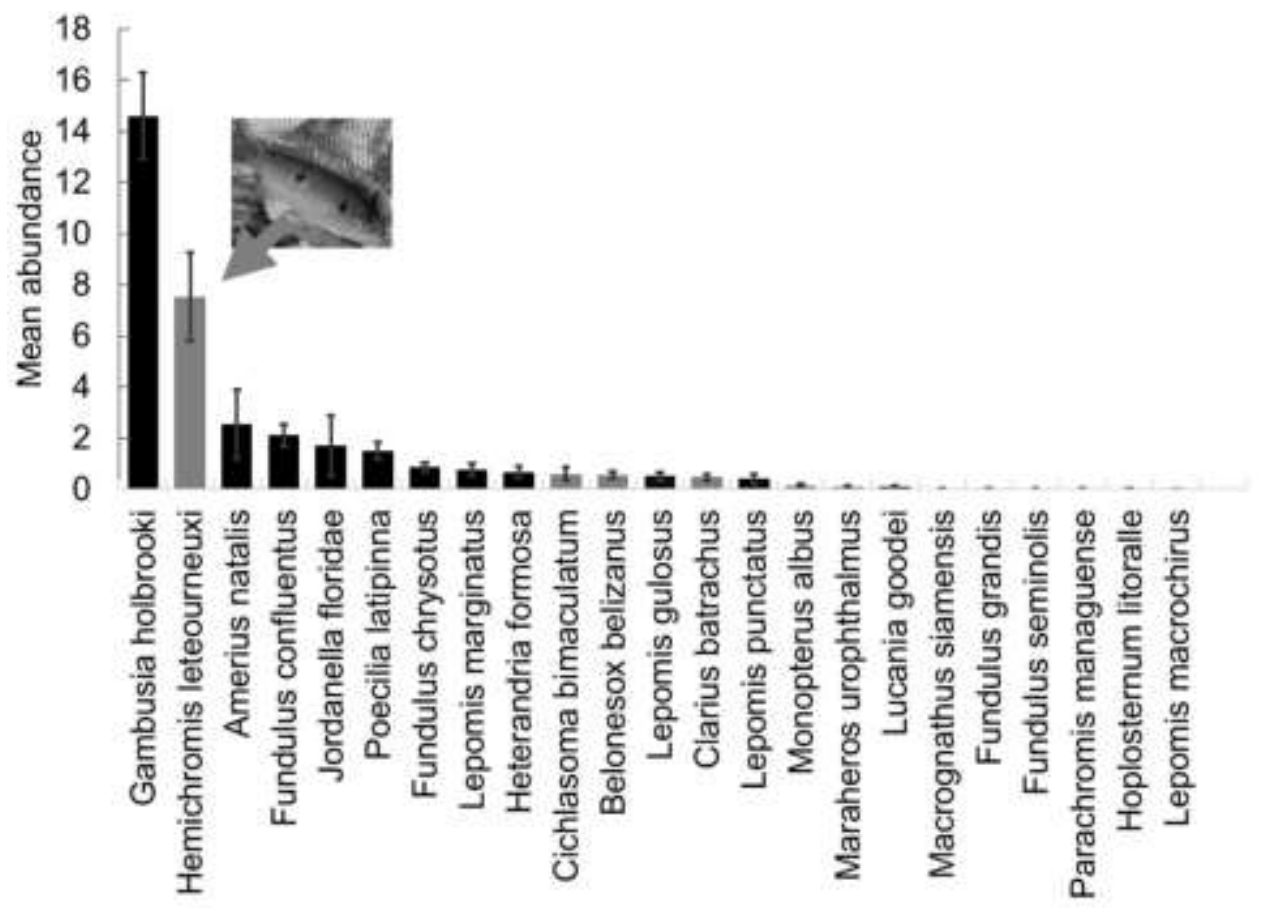

Figure 8 Mean abundance, and standard errors of the mean, of each species in modern (2013-2015) solution hole communities across all years. Black bars are natives, gray bars are non-natives and the focal species of this study, the African Jewelfish, is highlighted with the arrow. This species was the second most abundant fish, and was the most abundant non-native, encountered.

Overall, assembly of the solution hole communities was driven largely by dispersal distances and regional hydrology, with Jewelfish abundance as the third most influential factor overall, and the most influential local-scale factor (D.F. $=8, \mathrm{P}<0.001$, Global $\mathrm{R}_{\text {adj. }}^{2}=0.170$; Table 5 and Figure 9). Jewelfish were present in 64 of the 137 solution holes sampled over the 3 years, being present in a mean of $39.13 \pm 5.27 \%$ of all sites in a given year. 
Table 5 Biplot scores for RDAs 1 and 2. Higher absolute values denote higher relative influence on the metacommunity assembly process. The top three driving factors along each axis are shaded. Global $\mathrm{R}_{\text {adj }}^{2}=0.170$

\begin{tabular}{l|rr} 
Descriptor & RDA1 & RDA2 \\
\hline Rugosity & 0.196 & 0.473 \\
Surface area & 0.062 & 0.088 \\
Percent veg. cover & -0.083 & -0.288 \\
Depth & 0.253 & -0.011 \\
Distance to source & 0.629 & -0.363 \\
Regional hydroperiod & -0.852 & -0.028 \\
Recession rate & 0.237 & -0.274 \\
African Jewelfish abundance & -0.454 & 0.669
\end{tabular}

Communities where Jewelfish were present had significantly higher mean abundances (D.F. $=105.6, \mathrm{t}=2.610, \mathrm{P}=0.010)$ and diversity (D.F. $=104.05, \mathrm{t}=4.629, \mathrm{P}<0.001)$ with significantly more of both non-native (D.F. $=102.1, \mathrm{t}=3.685, \mathrm{P}<0.001)$ and native species (D.F. $=113.67, t=4.007, \mathrm{P}<0.001$; Figure 10) than those where Jewelfish were absent. The dissimilarity between the communities where Jewelfish were present and absent was statistically significant, but the ANOSIM's R was exceedingly small $(\mathrm{R}=0.056, \mathrm{P}=0.001)$ and there was a large amount of overlap in the NMDS despite a reasonably low stress value of 0.17 (Figure 11, Table 6) suggesting no true differences existed. The slight differences between these types of communities was largely caused by significant increases in two native prey species (Poecilia latipinna and Jordanella floridae) as well as a less abundant non-native piscivore (Belonesox belizanus) and a native benthic omnivore (Amerius natalis). 


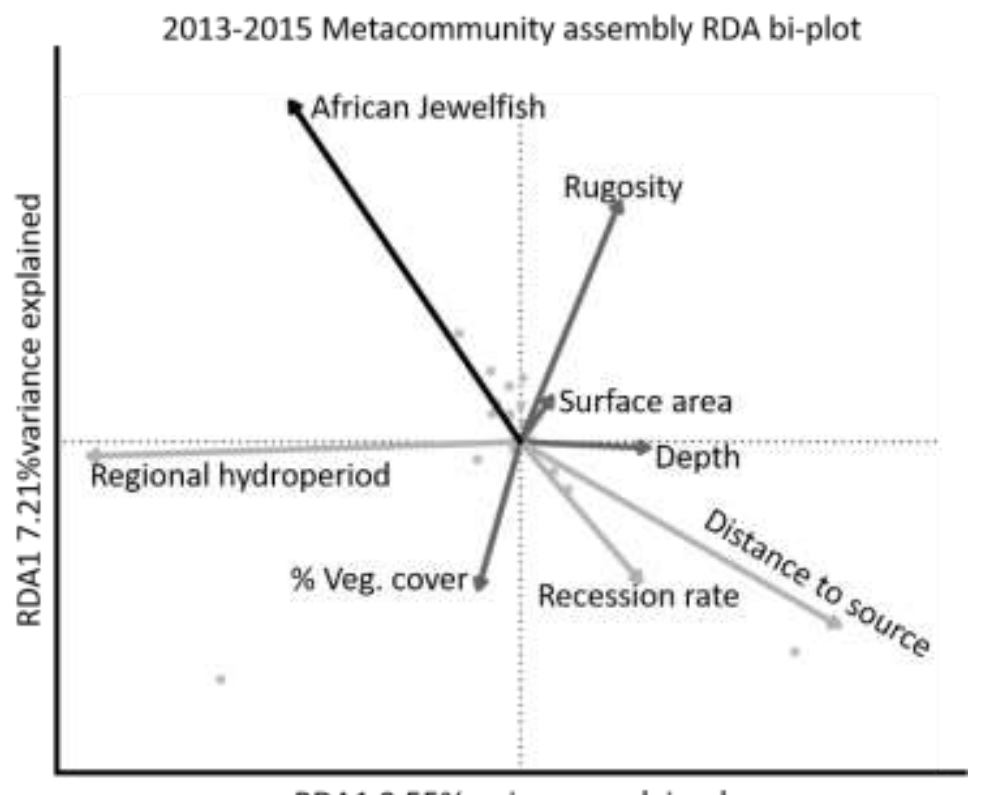

RDA1 9.55\%variance explained

Figure 9 Bi-plot of RDA scores describing Rocky Glades 2013-2015 fish metacommunity assembly. Vector colors reflect descriptor category (local=dark gray, regional=light gray and African Jewelfish=black), with the relative importance of each factor signified by the relative length of the vector and the direction of its influences signified by the direction. Gray points show where individual species sort along these gradients. Distance to source, regional hydroperiod and African Jewelfish abundance were the most influential factors overall. 


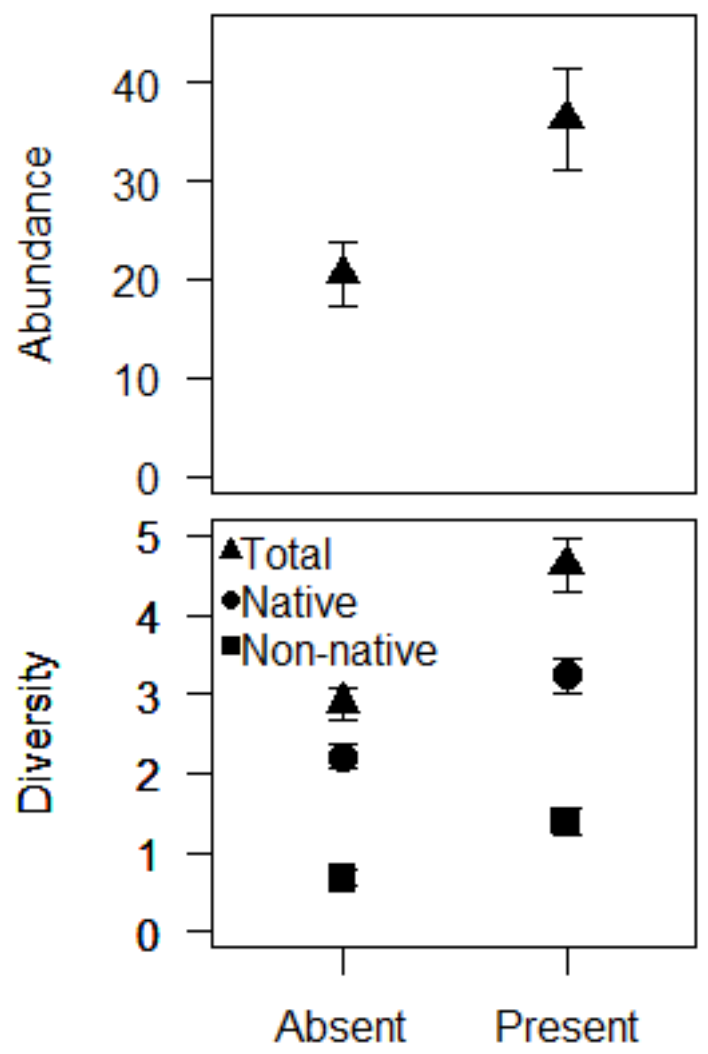

Figure 10 Significant differences in the mean total abundance (top) and diversity (bottom) of solution hole communities where African Jewelfish were present versus absent in the electrofishing data are shown. For diversity, the native only (circle), nonnative only (square) and total (triangle) diversity are shown. Error bars represent standard errors of the mean. 


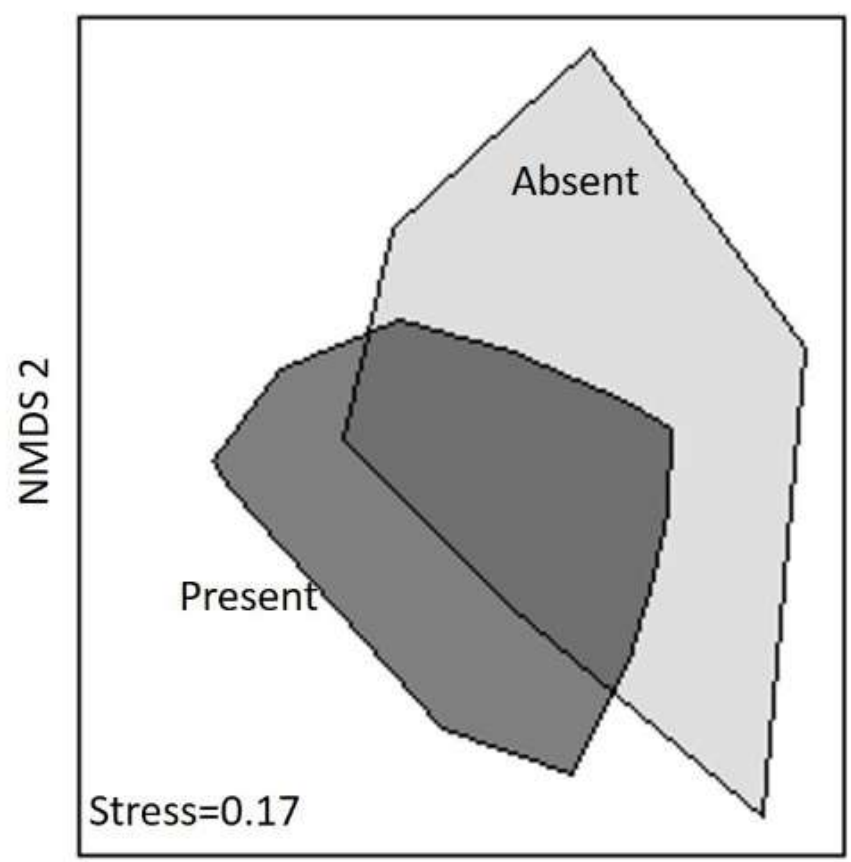

NMDS 1

Figure 11 NMDS of solution hole communities where African Jewelfish were present (dark gray) versus absent (white), across all three years of electrofishing data showing little dissimilarity between the two types of communities. The relatively low two dimensional stress suggests that the large amount of overlap shown is representative of reality.

Table 6 The ANOSIM R and P values are shown at the top of the table, demonstrating that there are negligible but significant differences between the communities. The table shows the results of the SIMPER analysis which describes the differences between communities where Jewelfish were present versus absent in terms of the species which explain a cumulative $80 \%$ of the variance in the differences. Species with significant variation between the two categories are denoted with an asterisk adjacent to the P-value, and the direction of the change in density $(\Delta \mathrm{D})$ of the species when Jewelfish are present. Non-natives are noted by ${ }^{\mathrm{NN}}$.

ANOSIM R= 0.056, $\mathrm{P}=0.001$

Species

Gambusia holbrooki

Fundulus confluentus

Poecilia latipinna

Ameirius natalis

Fundulus chrysotus

Jordanella floridae

Belonesox belizanus ${ }^{\mathrm{NN}}$
$\Delta D$ when present Cum. \% var. $P$

$\begin{array}{lll}= & 0.44 & 1 \\ = & 0.57 & 0.471 \\ + & 0.63 & 0.001^{*} \\ + & 0.70 & 0.001^{*} \\ = & 0.74 & 0.175 \\ + & 0.78 & 0.041^{*} \\ + & 0.82 & 0.001^{*}\end{array}$




\section{Literature review}

Very few studies have used comparable null model analyses to compare pre and post invasion assemblages. Despite an exhaustive search of the available literature, only five studies met our criteria (Figure 12). Two of these, Gotelli \& Arnet (2000) and Sanders et al. (2003) performed two independent experiments of pre and post invasion assemblages. These were treated separately. These five studies spanned multiple taxa: insects (Gotelli and Arnett 2000, Sanders et al. 2003), plants (Reshi et al. 2008, Kuebbing et al. 2014) and amphibians (Richter-Boix et al. 2013). All studies to date have found the same general pattern: the SES is reduced following the introduction of an invasive species, signifying a reduction in the amount of segregation in the community. While no studies noted a switch from segregation to aggregation, three observed shifts from segregation to neutrality (Gotelli and Arnett 2000, Sanders et al. 2003, Richter-Boix et al. 2013). Sanders et al. (2003) did however report on a time series of SES, following an ant community before and after an invasion. While the mean SES of this community following the invasion was neutral rather than the initial segregated state (Figure 2), the final-point in their time series was aggregative. Both Reshi et al. (2008) and Kuebbing et al. (2014) describe reductions in the level of segregation without the SES falling far enough to be considered neutral or aggregative. 


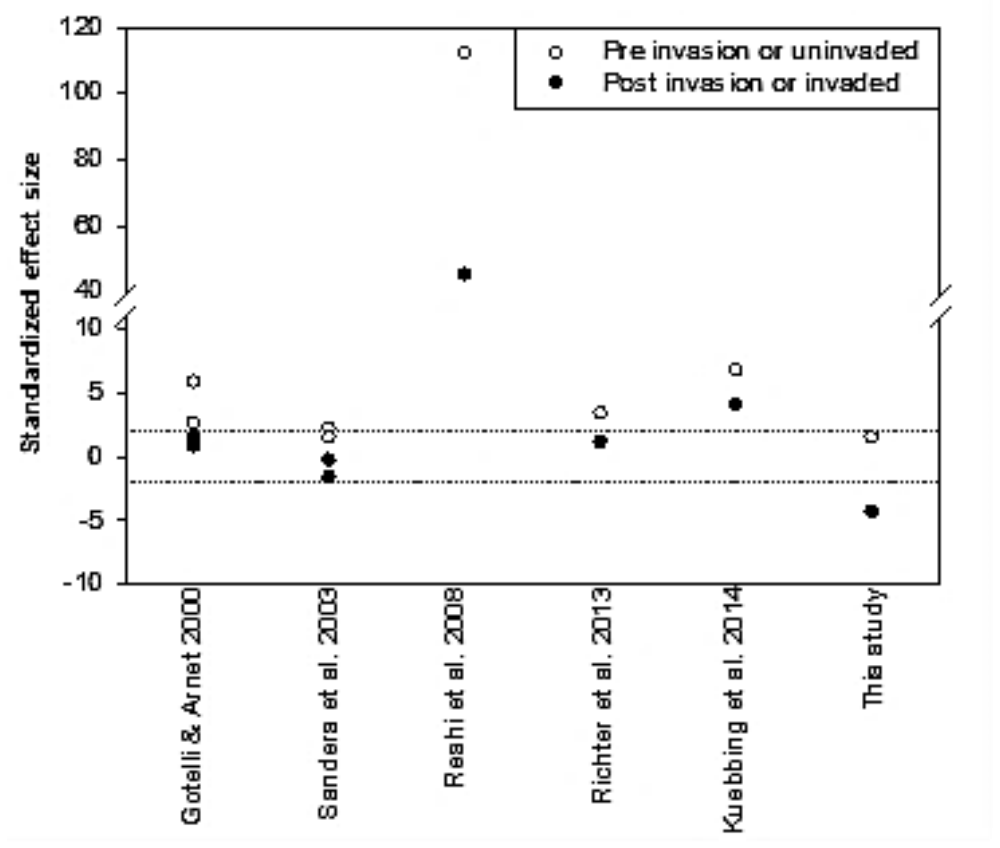

Figure 12. Standardized effect sizes, derived via comparable null model analyses, presented in papers assessing pre-invasion/uninvaded (black) and invaded (white) communities, showing consistent reductions in the standardized effect size upon invasion. Dashed lines represent approximate boundaries (1.96 standard deviations from 0 ) for significant deviations from random assembly to aggregation (lower standardized effect sizes) or segregation (higher standardized effect sizes).

\section{DISCUSSION}

Describing the rules of community assembly has been a primary goal of ecological studies for several decades (Diamond 1975, Gotelli and McCabe 2002). Recent works have demonstrated that the relative importance of individual species, and differences between species, can be more influential than environmental factors (e.g., Gianuca et al. 2016). Given this, and the ever increasing global rate of harmful biological invasions (Huang et al. 2011, Rehage and Blanchard 2016), it is prudent to now ask what influence the introduction of invasive species has on assembly rules. In this study we have three main findings. First, community assembly rules shift in a predictable fashion, toward reduced segregation, following the introduction of a new invasive species, as 
detectable with null model analyses, regardless of taxa or context (Gotelli and Arnett 2000, Sanders et al. 2003, Reshi et al. 2008, Richter-Boix et al. 2013, Kuebbing et al. 2014; Figure 2). Second, the Rocky Glades fish community, shifted from a random to an aggregative assembly immediately following the invasion of the African Jewelfish, and the aggregation appears to be maintained over 10 years post invasion. Finally, the invasive micropiscivorous Jewelfish is now not only the second most abundant fish in Rocky Glades solution hole communities, but also a driver of assembly patterns. We discuss these findings below.

Invaded assembly

The introduction of an invasive species shifts the assembly rules of existing metacommunities away from segregation. Such a consistent shift suggests that, while the mechanistic effects of invasions may be context dependent (Ricciardi and Kipp 2007, Habit et al. 2012, Benkwitt 2014), the introduction of a new invasive species will reduce segregation. Segregation can be generated by several potential mechanisms, such as the invader facilitating colonization of additional species such as through resource mobilization (e.g., Schreiber et al. 2002), or by competitive exclusion forcing potential colonists to aggregation in other sites (Stone and Roberts 1992).

As segregation within a community permits the co-existence of multiple competitive species (Holyoak et al. 2005, Cottenie 2005, Kadowaki et al. 2011, Chmara et al. 2013), a loss of segregated structure could have cascading effects on ecosystem processes. The most extreme example of such a cascade would be the sequential loss of poorly competitive species, and homogenization across the landscape resulting in 
substantially reduced biodiversity and abundances, as was the case with Africa's Nile Perch (Lates niloticus) invasion (Goudswaard et al. 2006). However, this extreme scenario would be the result of a total loss of segregation and require that no heterogeneity exist at the patch scale. The true effects of a loss of segregation are likely to be more muted, as are many noted invasion's impacts (Cucherousset and Olden 2011, Ricciardi et al. 2013). Importantly, all studies to date have noted a reduction of segregation within one sampling unit of the introduction of the invasive species, suggesting null model analyses could be useful tools to invasion managers.

A major challenge of invasion management is the fact that many species go undetected or unmanaged until they cause significant harm to the native ecosystem. Once a species is established and causing harm it is often too difficult, expensive, or in some cases damaging to remove the species (Simberloff et al. 2013, Dick et al. 2013). While presence in the biodiversity matrices used by null model analyses necessitates detection, which is probabilistically a function of density, the aggregative effect of invasive species presence could be used as an early warning sign to manage a new species before changes in native abundances or diversity take place, possibly before they're too integrated in the system to be removed. However, given the paucity of studies describing this response, more work is needed to derive a robust understanding of the subject. Nonetheless, we have shown here that available comparable evidence suggests invasive species increase the number of species co-occurrences. The consequences of such restructuring to assembling communities are, as discussed above, potentially dramatic (Gotelli and Arnett 2000, Sanders et al. 2003, Reshi et al. 2008, Richter-Boix et al. 2013, Kuebbing et al. 2014), but understudied. As this shift in assembly rules occurs relatively quickly, it may 
serve as a useful indicator for the identification of truly invasive species, before they degrade native ecosystems.

\section{How might invasions result in aggregation?}

Directed mechanistic experiments, which are beyond the scope of the present work and likely to be more context dependent than the overall pattern, are needed to identify the mechanisms behind invasions apparent effect of increased aggregation on assembly. As competition is generally assumed to generate segregation in a community (Sanders et al. 2007), with competing species preferring not to cohabitate and therefore avoid competition when possible, aggregation is considered a sign of a lack or loss of competition. As such the aggregative effect of invasions may be the result of facilitating mechanisms on the part of the invader. Native v. non-native interactions have been noted, in some cases, to liberate resources which would otherwise be more limited (Brenneis et al. 2011). Making resources more labile may facilitate a reduction in competition between species, facilitate colonization of species otherwise too resource limited in the patch or actively enhance the fitness and other species (Riley et al. 2008, Rogalski and Skelly 2012). others to colonize a patch that would have otherwise been unable to collect the resources themselves. However, it is worth noting that there is disagreement in the literature as to if patterns of segregation/aggregation can be used to infer patterns beyond 'non-neutral'. Specifically, Ulrich and Gotelli (2013) demonstrate that differentiation between segregative and aggregative mechanisms via null model analyses is subjective to matrix design resulting in potentially erroneous conclusions. As such, we would encourage caution when interpreting our results from a mechanistic perspective. Rather, 
our key finding is that there is a consistent pattern observable via null-model analyses which could be a useful signal of invasions to warrant further study.

\section{African Jewelfish invasion}

With respect to the African Jewelfish invasion itself, their impact on the Rocky Glades metacommunity appears to be complex. The species exhibits a novel color for the system, vibrant red, is exceptionally aggressive relative to the other species (Schofield et al. 2007), has violent bi-parental brood care (Frimpong and Angermeier 2009) unlike all native Everglades fishes, is capable of breeding successfully in the solution hole environment (personal observation) and is the only small bodied benthopelagic piscivore in the system (Rehage et al. 2014). This novelty opens the possibility of several mechanisms for their observed influence. One would expect their aggressive and predatory behaviors to result in reduced abundances and diversity in their presence, as potential settlers should naturally avoid them (Stier et al. 2013, Takatsu and Kishida 2015). Rather, we note the opposite is true: sites with Jewelfish had higher abundances and diversity (Figure 10), suggesting that Rocky Glades fishes, including the Jewelfish, follow similar assembly rules. Indeed, the driving forces behind assembly in our data were regional environmental factors; however, this was not the case prior to the invasion (Kobza et al. 2004). Also, the global RDA could only explain approximately $17 \%$ of the overall variance in the data, suggesting that the abundance of Jewelfish and the observed environmental forces are not the strongest drivers of assembly in this fish metacommunity (see chapter 1). Although, other taxa in the system do assemble primarily according to the natural gradients in these regional factors (Sokol et al. 2014). Recent works have suggested the behavior or functional traits of species may be more 
influential in assembly than their abundances or environmental factors (Aiba et al. 2013, Padial et al. 2014, Pavoine et al. 2014, Spasojevic et al. 2014). Following through with the concept of trait-based assembly, another hypothesis is that the effect of Jewelfish is a direct function of their novel traits. Further study is needed to evaluate the hypothesis of trait-based metacommunity assembly in the Rocky Glades, as no traits were quantified here, but it would provide a mechanism for the observed influence of African Jewelfish on assembly.

A key part of this trait-based effect would be the fact that they are predators which compete for space with their prey. Stier et al. (2013) describe the assembly of reef communities in the presence and absence of predatory hawkfish. They note that the timing of arrival and density of hawkfish have significant influences on the final total patch abundance and between patch diversity (Stier et al. 2013). While the study notes that abundance and diversity decline over time in the presence of the predator, ours was designed to avoid this temporal effect by only observing first assembly. Regardless, it is possible a similar mechanism is at work in the Rocky Glades. When a hawkfish settles on a reef patch it can exclude new settlers and compete for space with existing settlers (Stier et al. 2013), effectively stoping assembly at the point when the predator arrives. Other similar priority effects of predators have been described, suggesting that the presence of a predator can have disproportionately high influences on the assembly process (Stoks and McPeek 2003, Shurin et al. 2004, Benkwitt 2014). Personal observation of Jewelfish in solution holes would suggest that their aggression can also serve to prevent existing prey or competitors from leaving the patch. On numerous occasions Jewelfish were observed harassing Lepomis spp. when the sunfishes ventured beyond the structures along the 
periphery of the hole, forcing them to abandon the excursion. Jewelfish are slow to invade the marsh surface in the wet season (Loftus et al. 2006), and therefore are likely to settle in to solution holes later than other species. The observed higher abundance and diversity of holes with Jewelfish may be a result of them settling in to high quality patches which have been colonized by prey and competitors, then they behaviorally prevent emigration. A controlled study of Rocky Glades metacommunity assembly over time, within individual assembly events would be needed to evaluate this hypothesis.

\section{Conclusion}

Overall, we demonstrated there is a clear, repeating pattern of increasing numbers of species co-occurrences, aggregation, following the introduction of a truly invasive species. This pattern holds true across multiple taxa (insects-Gotelli and Arnett 2000, Sanders et al. 2003; plants-Reshi et al. 2008, Kuebbing et al. 2014; amphibians-RichterBoix et al. 2013; fish-this study) and may represent a cost effective means of evaluating the introduction of new species, before they cause irreparable harm to the native community, using existing biodiversity monitoring data. Further, we have demonstrated that this same effect took place in the Rocky Glades fish metacommunity in Everglades National Park immediately following the African Jewelfish invasion. Jewelfish are now the second most abundant fish in solution hole communities and are a driving force of annual metacommunity re-assembly events. As the population appears to be reproductively stable given their temporal persistence, is numerically dominant, is unlikely to go extinct without human intervention and is significantly influencing native communities in a protected wetland, we recommend the African Jewelfish be considered officially invasive in the Everglades ecosystem. We also urge other researchers to 
evaluate the rigor of the pattern we described above with additional case studies and suggest long-term monitoring programs consider using null model analyses as a first pass to screen new introductions for signs of invasiveness.

\section{REFERENCES}

Adler, P. B., J. Hillerislambers, and J. M. Levine. 2007. A niche for neutrality. Ecology Letters 10:95-104.

Aiba, M., M. Katabuchi, H. H. Takafumi, S. S. Matsuzaki, T. Sasaki, T. Hiura, and X. T. Botanical. 2013. Robustness of trait distribution metrics for community assembly studies under the uncertainties of assembly processes. Ecology 94:2873-2885.

Alvarez-Filip, L., N. K. Dulvy, J. a Gill, I. M. Côté, and A. R. Watkinson. 2009. Flattening of Caribbean coral reefs: region-wide declines in architectural complexity. Proceedings of the Royal Society/ Biological Sciences 276:3019-25.

Amarasekare, P. 2003. Competitive coexistence in spatially structured environments: a synthesis. Ecology Letters 6:1109-1122.

Benkwitt, C. E. 2014. Non-linear effects of invasive lionfish density on native coral-reef fish communities. Biological Invasions 17:1383-1395.

Blanchet, G., P. Legendre, and D. Borcard. 2008. Forward selection of spatial explanatory variables. Ecology 89:2623-2632.

Brenneis, V. E. F., A. Sih, and C. E. de Rivera. 2011. Integration of an invasive consumer into an estuarine food web: direct and indirect effects of the New Zealand mud snail. Oecologia 167:169-79.

Chmara, R., J. Szmeja, and W. Ulrich. 2013. Patterns of abundance and co-occurrence in aquatic plant communities. Ecological Research 28:387-395.

Cottenie, K. 2005. Integrating environmental and spatial processes in ecological community dynamics. Ecology Letters 8:1175-82.

Cucherousset, J., and J. D. Olden. 2011. Ecological Impacts of Non-native Freshwater Fishes. Fisheries 36:215-230.

Diamond, J. 1975. Assembly of species communities. Pages 342-444in M. Cody and J. Diamond, editors. Ecology and Evolution of Communities. Harvard University Press, Cambridge.

Dick, J. T. A., M. E. Alexander, J. M. Jeschke, A. Ricciardi, H. J. MacIsaac, T. B. Robinson, S. Kumschick, O. L. F. Weyl, A. M. Dunn, M. J. Hatcher, R. a. Paterson, K. D. Farnsworth, and D. M. Richardson. 2013. Advancing impact 
prediction and hypothesis testing in invasion ecology using a comparative functional response approach. Biological Invasions 16:735-753.

Frimpong, E. a., and P. L. Angermeier. 2009. Fish Traits: A Database of Ecological and Life-history Traits of Freshwater Fishes of the United States. Fisheries 34:487495.

Giacomini, H. C., D. L. DeAngelis, J. C. Trexler, and M. Petrere. 2013. Trait contributions to fish community assembly emerge from trophic interactions in an individual-based model. Ecological Modelling 251:32-43.

Gianuca, A. T., S. A. J. Declerck, M. W. Cadotte, C. Souffreau, T. De Bie, and L. De Meester. 2016. Integrating trait and phylogenetic distances to assess scaledependent community assembly processes. Ecography:1-11.

Goss, C. W., W. F. Loftus, and J. C. Trexler. 2014. Seasonal Fish Dispersal in Ephemeral Wetlands of the Florida Everglades. Wetlands January:1-11.

Gotelli, N. J., and A. E. Arnett. 2000. Biogeographic effects of red fire ant invasion. Ecology Letters 3:257-261.

Gotelli, N. J., and G. L. Entsminger. 2005. EcoSim700.

Gotelli, N. J., and D. J. McCabe. 2002. Species Co-Occurrence: A Meta-Analysis of J. M. Diamond's Assembly Rules Model. Ecology 83:2091.

Goudswaard, K., F. Witte, and E. F. B. Katunzi. 2006. The invasion of an introduced predator, Nile perch (Lates niloticus, L.) in Lake Victoria (East Africa): chronology and causes. Environmental Biology of Fishes 81:127-139.

Habit, E., J. Gonzalez, D. E. Ruzzante, and S. J. Walde. 2012. Native and introduced fish species richness in Chilean Patagonian lakes: inferences on invasion mechanisms using salmonid-free lakes. Diversity and Distributions 18:1153-1165.

Holyoak, M., M. A. Liebold, and R. D. Holt. 2005. Metacommunities: Spatial dynamics and ecological communities. University of Chicago Press.

Huang, D., R. a. Haack, and R. Zhang. 2011. Does global warming increase establishment rates of invasive alien species? A centurial time series analysis. PLoS ONE 6:e24733.

Hubbell, S. P. 2001. The unified neutral theory of species abundance and diversity. Princeton University Press, Princeton, N.J.

Kadowaki, K., R. a. B. Leschen, and J. R. Beggs. 2011. Competition-colonization dynamics of spore-feeding beetles on the long-lived bracket fungi Ganoderma in New Zealand native forest. Oikos 120:776-786.

Kline, J. L., W. F. Loftus, K. Kotun, J. C. Trexler, J. S. Rehage, J. J. Lorenz, and M. Robinson. 2014. Recent Fish Introductions Into Everglades National Park: An Unforeseen Consequence of Water Management? Wetlands 34:175-187. 
Kobza, R. M., J. C. Trexler, W. F. Loftus, and S. A. Perry. 2004. Community structure of fishes inhabiting aquatic refuges in a threatened Karst wetland and its implications for ecosystem management. Biological Conservation 116:153-165.

Kruskal, J. B., and M. Wish. 1978. Multidimensional scaling. Vol 11. Sage.

Kuebbing, S. E., L. Souza, and N. J. Sanders. 2014. Effects of co-occurring non-native invasive plant species on old-field succession. Forest Ecology and Management 324:196-204.

Lavender, T. M., B. S. Schamp, and E. G. Lamb. 2016. The Influence of Matrix Size on Statistical Properties of Co-Occurrence and Limiting Similarity Null Models. PloS one 11:e0151146.

Legendre, P., and M. J. Anderson. 2006. Distance-based redundancy analysis: testing multispecies responses in multifactorial ecological experiments. Ecological Monographs 69:1-24.

Loftus, W. F., R. A. Johnson, and G. H. Anderson. 1992. Ecological impacts of the reduction of groundwater levels in short-hydroperiod marshes of the Everglades. Pages 199-208. Proceedings of the First International Convergence on Ground Water Ecology.

Loftus, W. F., J. C. Trexler, K. Dunker, S. Liston, and J. Rehage. 2006. Introduced Fishes in Short-Hydroperiod Wetlands: Evaluation of Sampling, Status, and Potential Effects. Final Project Report to the National Park Service

Loftus, W. F., J. C. Trexler, J. S. Rehage, S. E. Liston, and K. J. Dunker. 2005. The Role of Aquatic Refuges in the Rockland Wetland Complex of Southern Florida, in Relation to System Restoration. Final Project Report to the National Park Service

Lopez, D. P. 2011. Trait Variation in an Everglades Invasive Species: Life histories, Boldness, and Dispersal in the African Jewelfish. Dissertation. Florida International University.

Loughnan, D., and B. Gilbert. 2017. Trait-mediated community assembly: distinguishing the signatures of biotic and abiotic filters. Oikos 126:1112-1122.

Mikkelson, G. M. 2005. Niche-Based vs. Neutral Models of Ecological Communities. Biology \& Philosophy 20:557-566.

Mouillot, D., N. a J. Graham, S. Villéger, N. W. H. Mason, and D. R. Bellwood. 2013. A functional approach reveals community responses to disturbances. Trends in Ecology \& Evolution 28:167-77.

Mouquet, N., M. F. Hoopes, and P. Amarasekare. 2005. The world is patchy and heterogeneous! Trade-off and source-sink dynamics in competitive metacommunities. Pages 237-262 in Metacommunities: Spatial dynamics and ecological communities. University of Chicago Press. 
Muneepeerakul, R., E. Bertuzzo, H. J. Lynch, W. F. Fagan, A. Rinaldo, and I. RodriguezIturbe. 2008. Neutral metacommunity models predict fish diversity patterns in Mississippi-Missouri basin. Nature 453:220-222.

Mutshinda, C. M., and R. B. O'Hara. 2011. Integrating the niche and neutral perspectives on community structure and dynamics. Oecologia 166:241-251.

Padial, A. A., F. Ceschin, S. A. J. Declerck, L. De Meester, C. C. Bonecker, F. A. Lansac-Tôha, L. Rodrigues, L. C. Rodrigues, S. Train, L. F. M. Velho, and L. M. Bini. 2014. Dispersal ability determines the role of environmental, spatial and temporal drivers of metacommunity structure. PLoS ONE 9:1-8.

Panek, F. M., and C. L. Densmore. 2013. Frequency and severity of trauma in fishes subjected to multiple-pass depletion electrofishing. North American Journal of Fisheries Management 33:178-185.

Pavoine, S., M. Baguette, V. M. Stevens, M. A. Leibold, C. Turlure, and M. B. Bonsall. 2014. Life-history traits, but not phylogeny, drive compositional patterns in a butterfly metacommunity. Ecology 95:1939-1970.

R Core, T. 2012. R: A language and environment for statistical computing. R Foundation for Statistical Computing, Vienna, Austria.

Rehage, J. S., and J. R. Blanchard. 2016. What Can We Expect from Climate Change for Species Invasions? Fisheries 41:405-407.

Rehage, J. S., S. E. Liston, K. J. Dunker, and W. F. Loftus. 2014. Fish community responses to the combined effects of decreased hydroperiod and nonnative fish invasions in a karst wetland: are Everglades solution holes sinks for native fishes? Wetlands:1-15.

Reshi, Z., I. Rashid, A. A. Khuroo, and B. A. Wafai. 2008. Effect of invasion by Centaurea iberica on community assembly of a mountain grassland of Kashmir Himalaya, India. Tropical Ecology 49:147-156.

Ricciardi, A., M. F. Hoopes, M. P. Marchetti, and J. L. Lockwood. 2013. Progress Toward Understanding the Ecological Impacts of Non-native Species. Ecological Monographs 83.3:1-68.

Ricciardi, A., and R. Kipp. 2007. Predicting the number of ecologically harmful exotic species in an aquatic system. Diversity and Distributions 14:374-380.

Richter-Boix, A., N. Garriga, A. Montori, M. Franch, O. San Sebastián, D. Villero, and G. a. Llorente. 2013. Effects of the non-native amphibian species Discoglossus pictus on the recipient amphibian community: niche overlap, competition and community organization. Biological Invasions 15:799-815.

Riley, L. A., M. F. Dybdahl, and R. O. Hall. 2008. Invasive species impact : asymmetric interactions between invasive and endemic freshwater snails. Journal of the North American Benthological Society 27:509-520. 
Rogalski, M. A., and D. K. Skelly. 2012. Positive Effects of Nonnative Invasive Phragmites australis on Larval Bullfrogs. PloS ONE 7:e44420.

Sanders, N. J., N. J. Gotelli, N. E. Heller, and D. M. Gordon. 2003. Community disassembly by an invasive species. Proceedings of the National Academy of Sciences of the United States of America 100:2474-7.

Santos, R. O., J. S. Rehage, R. Boucek, and J. Osborne. 2016. Shift in recreational fishing catches as a function of an extreme cold event. Ecosphere 7:1-16.

Schneider, C. A., W. S. Rasband, and K. W. Eliceiri. 2012. NIH Image to ImageJ: 25 years of image analysis. Nature Methods 9:671-675.

Schofield, P. J., and W. F. Loftus. 2014. Non-native fishes in Florida freshwaters: a literature review and synthesis. Reviews in Fish Biology and Fisheries:1-31.

Schofield, P. J., W. F. Loftus, and M. E. Brown. 2007. Hypoxia tolerance of two centrarchid sunfishes and an introduced cichlid from karstic Everglades wetlands of southern Florida, U.S.A. Journal of Fish Biology 71:87-99.

Schreiber, E. S. G., P. S. Lake, and G. P. Quinn. 2002. Facilitation of native stream fauna by an invading species? Experimental investigations of the interaction of the snail, Potamopyrgus antipodarum (Hydrobiidae) with native benthic fauna. Biological Invasions 4:317-325.

Sharma, S., P. Legendre, M. De Cáceres, and D. Boisclair. 2011. The role of environmental and spatial processes in structuring native and non-native fish communities across thousands of lakes. Ecography 34:762-771.

Shurin, J. B., P. Amarasekare, J. M. Chase, R. D. Holt, M. F. Hoopes, and M. a Leibold. 2004. Alternative stable states and regional community structure. Journal of Theoretical Biology 227:359-68.

Simberloff, D., J.-L. Martin, P. Genovesi, V. Maris, D. a Wardle, J. Aronson, F. Courchamp, B. Galil, E. García-Berthou, M. Pascal, P. Pyšek, R. Sousa, E. Tabacchi, and M. Vilà. 2013. Impacts of biological invasions: what's what and the way forward. Trends in Ecology \& Evolution 28:58-66.

Sokol, E. R., J. M. Hoch, E. Gaiser, and J. C. Trexler. 2014. Metacommunity Structure Along Resource and Disturbance Gradients in Everglades Wetlands. Wetlands 34:135-146.

Spasojevic, M. J., S. Copeland, and K. N. Suding. 2014. Using functional diversity patterns to explore metacommunity dynamics: a framework for understanding local and regional influences on community structure. Ecography 37:939-949.

Stier, A. C., S. W. Geange, K. M. Hanson, and B. M. Bolker. 2013. Predator density and timing of arrival affect reef fish community assembly. Ecology 94:1057-1068. 
Stoks, R., and M. A. McPeek. 2003. Predators and life histories shape Lestes damselfly assemblages along a freshwater habitat gradient. Ecology 84:1576-1587.

Stone, L., and A. Roberts. 1990. The checkerboard score and species distributions. Oecologia 85:74-79.

Stone, L., and A. Roberts. 1992. Competitive exclusion, or species aggregation? - An aid in deciding. Oecologia 91:419-424.

Takatsu, K., and O. Kishida. 2015. Predator cannibalism can intensify negative impacts on heterospecific prey. Ecology 96:1887-1898.

Telis, P. A., and H. Henkel. 2009. Everglades Depth Estimation Network (EDEN) Applications: Tools to view, extract, plot and manipulate EDEN data.

Thompson, P. D., and F. J. Rahel. 1996. Evaluation of depletion-removal electrofishing of brook trout in small rocky mountain streams. North American Journal of Fisheries Management 16:332-339.

Tilman, D. 2004. Niche tradeoffs, neutrality, and community structure: a stochastic theory of resource competition, invasion, and community assembly. Proceedings of the National Academy of Sciences of the United States of America 101:1085410861 .

Tummers, B. 2006. DataThief III.

Ulrich, W., and N. J. Gotelli. 2013. Pattern detection in null model analysis. Oikos 122:2-18.

Williamson, M., A. Fitter, and S. Url. 1996. The Varying Success of Invaders. Ecology 77:1661-1666. 


\section{CHAPTER III}

CAN INDIVIDUAL PERSONALITIES STRUCTURE DISPERSAL LIMITED METAPOPULATIONS AT ECOLOGICALLY RELEVANT SPATIOTEMPORAL SCALES? 


\begin{abstract}
The relative role of inter and intraspecific trait variation in metasystem (metapopulation, community, etc.) assembly has been of growing interest to ecologists over the past decade. Concurrently, intraspecific variation of individual personalities, traits that are not typically observable in field studies, have been shown to be influential to key metapopulation parameters. Typically, the personality types studied in this context are boldness and aggression, but less attention has been given to sociability despite empirical support. Sociability is defined as an individuals' propensity to associate with conspecifics and has been demonstrated to influence not only the tendency of propagules to disperse, but also their dispersal distance and final patch densities. However, this has only been described at small spatiotemporal (mesocosm) scales. I used an individual based model, designed and parameterized with data from a real metapopulation, to investigate the metapopulation influences of sociability at ecologically relevant spatiotemporal scales. I used this model to simulate dispersal and assembly of three separate populations with differing sociability distributions and a no-personality (neutral) control, using two different dispersal window lengths. My model demonstrates that sociability influences the key metapopulation parameters of individual dispersal distance and patch density. Both of these parameters were significantly influenced by an interaction with dispersal window length. Sociability had no influence on landscape occupation rates. This model also produces niche-based density-distance decays, which are indistinguishable from neutral model predictions. This begs the question: are neutrally structured metasystems following cryptic niche axes? Individuals with moderate sociabilities were also indistinguishable from neutral models, suggesting that while sociability potentially plays
\end{abstract}


a key role in the structuring of metasystems, it could add unnecessary complexity to models not describing populations with skewed sociability distributions. I finish by posing hypotheses, supported by this model and previous works, and recommend their evaluation in a field-based study.

\section{INTRODUCTION}

Metapopulation structure emerges from the dispersal of propagules among patches embedded in a low-quality matrix (Hanski and Gilpin 1991). The reason and rate at which these propagules disperse (Gotelli 1991), the pathways they use (Baguette and Van Dyck 2007, Altermatt et al. 2011), and their use of environmental information (Proulx et al. 2013) as it relates to immigration and emigration have dominated the metapopulation discussion. Typically, these individual propagules are considered functional equivalents within a metapopulation. However, recent works have demonstrated that intraspecific trait variation can influence emergent metapopulation structure through dispersal mediation (e.g., Hawkes, 2009; Sutherland et al., 2014). Of the traits influencing dispersal, personality-type (PT) is now recognized as a particularly important behavioral trait mediating metapopulation structure (Conrad et al. 2011, Spiegel et al. 2017).

A PT, also referred to as behavioral-type, is the consistent response of individuals to given stimuli, relative to conspecifics, regardless of environmental context (Sih et al. 2004, 2012, Conrad et al. 2011, Wolf and Weissing 2012). Variation in PT has been demonstrated to influence key features of metapopulation dynamics, such as propagule dispersal tendencies (Duckworth and Badyaev 2007, Cote et al. 2010a, Myles-Gonzalez 
et al. 2015), dispersal speed (Maes et al. 2013), dispersal distances (Cote et al. 2010b), competitive abilities (Groen et al. 2012, Capelle et al. 2015), physiological states (MylesGonzalez et al. 2015), parental abilities (Duckworth and Badyaev 2007), and colonization behaviors (Duckworth 2008, Groen et al. 2012). To influence metapopulation structure through dispersal, a single PT needs to, at minimum, affect both the spatial (e.g., distance) and temporal (e.g., speed) components of dispersal, at ecologically-relevant scales. Typically, this is considered by way of the personality dependent dispersal (PDD) concept, which relies on the idea that an individual's personality is going to be a primary determinant of their net dispersal behavior. Most often PDD is studied as a function of boldness or life-history related personality traits. Work to date has shown that the spatiotemporal distribution of animals can be influenced by their boldness and aggression, with fitness consequences and related energetic tradeoffs, such that more bold and aggressive individuals tend to travel first and furthest. Sociability, the propensity of an individual to associate with conspecifics (Cote and Clobert 2007), has also been suggested to affect both of these aspects of dispersal by mediating emigration and immigration probabilities, as well as dispersal distances (Cote et al., 2010a; 2010b). However, it has received far less experimental attention than other traits.

The potential for sociability to influence metapopulation structure stems from density-dependent individual decisions influenced by patch conditions. As first conceptualized by Cote et al. (2010b), asocial individuals or those that prefer low conspecific densities, disperse away from high density source patches in search of preferable conditions. In doing so, the patch may be sufficiently depleted as to encourage emigration of social individuals in search of conspecifics. Multiple iterations of this result 
in a metapopulation being structured in both space and time, with the emergent structure depending on the population's sociability and the length of the dispersal-window (Cote et al. 2010a). Some evidence exists for this, at small spatial scales. Cote et al (2010a) demonstrated a negative relationship between sociability, and individual dispersal distances in a fish mesocosm. Similarly, in a reptile macrocosm, dispersal from low density patches was attributed to higher sociality, and visa-versa (Cote and Clobert 2007). However, there is still a lack of information regarding how this translates to ecologically relevant spatial scales (10s-100s of $\mathrm{km})$, and how it interacts with time.

This knowledge gap is particularly pressing because, while many habitats are temporally stable with functionally unlimited dispersal-windows, dispersal-window lengths in ephemeral landscapes are often tied to climatic patterns via hydrology (Lindenmayer and Hobbs 2007). As the global climate shifts, many ephemeral landscapes may experience changes to the drivers of their dispersal-windows, resulting in currently not understood changes to the spatiotemporal structures of metapopulations. To understand these effects, we need to understand how changes in dispersal-windows influence temporally-dependent dispersal mechanisms, such as sociability-dependent dispersal (SDD). To begin filling this need, and to evaluate the effects of SDD at ecologically relevant spatiotemporal scales, we used a simulation approach to test and refine hypotheses of metapopulation structuring, at multiple scales (individual, local and regional), which can be directly evaluated in future field-based studies.

For this simulation, our goal was to build an understanding of observable SDD patterns in ephemeral metapopulations. To do this, we built a behavioral individual-based 
model (IBM), parameterized with information from an existing ephemeral wetland; short hydroperiod wetlands in the Everglades. Using this IBM, we experimentally manipulated the sociability of individuals (fishes) and dispersal-windows (relative to a no personality control), to examine the effects of SDD on the dispersal distances of individuals, the density of individuals within patches, and the proportion of the landscape colonized (see Table 1 for detailed hypotheses). We also examined the interacting effects of sociability and varying dispersal windows (long vs. short) on these three variables. Per results of the model, we refine these hypotheses and suggest how each could be tested with a long-term field study aimed at understanding the role of SDD in real-world metapopulation structuring, and how this will interact with shifting climatic regimes to alter contemporary patterns. 
Table 7 Hypotheses to be tested at each scale of interest. N.P. represents a no personality (control) treatment.

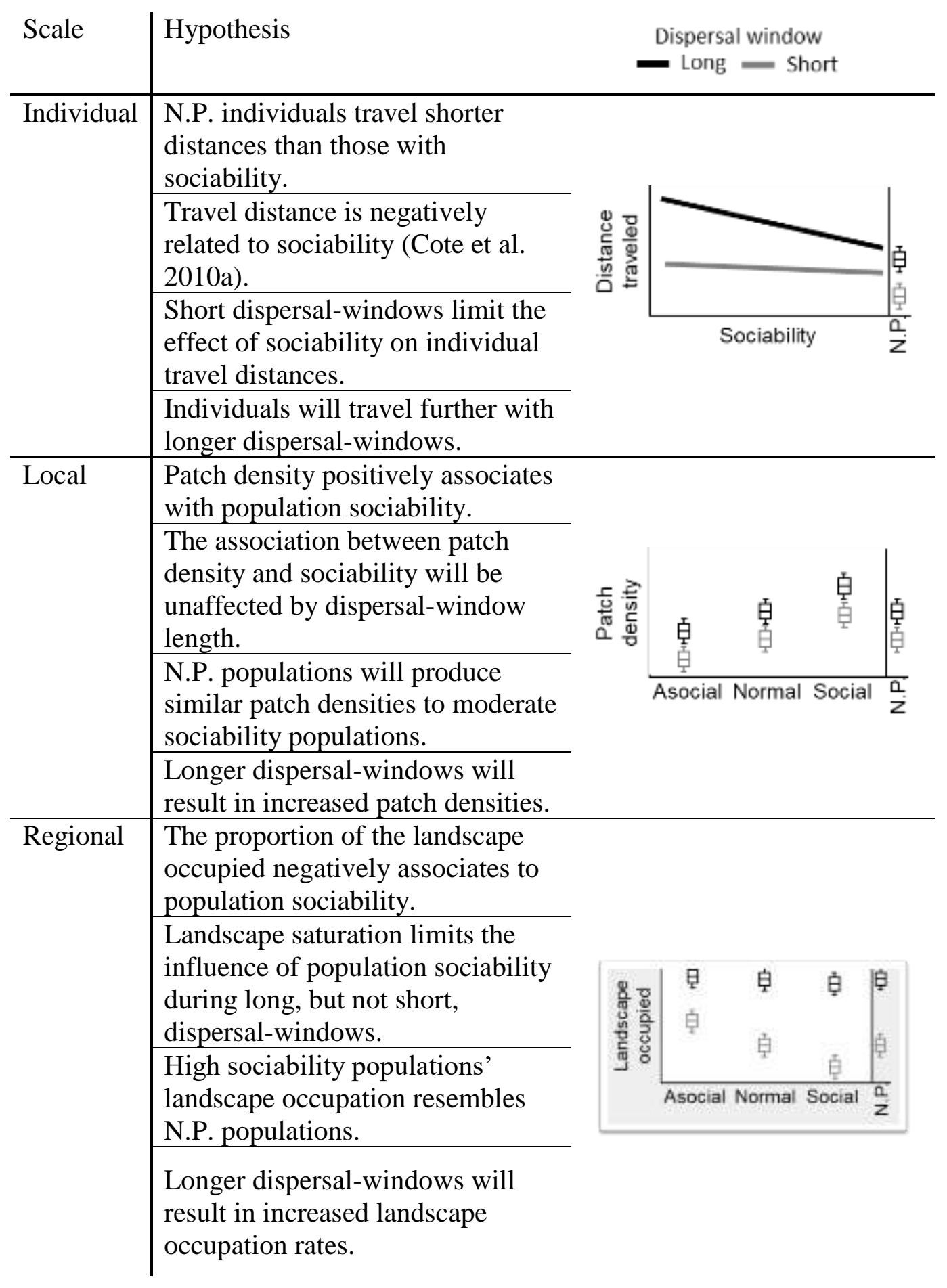




\section{MATERIALS AND METHODS}

To address the questions of this study, a simple IBM was built to simulate the structuring of a metapopulation based on intraspecific variation in sociability, in the context of two different dispersal treatments, using NetLogo v. 5.3.1 (Wilensky 1999). See conceptual flow chart and complete overview, design concepts and details (ODD, Grimm et al., 2006) in Appendix 3 for full details. While we did not strive to accurately represent the immense complexity of any real-world metapopulation with our IBM, our goal was to simulate ecologically relevant spatial and temporal scales, as well as movement rules and patch densities. To do this, we designed our model with parameters from a simplified real-world metapopulation. Specifically, our model design and rules were inspired by the Rocky Glades (RG) region of Everglades National Park. This was a useful system to examine temporally-dependent dispersal as it has been studied enough to design and parameterize model agents. However, it is important to note that this landscape was used as a source of parameters and rules, but the model itself is not context dependent and can be extrapolated to other systems. Specifically, this model simulates the pattern of flooding and drying using discrete dispersal windows of relevant length with a single large source population along the western edge, as in the RG. The most abundant fish in this habitat, Eastern Mosquitofish (Gambusia holbrooki) has also been studied sufficiently as to provide reasonable dispersal rules and distances within this environment.

\section{Modeled system}

The RG is a short-hydroperiod karstic marsh located in peripheral wetlands of the Everglades (McVoy et al. 2011). The region is characterized by a large number of 
solution holes, or depressions in the exposed limestone matrix, distributed throughout a seasonally- connected landscape (Loftus et al. 1992, McVoy et al. 2011). Under modern hydrology, a typical wet season is approximately four to six months long, whereas severe droughts can reduce this to less than one month (Loftus et al. 1992, McVoy et al. 2011, Kotun and Renshaw 2014). Within a matter of hours of inundation at the start of the wet season, fish disperse from long hydroperiod habitats (i.e., source habitats; Goss et al., 2014) to colonize this landscape. Under current post-drainage hydrology; solution holes are extirpated annually as the dry season progresses (Rehage et al. 2014), so each dispersal and structuring event occurs largely in the absence of priority effects(effects of existing colonists on potential new immigrants; i.e.; Dibble et al., 2014; Drake, 1990) and prior knowledge (knowledge of the environment from previous dispersal bouts; i.e.

Clobert et al., 2009; Mueller and Fagan, 2008).

\section{Scales of interest}

We focused on three scales of interest to metapopulation ecology: individual, local and regional scales (Revilla et al. 2004, Cadotte 2007). Here, the individual scale represents consequences for the individual animals, which in this case consists of the total distance individuals travel. At the local scale, we quantified the density of colonists within patches or patch density, while the regional scale represents all viable patches in the landscape. At this scale, our hypotheses (Table 7) focused on the proportion of the landscape occupied.

\section{Model environment}

The model environment is a $200 * 100$ cell bounded rectangle, with each cell representing $100 \mathrm{~m}^{2}$. Of the cells, 50 were assigned as viable patches. The locations of 
patches were randomly generated once and fixed to those coordinates (Figure 13) to control for the effect of patch distribution, which is known to influence many ecological properties (Tscharntke et al., 2012). This patch distribution was used because there is currently no available information regarding the true spatial distribution or density of solution holes in the RG landscape. The other important environmental parameter in the model was the run time, which represented the time allowed for dispersal, or the dispersal window, for fish to colonize the region, determined by the duration of the wet season. To investigate the interaction of dispersal-limitation with SDD, high and low dispersal window treatments were used. The run time was set to 200 days for the high dispersal window treatment or longer wet season, and 20 days for the low dispersal window treatment; a very short dry season. Modern hydrological conditions in the RG result in a median dispersal-window length of 206.5 days and a standard deviation of 60.4 days over the past 16 years (Blanchard et al. Chapter 2). A 200 days dispersal-window is common under modern RG hydrology, whereas system wide 20-day dispersal-window is exceptionally short, but plausible (Blanchard et al. Chapter 2). 

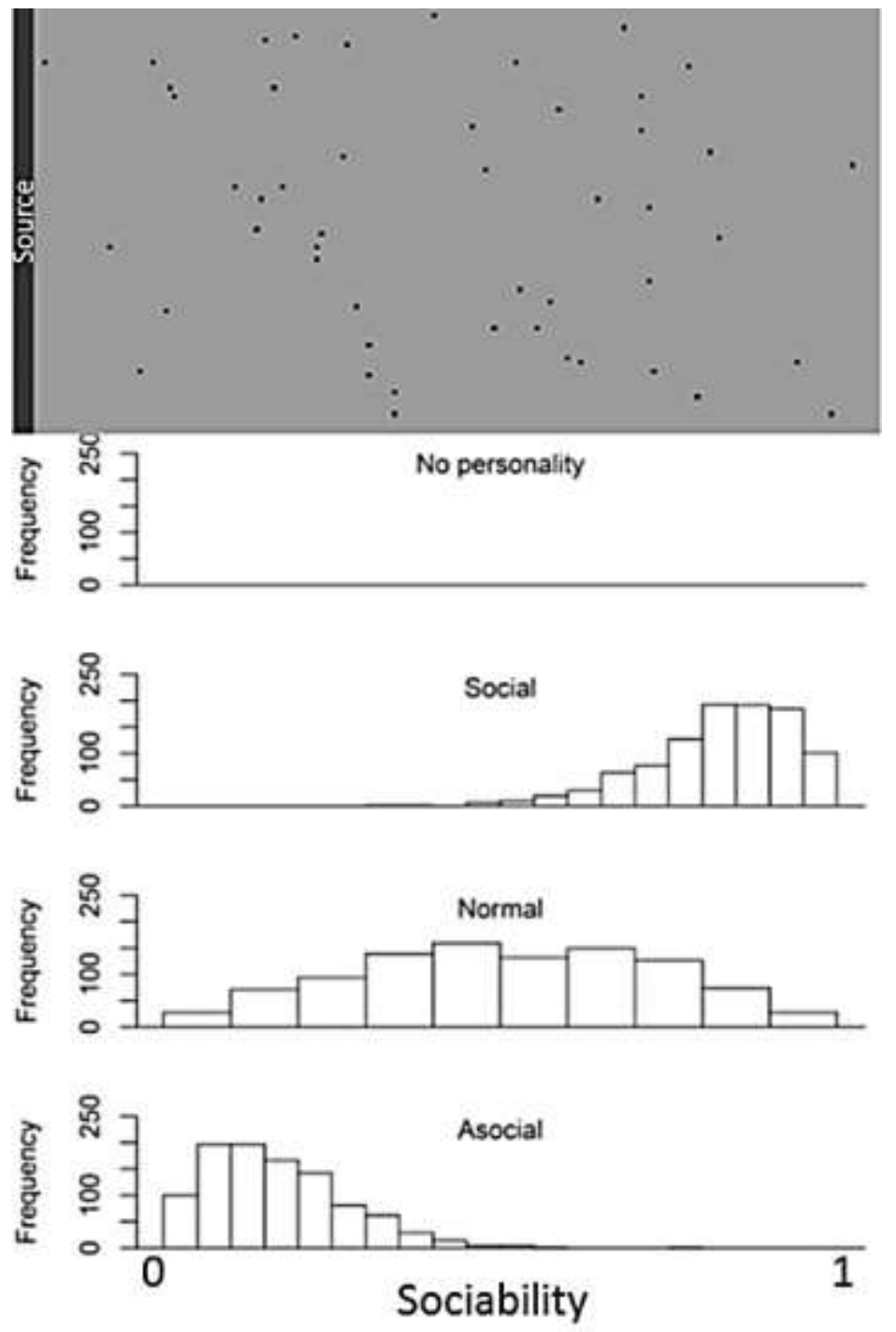

Figure 13 The top panel shows the model landscape based on a random allocation of habitat patches (solution holes) in a 20 by $10 \mathrm{~km}$ matrix. Dots represent patches, gray is the dispersal matrix and the black band to the left is the source area. Panels below show example distributions of the four source population sociability treatments.

\section{Model operation}

The model simulated a single metapopulation moving through a non-interactive landscape, dispersing from a single source area (Figure 13). Each agent uses an arearestricted search procedure to find a patch to colonize, an empirically supported search pattern commonly used in behavioral IBMs (e.g., Spiegel et al., 2017), coupled with a 
random walk (Fagan and Calabrese 2014), to move among patches in the landscape.

Once found, conspecific density is evaluated by the agent by comparing the density to what it finds acceptable. The acceptable range is dependent on the sociability of the agent and the density of the patch. For instance, asocial agents will depart a patch if density is too high. For our model, this acceptable range is based on a maximum target value of 40 conspecifics, which is within one standard deviation of the mean observed density of Eastern Mosquitofish in RG solution holes over three years of field sampling (Blanchard unpublished data). Each agent's target density, the mid-point of the acceptable range, is defined as target density $=$ individual sociability $* 40$. Any density within $25 \%$ of the target was considered 'acceptable'.

If local conspecific density is acceptable, the agent stays until conditions change. If the density is unacceptable, then the agent will decide if it should wait for conditions to improve or not. This parameter was included as an animal's perception of local conditions is not necessarily binary, and patch abandonment will not always occur immediately upon the patch becoming unacceptable (Sih, 1992). This is done, at each newly discovered patch upon arrival, by calculating the agent's 'hang-out-time' $(H)$ as $H=$ sociability $* H_{\max }$, where $\mathrm{H}_{\max }$ is the maximum amount of time any individual will stay in an unacceptable patch. If a randomly drawn real number between 0 and $\mathrm{H}_{\max }$ is $>\mathrm{H}$, then the agent will leave the patch. If not, then the agent stays for another day. Stayers experience a $10 \%$ daily reduction in $\mathrm{H}$ for each day with an unacceptable patch density, which reduces their probability of staying. A sensitivity analysis was performed to evaluate the impact of $\mathrm{H}_{\max }$, as it was not empirically derived. Total distance traveled, 
and final patch densities were sensitive to $\mathrm{H}_{\max }$ at values less than 5 days but were unaffected at longer times (maximum tested was 200 days). A fixed value of 5 days was used for $\mathrm{H}_{\max }$. Similarly, the model assumes each agent remembers the last patch it evaluated and will not return to it until a new patch has been found and evaluated. The core of this assumption is that animals are seeking different, more favorable conditions when dispersing (Rehage et al. 2016), and therefore would not immediately return to a previously unacceptable patch (e.g., with an undesirable conspecific density per the personality type of the agent).

Agents lacking personalities, the control treatment, were functionally identical in all search parameters. However, as they have no basis for evaluating the conspecific density of patches, they settle in to any newly-detected patch. Their probability of staying in the patch is purely random, drawing a random integer between -1 and 101 . If this is $>50$, they emigrate. If this value is $<50$, they stay for another day. This stochastic emigration and distance dependent immigration with an adaptive random walk is functionally similar to neutral dispersal. Last, at the end of the run (either 20 or 200 days), the model provided the following metrics: individual distance traveled, individual location (cartesian plane coordinates), and individual sociability. These metrics were exported for further analysis.

\section{Model agents}

Agent design was modeled after the Eastern Mosquitofish, Gambusia holbrooki. This is the most common fish in the RG (Kobza et al., 2004, Blanchard UPD), and is a congener of the Western Mosquitofish, Gambusia affinis, used in previous sociability studies (e.g., Cote et al., 2013, 2010a, 2010b; Rehage et al., 2005). This globally invasive 
genus (Deacon et al. 2011) is also known to exhibit significant intra-population behavioral heterogeneity and individual behavioral consistency (Rehage et al. 2016).

At the onset of each model run, which simulates one dispersal and assembly event, 1000 fish were generated in the source area (the five western-most cell columns, Figure 13) with a sociability randomly drawn from one of three distributions: asocially skewed, normal, socially skewed; or from a no-personality control (Figure 13). For the purposes of this model, sociability was bound between 0 and 1 with higher values representing higher degrees of sociality. Each sociability distribution was derived from beta distributions with the parameters: asocial $\boldsymbol{\alpha}=2, \mathbf{B}=10$; social $\boldsymbol{\alpha}=10, \mathbf{B}=2$; and normal $\boldsymbol{\alpha}=2, \mathbf{B}=2$. Each of these parameter combinations skews the distribution left, normal, or right respectively. These three personality distributions were chosen as they likely best represent distributions in natural or invading populations. In particular, selective forces and genetic founders effects can cause a skewing of behavioral distributions (Conrad et al. 2011, Sih et al. 2012, Cote et al. 2013). The normal distribution however likely represents a natural population which is not subjected to frequent selective disturbances. For example, we might expect an ephemeral marsh to select for highly dispersive phenotypes if the source habitat is risky or also temporary, resulting in a left skewed distribution, or non-dispersive phenotypes if the source is stable and safe, as is the case in the RG, resulting in a right skewed distribution. Conversely, stable landscapes, such as permanent ponds, would likely select for a normal distribution as neither extreme is particularly disadvantageous. 
The distance an agent can move on any given time step, day, was randomly chosen between 0 and $3 \mathrm{~km}$, shown to be a reasonable maximum daily movement distance for Eastern Mosquitofish, based on a maximum swimming speed of $4 \mathrm{~cm} / \mathrm{s}(\mathrm{J}$. Gatto unpublished data) for 24 hours. Each agent was afforded complete knowledge of the area within $750 \mathrm{~m}\left(0.25^{*} 3000 \mathrm{~m}\right)$ on a daily time step, based on the assumption that an individual will explore the local area when choosing a place to settle. All agents moved in ranked order of their sociability, such that lower scores move first, as per Cote et al.'s (2010a) proposed mechanism. In the case that two agents have the same sociability, the one their movement rank is decided by random selection.

\section{Statistical analyses}

As data at some scales were heteroscedastic, and medians provide more robust measures of central tendency than means (Zar 1999), nearly all statistical methodologies used were non-parametric. The only exception was linear regressions used on the homoscedastic individual and regional scale data.

At the individual scale, differences between how far individuals moved in personality and no personality treatments were evaluated with a Kruskal-Wallace test. This test, and subsequent multiple comparison tests were performed via 'Kruskal.test' and 'kruskalmc', from the 'stats' and 'pgirmess' packages respectively, in R (R Core 2012). Associations between distance traveled and individual sociability for each low and high treatment were evaluated with linear models, ' $1 \mathrm{~m}$ ' from 'stats'. The slopes of these models were compared with a non-parametric analysis of covariance (NpANCOVA) using 'T.aov' from the 'fANCOVA' package. 
At the local scale, the association between patch density and sociability treatment were evaluated we used a Kendall's-tau correlation, using the mean treatment sociability (Table 8) as the categorical ranked $\mathrm{X}$ values for each dispersal window. Mean patch densities of all socially informed and uninformed populations were compared within and across dispersal-window treatments using Kruskal-Wallace and associated multiple comparisons tests. The slopes of these associations were compared using a NpANCOVA. Correlations were performed using 'cor.test' from the 'stats' package in R (R Core 2012).

Table 8 Mean sociability values used for each treatment in statistical analyses.

\begin{tabular}{l|c} 
Treatment & Mean sociability \\
\hline \hline No personality & - \\
Asocial & 0.16 \\
Normal & 0.5 \\
Social & 0.83
\end{tabular}

Last at the regional scale, the proportion of the landscape occupied in each sociability and dispersal window treatment, as well as between dispersal treatments, were compared with Kruskal-Wallace and subsequent multiple comparisons tests where appropriate. As these were proportion data, we performed all analyses on arcsine square root transformed data. Associations between sociability treatment and the proportion of the landscape occupied were evaluated with a Kendall's-tau correlation, using mean treatment sociability (Table 8 ) as the ranked $\mathrm{X}$ categorical value. The slopes of these associations were compared using a NpANCOVA.

To evaluate the relationship between mean patch sociability and distance from the source, as well as mean patch density and distance from the source, we focused 
specifically on the normally distributed and no-personality treatments only. These relationships were evaluated using linear models which were compared with NpANCOVAs. Distance from the source area was calculated as the $\mathrm{X}$ coordinate on a cartesian plane, as the source marked the western boundary $(\mathrm{x}=0-5)$. Mean patch sociability was calculated as the mean sociability of individuals within occupied patches at the end of the run. Similarly, mean patch density was calculated as the mean density of occupied patches at the end of the run.

\section{RESULTS}

\section{Individual scale}

As we predicted, asocial agents in the model dispersed further, particularly with the longer dispersal window of 200 days. The distance traveled by individuals was negatively related to their sociability under both long $\left(\mathrm{F}=1.073 * 10^{4}, \mathrm{R}_{\text {adj. }}^{2}=0.7816\right.$, $\mathrm{P}<0.001)$ and short $\left(\mathrm{F}=284.1, \mathrm{R}_{\text {adj. }}^{2}=0.09, \mathrm{P}<0.001\right)$ dispersal windows, with a stronger relationship and significantly greater median individual distances traveled for longer dispersal-windows for both socially-informed $\left(\chi^{2}=4499.3, \mathrm{P}<0.001\right)$ and no-personality $\left(\chi^{2}=1499.3, \mathrm{P}<0.001\right)$ treatments (Figure 14). The slope of these relationships was significantly larger for the longer dispersal window $\left(\mathrm{T}=9.18 * 10^{5}, \mathrm{P}<0.005\right)$, resulting in greater variation in dispersal distances for this treatment.

When comparing socially informed treatments, there were significant differences in individual travel distances among treatments $\left(\chi^{2}=4499.3, \mathrm{P}<0.001\right.$, Figure 14). Treatments with normal sociability distributions closely resembled neutral (nopersonality) predictions, since at short dispersal windows, there was no significant difference between the no-personality and normal individual distance traveled for the 
short dispersal windows, $(\alpha=0.05)$. However, there was a small, but significant difference with a long dispersal window. The social treatment was also not significantly different from the no-personality treatment under the short dispersal window but were significantly different with the longer dispersal window. Aside from normal and asocial treatments not significantly differing under short dispersal windows, all remaining treatments' median individual distances traveled significantly differed at $\alpha=0.05$. 

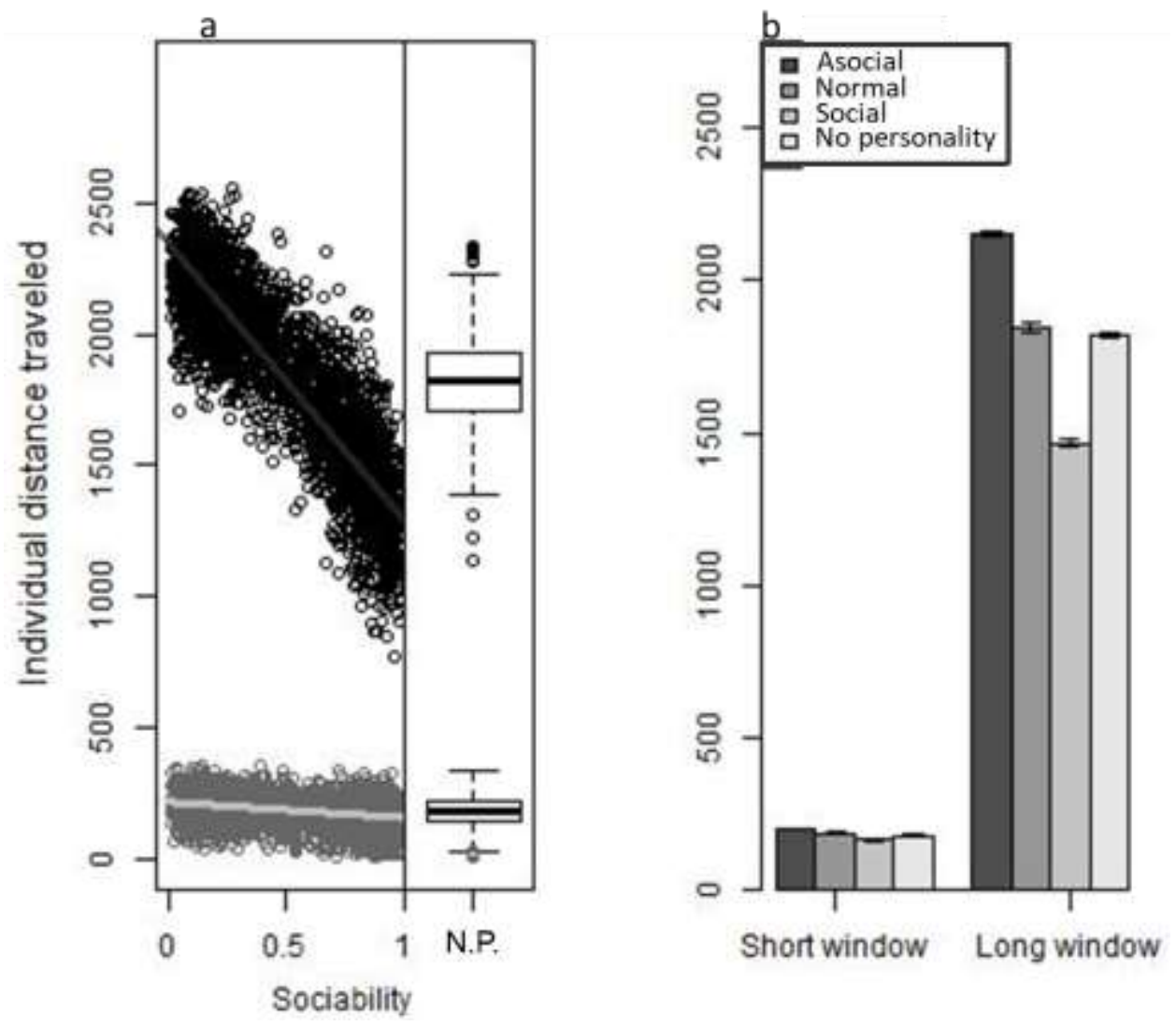

Figure 14 The distance individuals traveled, in the unit of $100 \mathrm{~m}^{2}$ cells, was negatively related to individual sociability and varied with dispersal window length. Panel a shows the raw distance traveled by all socially informed individuals, with the line of best fits for each dispersal window (black= long, gray=short), as well as boxplots of the distances nopersonality (N.P.) individuals traveled. Note sociability ranges from $0=$ extremely asocial to $1=$ extremely social. Panel $b$ shows the means and standard errors of individual travel distances for each of the treatments, demonstrating that asocials move further, socials move the least the normal distribution resembles the N.P. control, and longer dispersal windows result in longer dispersal distances.

\section{Local scale}

Patch density was consistently higher for the short dispersal window than the long window. Each treatment with and without a personality produced significantly different median patch densities within and between dispersal treatments at $\alpha=0.05\left(\chi^{2}=7464.1\right.$, $\mathrm{P}<0.001$ ), except for the no-personality and normally distributed treatments which did not vary within dispersal window treatments. Patch density was positively associated with 
treatment sociability for both short $(\tau=0.816, \mathrm{P}<0.001)$ and long $(\tau=0.819, \mathrm{P}<0.001)$ dispersal windows, with similar slopes $(\mathrm{T}=2.631, \mathrm{P}=1$; Figure 15$)$ and socially informed treatments consistently producing the highest densities.

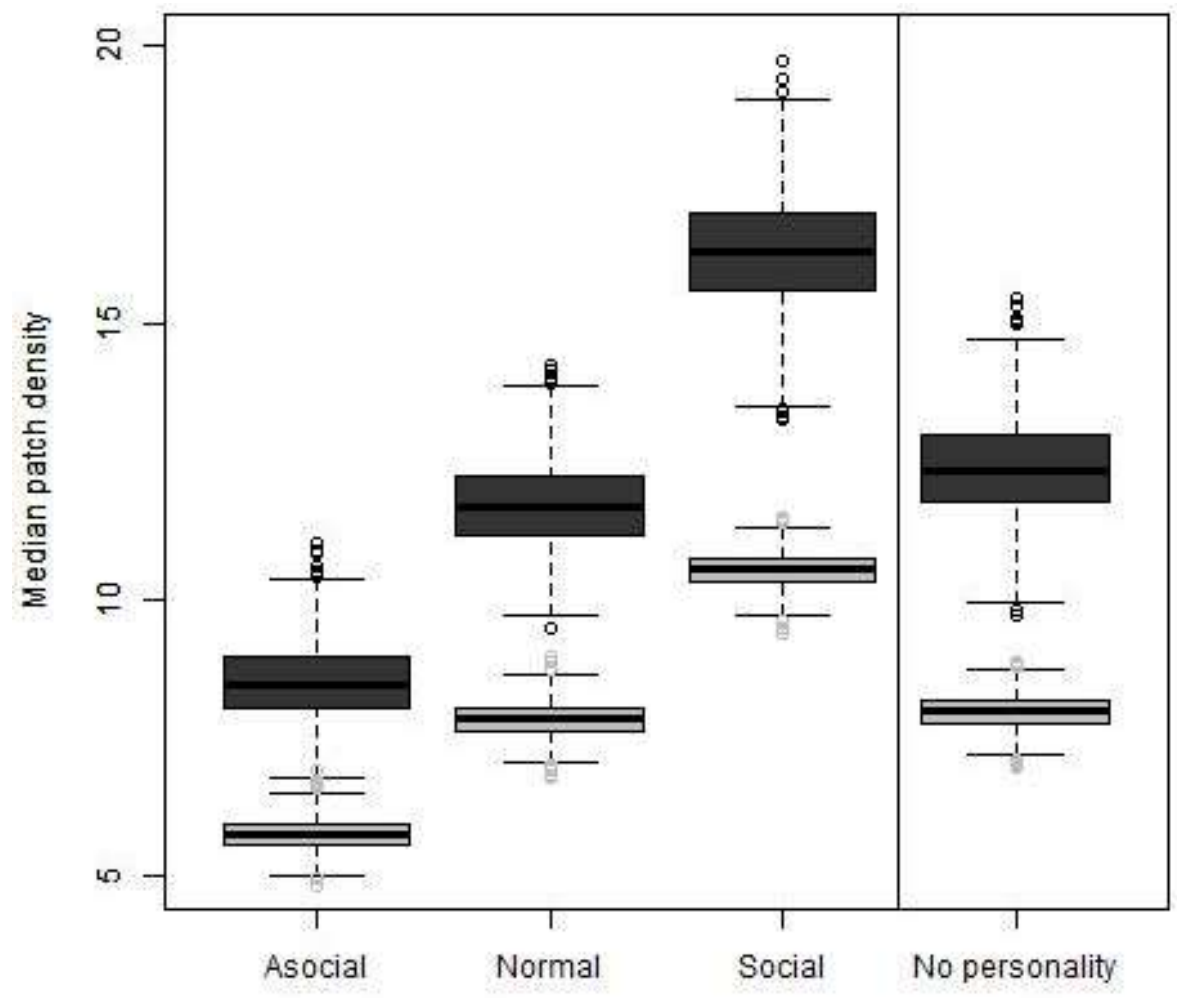

Figure 15 Median patch density from the four sociability treatments in the low (dark) and high (light) dispersal window treatments positively associated with mean population sociability, and the normal treatment was not significantly different from the no personality control. Circles denote outliers.

\section{Regional scale}

There was a weak positive association between patch occupation and sociability with long dispersal windows $(\tau=0.303, \mathrm{P}<0.001)$, but no such pattern was observed for the short dispersal windows ( $\tau=0.005, \mathrm{P}=0.741$, Figure 16 ). The slopes for the two dispersal treatments were different $(\mathrm{T}=0.030, \mathrm{P}=0.005)$. Short dispersal windows, regardless of sociability treatment, resulted in a median landscape occupation of 
approximately $52 \%$, while for the long dispersal window treatment, the median landscape occupation was $99 \%$, with only minor differences among personality treatments.

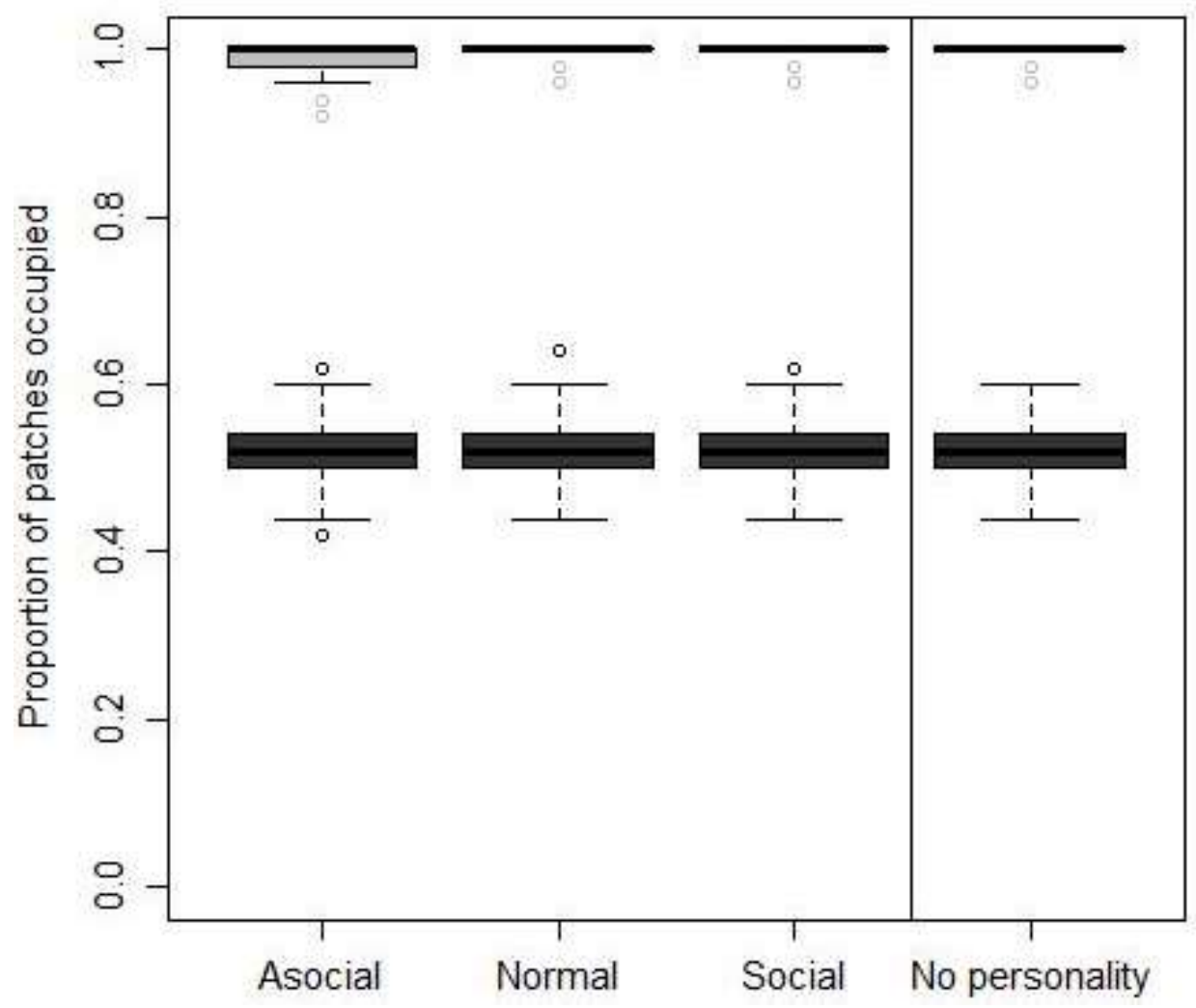

Figure 16 Boxplots showing the proportion of the patches which were occupied during each of the four sociability treatments under low (dark) and high (light) dispersal treatments. Circles are outliers.

Mean patch sociability significantly decreased as a function of distance from the source for the short $\left(\mathrm{F}=1903, \mathrm{R}^{2}{ }_{\text {adj }}=0.656, \mathrm{t}=-43.62, \mathrm{P}<0.001\right)$ and long $(\mathrm{F}=24.48$, $\mathrm{R}^{2}{ }_{\text {adj }}=0.023, \mathrm{t}=-4.95, \mathrm{P}<0.001$ ) dispersal windows (Figure 17). There was also a negative relationship between mean patch density and distance from the source for both dispersal window treatments with socially informed (short: $\mathrm{F}=731.9, \mathrm{R}^{2}=0.423, \mathrm{t}=-27.05$, $\mathrm{P}<0.001$; long: $\left.\mathrm{F}=157.6, \mathrm{R}^{2}=0.136, \mathrm{t}=-12.55, \mathrm{P}<0.001\right)$ and no-personality treatments 
(short: $\mathrm{F}=654, \mathrm{R}^{2}=0.395, \mathrm{t}=-25.57, \mathrm{P}<0.001$; long: $\mathrm{F}=178, \mathrm{R}^{2}=0.151, \mathrm{t}=-13.34, \mathrm{P}<0.001$ ). The slopes of the relationship significantly varied with dispersal-window length for both treatment types (with personality: $\mathrm{T}=43.36, \mathrm{P}=0.005$; no-personality: $\mathrm{T}=40.31, \mathrm{P}=0.005$ ), with short windows resulting in the more negative relationship. This relationship did not significantly differ between treatments with and without personalities within dispersal window treatments (short: $\mathrm{T}=0.446, \mathrm{P}=0.10$; long dispersal: $\mathrm{T}=0.009, \mathrm{P}=0.776$ ).
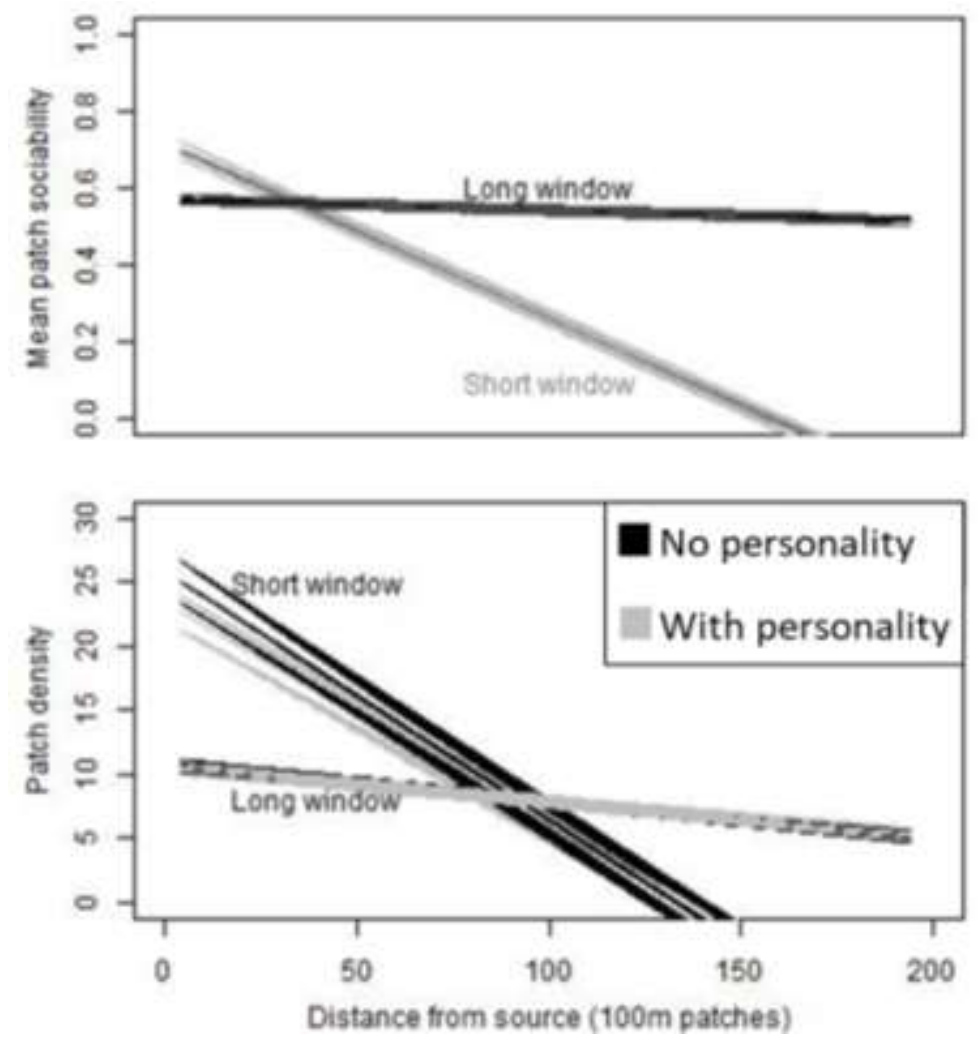

Figure 17 The top panel shows a linear model of the mean sociability of patches as a function of distance from the source, in the unit of patches, and associated standard errors for each level of dispersal. The bottom panel shows the mean patch density as a function of distance from the source, and associated standard errors, for the with and without personality treatments under each dispersal window treatment. Note that the with personality treatment shown here is only the normal distribution treatment as other sociability treatments violated parametric assumptions. 


\section{DISCUSSION}

The mechanisms structuring metapopulations have been, and still are, of central interest to ecologists for several decades (e.g., Deans and Chalcraft, 2017; Gotelli, 1991; Govindan et al., 2015; Harrison et al., 1988). While environmental factors and interspecific interactions are known to be influential (Pringle 2003, Bond et al. 2015), recent work has suggested individual personalities can also be significant structuring forces by encouraging personality-dependent dispersal (PDD; e.g., Cote et al., 2010a, 2010b; Cote and Clobert, 2007; Spiegel et al., 2015). However, few studies to date have observed PDD at ecologically relevant spatiotemporal scales, and none have done so using sociability. We have demonstrated here that individual sociability, can have significant structuring influences on assembling ephemeral metapopulations at multiple scales (individual, local and regional), and that these influences can vary depending on the length of the dispersal window. In the following sections, we discuss five key findings from this model: 1) the total distance a propagule dispersed was negatively related to their sociability, a relationship which became stronger as the length of the dispersal window increased. 2) Patch density was positively associated with the sociability of the source population; and the strength of this relationship was unaffected by dispersal window length, but mean patch densities decrease with longer dispersal windows. 3) The proportion of the landscape occupied was unaffected by sociability under the conditions tested, but was higher under the longer dispersal window. 4) Mean patch sociability was negatively related to the distance from the source, mirroring patch density distance decays typical of neutrally structured populations. Below, we discuss the 
implications of these results at each scale and refine hypotheses to be tested in future field studies.

\section{Individual scale- dispersal distance}

With our model, we have shown that an individual's sociability can be negatively related to the distance they disperse at ecologically relevant spatiotemporal scales (e.g., beyond mesocosms scales), as hypothesized by Cote et al. (2010a), and that this relationship is temporally-dependent (Figure 14). The temporal dependence is conceptually simple, as longer dispersal windows allow more time for individual differences to be accentuated. However, this finding is worth noting since it suggests that short-dispersal windows may mask the relationship between sociability and dispersal.

A key consequence of the negative relationship between individual sociability and travel distance is that it suggests there is a greater metabolic cost for being asocial in metapopulations, as more energy will likely be spent on dispersal the more asocial an individual is. This added metabolic cost could have fitness consequences. In Round Gobies (Neogobius melanostomus) for example, the most dispersive, boldest, individuals have higher resting metabolic rates and allocate less energy to reproductive efforts during dispersal (Myles-Gonzalez et al. 2015). These gobies are able to offset the fitness consequences of their dispersive phenotype by re-allocating energy back toward reproductive pathways when not dispersing (Myles-Gonzalez et al. 2015); however, it is unlikely that this compensation occurs in all species. In the absence of such compensatory mechanisms, asociality would then be maladaptive in stable environments, assuming no added benefits to dispersal such as inbreeding avoidance, territoriality or 
reduced competition for resources (see Bonte et al., 2012 for a review of the 'costs and benefits' of dispersal).

Conversely, dynamic environments, such as ephemeral wetlands, may select for more dispersive phenotypes through stochastic extirpations of high density areas. Population resilience to such events requires satellite populations, likely consisting of dispersive asocial individuals, to recolonize extirpated patches (i.e. the rescue effect, see Gotelli, 1991). Depending on the frequency and severity of these selective events, this could result in asocially skewed or normally distributed sociabilities. Therefore, we hypothesize that metapopulations in stable environments will be socially skewed, while those in dynamic environments will have asocially skewed or normally distributed sociabilities. These hypothesized multigenerational patterns could be tested with an extension of our IBM that incorporates individual fitness, multigenerational population dynamics and different degrees of environmental stochasticity.

Effects of sociability at the patch scale

Our model demonstrated a positive association between patch density and population sociability (Figure 15). While this is an empirically supported pattern, observed in both fish (Cote et al. 2010b) and reptiles (Cote and Clobert 2007), it was an imposed feature of the model and therefore is not an emergent property. The significantly reduced densities under longer dispersal windows, however, are. This pattern was a function of individuals searching longer and further for preferable densities, thereby discovering and settling more patches when the dispersal window allowed. While intuitive, this provides another avenue by which certain phenotypes may be maladaptive in environments with short dispersal windows. The high densities caused by short 
dispersal windows may cause increased stress levels in asocial individuals. Conversely, the low densities typical of long dispersal windows may be stressful for social individuals. When chronic, stress can have a wide array of physiological effects ranging from increased aggression to reduced fitness and eventually degradation of organ systems (McEwen and Wingfield 2003, Romero 2004, Baker et al. 2013). Therefore, we hypothesize that long dispersal windows in ephemeral habitats will select for asociality, whereas short windows select for sociality.

\section{Regional scale effects}

The role of personality types in landscape occupancy has particular interest to invasion ecologists, as it is a key factor for assessing pest status (Ricciardi et al. 2013). It has long been hypothesized that more dispersive personalities in invading populations would result in faster landscape occupation (see Sih et al., 2012 for discussion).

However, we found no evidence for the hypothesized negative relationship between population sociability and landscape occupancy. Rather, we found that all populations occupied approximately the same proportion of the landscape within the same dispersal window, regardless of personality. We also expected to see a flattening of the negative relationship between landscape occupancy and sociability with the longer dispersal windows due to landscape saturation. Contrary to these expectations, the only thing that influenced landscape occupancy in our model was the length of the dispersal window.

Landscape saturation may explain the lack of a relationship for the longer dispersal window, but not the short. Rather, this may be a function of short exploration times interacting with the random-walks used by our agents. Random walks are widely used in IBMs as they have been demonstrated to approximate animal movement patterns 
(Proulx et al. 2013, Fagan and Calabrese 2014). They do, however, assume a total lack of directional bias and an absence of prior knowledge. This results in an tendency to heavily explore an area before making random long dispersal movements, even with the arearestricted search procedure used in this study and others (Spiegel et al. 2017). While the addition of a directional bias would limit search intensity, and may produce the expected patterns, there is currently no empirical evidence that it would accurately represent Eastern Mosquitofish dispersal in the modeled system or others. Rather, our model species is known to colonize the Rocky Glades immediately following re-flood (start of the dispersal window), and has been observed moving in all directions (lacking a directional bias) throughout most of the dispersal window (Goss et al. 2014). Future field and simulation studies should further evaluate the hypothesis that landscape occupancy is negatively related to population sociability.

In Cote et al.'s (2010a) hypothesis, asocial individuals traveled further in to the landscape establishing low density patches at larger distances from source populations. While not discussed as such, the net result of this mechanism would be negative relationships between mean patch sociability and distance from the source, as well as density and distance from the source. We find evidence for both such patterns resulting from differences in individual sociability. This pattern of lower population densities at greater distances from sources, or density-distance decay, is a typical emergent property of neutral models (Hubbell 2001a). Here, we show that a population density-distance decay relationship can emerge from variation in behavioral types. This suggests that the sorting of individuals along cryptic behavioral gradients may produce neutral patterns, raising the possibility that metasystems (e.g., metapopulations, metacommunities, 
metaecosystems) considered to be neutrally structured (e.g., Muneepeerakul et al., 2008) may in fact be structured along some latent and unmeasured behavioral gradient. This novel mechanism for a classic neutral pattern may shed additional light into one of ecologies longest running debates: niche vs. neutrality (see Adler et al., 2007; Alonso et al., 2006; Mutshinda and O’Hara, 2011). We suggest a behaviorally based re-evaluation of seemingly neutrally structured metasystems, as there may be cryptic structuring mechanisms at work. In the case of managed metasystems, such as our model system, it is of particular interest to know how these cryptic niche mechanisms will interact with shifting climatic parameters that may affect dispersal opportunities. However, our findings also suggest that, while personalities likely do influence assembly mechanisms, PDD may add unnecessary complexity if the target population does not have a skewed personality distribution. At each scale observed, moderate sociabilities resulted in patterns resembling those of the no personality, neutral, treatment.

We have uncovered two key considerations for sociabilities in the real-world. First, individual personalities can structure metasystems as a form of cryptic niche structuring and can be assimilated in to ecological theory via niche theories. Second, when modeling a metapopulation; if the subject has a high proportion of moderate sociabilities, then the emergent patterns can be approximated by simpler neutral models. If the distribution of sociabilities is skewed, then neutral models will not be applicable, and individual personalities should be considered.

\section{Hypotheses for future studies}

Our main goal with this study was to generate, refine and pose testable hypotheses, using this simple IBM, for testing. In doing so, it is our hope to inspire field-based 
evaluations of these hypotheses to facilitate mechanistic integration of sociability dependent dispersal and metasystem theory. Specifically, these data support the following hypotheses (Figure 18) that at the:

1) Individual scale

a) Individual travel distance is negatively related to sociability.

b) Short dispersal windows reduce the effect of PDD on individual dispersal (Figure 18a).

2) Local scale

a) Mean patch density is positively associated with mean population sociability, regardless of dispersal window length.

3) Regional scale

a) Mean patch sociability decreases as a function of distance from a source with limited, but not unlimited, dispersal window length (Figure 18c).

4) Multigenerational scale

a) Dynamic landscapes will select for normal or asocially skewed sociability distributions (Figure 18d top).

b) Stable landscapes will select for socially skewed populations (Figure 18d bottom). 

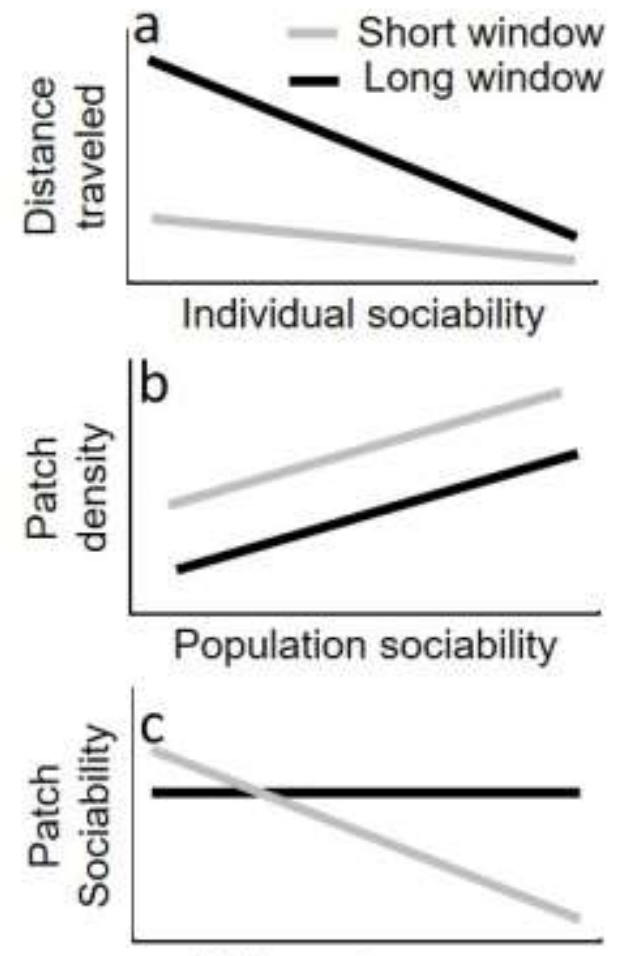

Distance to source
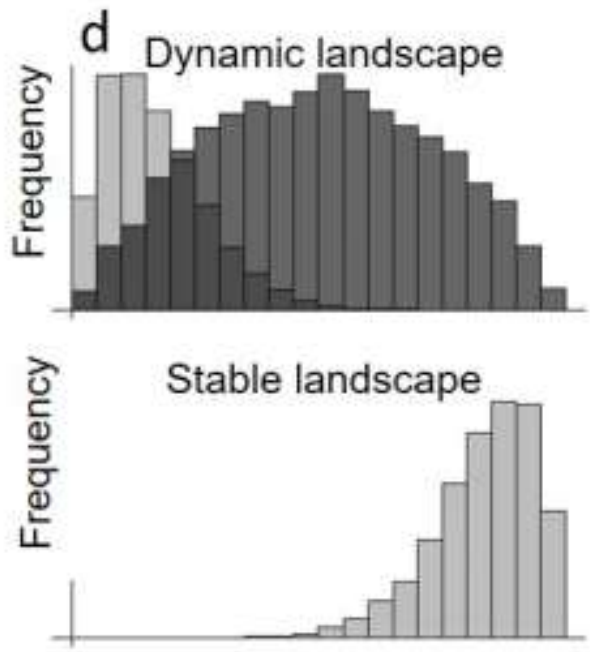

Individual sociability

Figure 18 Proposed hypotheses to be evaluated in natural metasystems. The left panel shows relationships which our data suggest should emerge because of sociability dependent dispersal. The right panel shows the two hypothesized population sociability distributions for dynamic (top) and stable (bottom) landscapes.

\section{Evaluating these predictions with field data}

These hypotheses (Figure 18) now need to be rigorously evaluated with empirical real-world data. The relationship between traveling distance and sociability has been experimentally demonstrated (Cote et al. 2010b), though it has not yet been studied at ecologically meaningful spatial scales (10's-100's km). Similarly, leading edges of range expansions tend to have more dispersive phenotypes such as longer legs or higher boldness (Maes et al. 2013, Myles-Gonzalez et al. 2015), though how this relates to patch sociability over space has not been investigated. The remainder of these factors have yet to be directly empirically addressed. Similarly, to our knowledge, the interaction of 
sociability and environmentally mediated dispersal, as it relates to metapopulation dynamics, has yet to be studied in any explicit detail. While admittedly not a simple task, these hypotheses could be tested empirically by observing the densities of a natural closed metapopulation, with known source populations, along a transect from source to the far edge of the system. A subsample of individuals from each patch would then need to have their sociability assayed (see Cote et al., 2013, 2010a, 2010b for methodology). To assess the effects of differing levels of dispersal, this study should span multiple years to capture different natural conditions of dispersal-limitation (e.g., different hydroperiod lengths). These data could then be analyzed via a trait-based variance partitioning approach, such as used by Michelson et al. (2016), which would tease apart the relative importance of behavioral types in the context of a natural metapopulation. Concurrently, a passive-tracking system (e.g., telemetry array) would facilitate understanding individual differences in movement behavior, and how those relate to individual sociability. In doing so, such a study would generate the knowledge necessary for empirically integrating individual personalities into macroecological theory, a necessary next step for the field (Beekman and Jordan 2017, Pruitt 2017).

\section{Conclusions}

Overall, our results support the growing evidence that individual personalities are particularly important in the field of metasystem ecology, as they influence dispersal rates and density-dependent processes. It is also worth noting that one of the advantages of metasystem theories, in general, is that they are hierarchical in nature and their properties scale (Chesson et al. 2005, Holyoak et al. 2005, Holt and Chesson 2016). A metaecosystem is little more than a group of metacommunities linked by some form of 
dispersal across a low-quality matrix (Gravel et al. 2010). The individual

metacommunities themselves comprise a group of co-occurring and interacting

metapopulations (Holyoak et al. 2005, Logue et al. 2011). We have shown here that

individual personalities can influence metapopulation properties. It follows then that

similar effects exist at other metasystem scales as well. Future works should seek to

evaluate the hypotheses we propose (Figure 18), as well as the broader influences of

individual personalities at each metasystem scale, for us to better understand how these

cryptic niche-determining traits form the patterns we observe in nature.

\section{REFERENCES}

Adler, P. B., J. Hillerislambers, and J. M. Levine. 2007. A niche for neutrality. Ecology Letters 10:95-104.

Alonso, D., R. S. Etienne, and A. J. McKane. 2006. The merits of neutral theory. Trends in Ecology and Evolution 21:451-457.

Altermatt, F., A. Bieger, F. Carrara, A. Rinaldo, and M. Holyoak. 2011. Effects of connectivity and recurrent local disturbances on community structure and population density in experimental metacommunities. PloS ONE 6:e19525.

Baguette, M., and H. Van Dyck. 2007. Landscape connectivity and animal behavior: Functional grain as a key determinant for dispersal. Landscape Ecology 22:11171129.

Baker, M. R., K. S. Gobush, and C. H. Vynne. 2013. Review of factors influencing stress hormones in fish and wildlife. Journal for Nature Conservation 21:309-318.

Beekman, M., and L. A. Jordan. 2017. Does the field of animal personality provide any new insights for behavioral ecology? Behavioral Ecology.28.3:617-623

Bond, A. N. R., S. R. Balcombe, D. Crook, and J. C. Marshall. 2015. Fish population persistence in hydrologically variable landscapes. Ecological applications 25:901913.

Bonte, D., H. Van Dyck, J. M. Bullock, A. Coulon, M. Delgado, M. Gibbs, V. Lehouck, E. Matthysen, K. Mustin, M. Saastamoinen, N. Schtickzelle, V. M. Stevens, S. 
Vandewoestijne, M. Baguette, K. Barton, T. G. Benton, A. Chaput-Bardy, J. Clobert, C. Dytham, T. Hovestadt, C. M. Meier, S. C. F. Palmer, C. Turlure, and J. M. J. Travis. 2012. Costs of dispersal. Biological Reviews 87:290-312.

Cadotte, M. W. 2007. Competition-Colonization Trade-offs and Disturbance Effects at Multiple Scales. Ecology 88:823-829.

Capelle, P. M., E. S. Mccallum, and S. Balshine. 2015. Aggression and sociality: conflicting or complementary traits of a successful invader? Behavior 152:127146.

Chesson, P., M. J. Donahue, B. A. Melbourne, and A. L. W. Sears. 2005. Scale transition theory for understanding mechanisms in metacommunities. Pages 279-306in M. Holyoak, M. A. Leibold, and R. D. Holt, editors. Metacommunities. The University of Chicago Press, Chicago and London.

Clobert, J., J.-F. F. Le Galliard, J. Cote, S. Meylan, and M. Massot. 2009. Informed dispersal, heterogeneity in animal dispersal syndromes and the dynamics of spatially structured populations. Ecology Letters 12:197-209.

Conrad, J. L., K. L. Weinersmith, T. Brodin, J. B. Saltz, and A. Sih. 2011. Behavioral syndromes in fishes: a review with implications for ecology and fisheries management. Journal of Fish Biology 78:395-435.

Cote, J., and J. Clobert. 2007. Social personalities influence natal dispersal in a lizard. Proceedings. Biological Sciences/The Royal Society 274:383-390.

Cote, J., J. Clobert, T. Brodin, S. Fogarty, and A. Sih. 2010a. Personality-dependent dispersal: characterization, ontogeny and consequences for spatially structured populations. Philosophical transactions of the Royal Society of London. Series B, Biological Sciences 365:4065-76.

Cote, J., S. Fogarty, T. Brodin, K. Weinersmith, and A. Sih. 2010b. Personality traits and dispersal tendency in the invasive mosquitofish (Gambusia affinis). Proceedings of the Royal Society/ Biological Sciences 278:1670-8.

Cote, J., S. Fogarty, B. Tymen, A. Sih, and T. Brodin. 2013. Personality-dependent dispersal cancelled under predation risk. Proceedings of the Royal Society B: Biological Sciences 280:20132349.

Deacon, A. E., I. W. Ramnarine, and A. E. Magurran. 2011. How reproductive ecology contributes to the spread of a globally invasive fish. PloS ONE 6:e24416.

Deans, R. A., and D. R. Chalcraft. 2017. Matrix context and patch quality jointly determine diversity in a landscape-scale experiment. Oikos 126:874-887. 
Dibble, C. J., S. R. Hall, and V. H. W. Rudolf. 2014. Intraspecific priority effects and disease interact to alter population growth. Ecology 95(12): 3354-3363

Drake, J. A. 1990. The Mechanics of Community Assembly and Succession. Journal of Theoretical Biology 147:213-233.

Duckworth, R. A. 2008. Adaptive dispersal strategies and the dynamics of a range expansion. The American Naturalist 172: S4-S17.

Duckworth, R. a., and A. V Badyaev. 2007. Coupling of dispersal and aggression facilitates the rapid range expansion of a passerine bird. Proceedings of the National Academy of Sciences of the United States of America 104:15017-22.

Fagan, W. F., and J. M. Calabrese. 2014. The Correlated Random Walk and the Rise of Movement Ecology. Bulletin of the Ecological Society of America 95:204-206.

Goss, C. W., W. F. Loftus, and J. C. Trexler. 2014. Seasonal Fish Dispersal in Ephemeral Wetlands of the Florida Everglades. Wetlands January:1-11.

Gotelli, N. J. 1991. Metapopulation models: the rescue effect, the propagule rain, and the core-satellite hypothesis. The American Naturalist 138:768-776.

Govindan, B. N., Z. Feng, Y. D. DeWoody, and R. K. Swihart. 2015. Intermediate disturbance in experimental landscapes improves persistence of beetle metapopulations. Ecology 96:728-736.

Gravel, D., N. Mouquet, M. Loreau, and F. Guichard. 2010. Patch Dynamics, Persistence, and Species Coexistence in Metaecosystems. The American Naturalist 176:289302.

Grimm, V., U. Berger, F. Bastiansen, S. Eliassen, V. Ginot, J. Giske, J. Goss-Custard, T. Grand, S. K. Heinz, G. Huse, A. Huth, J. U. Jepsen, C. Jørgensen, W. M. Mooij, B. Müller, G. Pe'er, C. Piou, S. F. Railsback, A. M. Robbins, M. M. Robbins, E. Rossmanith, N. Rüger, E. Strand, S. Souissi, R. A. Stillman, R. Vabø, U. Visser, and D. L. DeAngelis. 2006. A standard protocol for describing individual-based and agent-based models. Ecological Modelling 198:115-126.

Groen, M., N. M. Sopinka, J. R. Marentette, A. R. Reddon, J. W. Brownscombe, M. G. Fox, S. E. Marsh-Rollo, and S. Balshine. 2012. Is there a role for aggression in round goby invasion fronts? Behavior 149:685-703.

Hanski, I., and M. Gilpin. 1991. Metapopulation dynamics: brief history and conceptual domain. Biological Journal of the Linnean Society 42:3-16. 
Harrison, S., D. D. Murphy, and P. R. Ehrlich. 1988. Distribution of the Bay Checkerspot Butterfly, Euphydryas editha bayensis: Evidence for a Metapopulation Model. The American Naturalist 132:360-382.

Hawkes, C. 2009. Linking movement behaviour, dispersal and population processes: Is individual variation a key? Journal of Animal Ecology 78:894-906.

Holt, G., and P. Chesson. 2016. Scale-Dependent Community Theory for Streams and Other Linear Habitats. The American Naturalist 188 (3): E59-E73.

Holyoak, M., M. A. Liebold, and R. D. Holt. 2005. Metacommunities: Spatial dynamics and ecological communities. University of Chicago Press.

Hubbell, S. P. 2001. The unified neutral theory of species abundance and diversity. Pages 96-97in S. P. Hubbell (2004), editor. Quarterly Review of Biology. Princeton University Press, Princeton, N.J.

Kobza, R. M., J. C. Trexler, W. F. Loftus, and S. A. Perry. 2004. Community structure of fishes inhabiting aquatic refuges in a threatened Karst wetland and its implications for ecosystem management. Biological Conservation 116:153-165.

Kotun, K., and A. Renshaw. 2014. Taylor Slough Hydrology. Wetlands 34:9-22.

Lindenmayer, D. B., and R. J. Hobbs. 2007. Corridors, Connectivity and Biological Conservation. Page Managing and Designing Landscapes for Conservation: Moving from Perspectives to Principles. Pages 249-262

Loftus, W. F., R. A. Johnson, and G. H. Anderson. 1992. Ecological impacts of the reduction of groundwater levels in short-hydroperiod marshes of the Everglades. Pages 199-208 Proceedings of the First International Conference on Ground Water Ecology.

Logue, J. B., N. Mouquet, H. Peter, and H. Hillebrand. 2011. Empirical approaches to metacommunities: a review and comparison with theory. Trends in Ecology \& Evolution 26:482-91.

Maes, J., R. Van Damme, and E. Matthysen. 2013. Individual and among-population variation in dispersal-related traits in Natterjack toads. Behavioral Ecology 24:521-531.

McEwen, B. S., and J. C. Wingfield. 2003. The concept of allostasis in biology and biomedicine. Hormones and Behavior 43:2-15. 
McVoy, C. W., W. P. Said, J. Obeysekera, J. Van Arman, and T. Dreschel. 2011. Landscapes and Hydrology of the Predrainage Everglades. University Press of Florida.

Mueller, T., and W. F. Fagan. 2008. Search and navigation in dynamic environmentsfrom individual behaviours to population distributions. Oikos 117:654-664.

Muneepeerakul, R., E. Bertuzzo, H. J. Lynch, W. F. Fagan, A. Rinaldo, and I. RodriguezIturbe. 2008. Neutral metacommunity models predict fish diversity patterns in Mississippi-Missouri basin. Nature 453:220-222.

Mutshinda, C. M., and R. B. O'Hara. 2011. Integrating the niche and neutral perspectives on community structure and dynamics. Oecologia 166:241-251.

Myles-Gonzalez, E., G. Burness, S. Yavno, A. Rooke, and M. G. Fox. 2015. To boldly go where no goby has gone before: boldness, dispersal tendency, and metabolism at the invasion front. Behavioral Ecology 26:1083-1090.

Pringle, C. 2003. What is hydrologic connectivity and why is it ecologically important? Hydrological Processes 17:2685-2689.

Proulx, C. L., L. Proulx, and G. Blouin-Demers. 2013. Improving the realism of random walk movement analyses through the incorporation of habitat bias. Ecological Modelling 269:18-20.

Pruitt, J. N. 2017. Are personality researchers painting the roses red? Maybe: a comment on Beekman and Jordan. Behavioral Ecology.28.3:628-629

R Core, T. 2012. R: A language and environment for statistical computing. R Foundation for Statistical Computing, Vienna, Austria.

Rehage, J. S., B. K. Barnett, and A. Sih. 2005. Behavioral responses to a novel predator and competitor of invasive mosquitofish and their non-invasive relatives (Gambusia sp.). Behavioral Ecology and Sociobiology 57:256-266.

Rehage, J. S., J. Cote, and A. Sih. 2016. The Role of Dispersal Behaviour and Personality in Post-establishment Spread. Pages 96-115in J. S. Weis and D. Sol., editors. Biological Invasions and Animal Behaviour. Cambridge University Press.

Rehage, J. S., S. E. Liston, K. J. Dunker, and W. F. Loftus. 2014. Fish community responses to the combined effects of decreased hydroperiod and nonnative fish invasions in a karst wetland: are Everglades solution holes sinks for native fishes? Wetlands:1-15. 
Revilla, E., T. Wiegand, F. Palomares, P. Ferreras, and M. Delibes. 2004. Effects of matrix heterogeneity on animal dispersal: from individual behavior to metapopulation-level parameters. The American Naturalist 164:E130-E153.

Ricciardi, A., M. F. Hoopes, M. P. Marchetti, and J. L. Lockwood. 2013. Progress Toward Understanding the Ecological Impacts of Non-native Species. Ecological Monographs:1-68.

Romero, L. M. 2004. Physiological stress in ecology: Lessons from biomedical research. Trends in Ecology and Evolution 19:249-255.

Sih, A. 1992. Prey uncertainty and the balancing of antipredator and feeding needs. The American Naturalist 139:1052-1069.

Sih, A., A. M. Bell, J. C. Johnson, and R. E. Ziemba. 2004. Behavioral syndromes: an integrative overview. The Quarterly Review of Biology 79:135-160.

Sih, A., J. Cote, M. Evans, S. Fogarty, and J. Pruitt. 2012. Ecological implications of behavioural syndromes. Ecology Letters 15:278-89.

Spiegel, O., S. T. Leu, C. M. Bull, and A. Sih. 2017. What's your move? Movement as a link between personality and spatial dynamics in animal populations. Ecology Letters 20:3-18.

Spiegel, O., S. T. Leu, A. Sih, S. S. Godfrey, and C. M. Bull. 2015. When the going gets tough: behavioural type-dependent space use in the sleepy lizard changes as the season dries. Proceedings of the Royal Society B: Biological Sciences 282:20151768.

Sutherland, C. S., D. A. Elston, and X. Lambin. 2014. A demographic, spatially explicit patch occupancy model of metapopulation dynamics and persistence. Ecology 95:3149-3160.

Tscharntke, T., J. M. Tylianakis, T. a. Rand, R. K. Didham, L. Fahrig, P. Batáry, J. Bengtsson, Y. Clough, T. O. Crist, C. F. Dormann, R. M. Ewers, J. Fründ, R. D. Holt, A. Holzschuh, A. M. Klein, D. Kleijn, C. Kremen, D. a. Landis, W. Laurance, D. Lindenmayer, C. Scherber, N. Sodhi, I. Steffan-Dewenter, C. Thies, W. H. van der Putten, and C. Westphal. 2012. Landscape moderation of biodiversity patterns and processes - eight hypotheses. Biological Reviews 87:661-685.

Wilensky, U. 1999. NetLogo. Center for Connected Learning and Computer-Based Modeling, Northwestern University, Evanston, IL. [ http://ccl.northwestern.edu/netlogo/]. 
Wolf, M., and F. J. Weissing. 2012. Animal personalities: consequences for ecology and evolution. Trends in Ecology \& Evolution 27:452-61.

Zar, J. H. 1999. Biostatistical Analysis. Page (D. Lynch, Ed.) Prentice Hall New Jersey. fourth. Pearson education. 


\section{CONCLUSIONS AND DISCUSSION}

Metacommunity assembly is a complex process driven by a combination of stochastic events, local and regional environmental factors as well as the interactions between species (Holyoak et al. 2005, Adler et al. 2007, Mutshinda and O'Hara 2011, Logue et al. 2011, Winegardner et al. 2012). Despite several decades of work on the subject, ecologists still lack a clear understanding of the mechanisms driving it. Interspecific interactions, local and regional environmental factors have each been demonstrated to drive assembly (Logue et al. 2011), with the suggestion that the level of dispersal during each event will determine which factor is of ultimate influence (Winegardner et al. 2012). However, these factors typically explain a limited amount of variance in metacommunity assembly (Soininen 2014). Interspecific trait differences influence the way species differentially interact with the environment, and underlie the influence of traditionally considered metacommunity drivers (Petchey and Gaston 2006, Loughnan and Gilbert 2017), and explain more variance in assembly data than environmental factors do alone (Gianuca et al. 2016).

In Chapter I, I provide evidence that the relative influence of traits, local and regional factors shift along a dispersal-limitation gradient, in general agreement with Winegardner et al. (2012). Overall, increasing levels of dispersal-limitation resulted in a decreasing relative influence of species traits and local factors, with a corresponding increase in the importance of regional factors. The most important traits interacting with environmental factors were parental care and trophic level, but the most influential independent trait was the dispersal related colonization tendency. In the ephemeral 
wetland metacommunity observed in this study, our findings suggest that when time and dispersal-limitation permit, under low limitation, local habitat selectivity is particularly influential, with competitive structuring and patch complexity interacting to drive the process. This local selectivity is lost as limitation becomes more severe, being replaced by regional hydrology and competitive traits, with dispersal traits having consistently high influence regardless of changes in dispersal-limitation. This generally agrees with previous work which suggests assembly needs be considered along a trait-based dispersal-limitation gradient (Ellis et al. 2006, Winegardner et al. 2012, Kuglerová et al. 2014, Gianuca et al. 2016), but also suggest that greater thought be given to the mechanisms driving observed patterns by incorporating traits in to assessments of metacommunity assembly (Violle et al. 2007).

Chapter II investigated the reasons behind some of the structuring described in Chapter I by investigating the relative role of environmental factors and a recent invader, the African Jewelfish (Hemichromis letourneuxi), as well as invasive species in general. The observed metacommunity was neutrally structured before this invasion, and was significantly less segregated in the sample immediately following the invasion. This condition has persisted more than a decade later. The African Jewelfish is now the second most abundant species in the system, and is functionally unique in many ways. As described in chapter I, parental care and trophic level are key drivers of assembly. African Jewelfish exhibit bi-parental brood care, which no native fish in the Everglades do, and is a voracious piscivore despite its small body size. Predators are known to increase preference for high patch complexity, which offers structural refugia (Arrington et al. 2005, Hovel and Regan 2008, Bellmorea et al. 2014). I hypothesize that the 
predatory nature and novel aggressive bi-parental brood care of African Jewelfish causes other species to seek patches with high structural refugia. However, this structuring will be less influential during drier years, as regional factors become more important. Comparing my results to previous literature, the same general pattern of reduced segregation was found to be universal across all studies, regardless of taxa (insects: Gotelli and Arnett 2000, Sanders et al. 2003; plants: Reshi et al. 2008, Kuebbing et al. 2014; amphibians: Richter-Boix et al. 2013; and fish: this study). As segregation permits competitive co-existence and diversity (Amarasekare 2003), the implications of this could be dramatic for invaded communities (e.g., reduced diversity, increased competitive structuring, etc.) and may partially be responsible for the multi-scale effects of some invasions (Cucherousset and Olden 2011). Interestingly, all studies found this pattern within one sampling unit of the invasion. I submit that the use of null model analyses (Stone and Roberts 1990, Ulrich and Gotelli 2013) with long term biodiversity data may be a valuable tool for detecting the introduction of truly invasive species before their densities achieve pest status, before it is too difficult or damaging to remove them. Given the paucity of studies employing this technique so far however, this must be rigorously evaluated before being widely implemented.

In the final chapter, I investigated another type of trait which I could not measure within the scope of the field data. Using an individual based model, I demonstrate that individual sociability can structure a metapopulation in both space and time at the individual, local and regional scales with potential implications for multigeneration dynamics. From the emergent properties of this model, and previous works, I hypothesize that dispersal distance is negatively related so sociability, a relationship which becomes 
stronger with longer dispersal windows, patch density is positively associated to population sociability regardless of dispersal window, and that the sociability of a population can be directly influenced by the relative stability of the landscape overall. Perhaps most interestingly is the hypothesis that community sociability at the patch level negatively relates to distance from the source for short but not long dispersal windows. The net result of this would be the generation of density distance decays, as patch density negatively associates with sociability, via a cryptic trait that operates along a historically unmeasured niche axis (sociability). This suggests that famously neutrally structured metapopulations (e.g., Muneepeerakul et al. 2008) may actually be niche structured. I also note however, that only populations with heavily skewed sociabilities which deviate from these neutral predictions. As a result, when modeling metapopulations with high proportions of moderate sociabilities, it is likely only necessary to account for sociability when the population has a skewed distribution of this trait.

In conclusion, metasystem assembly is a complex multivariate process. I have empirically demonstrated that the forces driving metacommunity assembly differentiate along a dispersal-limitation gradient, species traits consistently explain more variance than environmental factors regardless of dispersal-limitation, and invasive species introductions can desegregate the metacommunity. I have also demonstrated that individual personalities can have structuring influences on metapopulation assembly at all scales investigated (individual, local and regional) with hypothesized multigenerational implications. I suggest that future considerations of metasystem assembly be conducted in a trait-based fashion, accounting for the personalities of propagules as traits where applicable (animal metasystems with skewed personality distributions), and that changes 
in the dispersal-limitation of a system can significantly shift the relative influences of each factor. I also submit that significant reductions in the level of segregation in a metacommunity may be indicative of the introduction of a new invasive species, and such a signal should trigger directed management actions against the most recent invader to prevent them from achieving pest status.

\section{REFERENCES}

Adler, P. B., J. HilleRisLambers, and J. M. Levine. 2007. A niche for neutrality. Ecology Letters 10:95-104.

Amarasekare, P. 2003. Competitive coexistence in spatially structured environments: a synthesis. Ecology Letters 6:1109-1122.

Arrington, D. A., K. O. Winemiller, and C. a Layman. 2005. Community assembly at the patch scale in a species rich tropical river. Oecologia 144:157-67.

Bellmorea, J. R., C. V. Baxter, and P. J. Connolly. 2014. Spatial complexity reduces interaction strengths in the meta-food web of a river floodplain mosaic. Ecology 96:274-283.

Cucherousset, J., and J. D. Olden. 2011. Ecological Impacts of Non-native Freshwater Fishes. Fisheries 36:215-230.

Ellis, A. M., L. P. Lounibos, and M. Holyoak. 2006. Evaluating the long-term metacommunity dynamics of tree hole mosquitoes. Ecology 87:2582-2590.

Gianuca, A. T., S. A. J. Declerck, M. W. Cadotte, C. Souffreau, T. De Bie, and L. De Meester. 2016. Integrating trait and phylogenetic distances to assess scaledependent community assembly processes. Ecography:1-11.

Gotelli, N. J., and A. E. Arnett. 2000. Biogeographic effects of red fire ant invasion. Ecology Letters 3:257-261.

Holyoak, M., M. A. Liebold, and R. D. Holt. 2005. Metacommunities: Spatial dynamics and ecological communities. University of Chicago Press.

Hovel, K. A., and H. M. Regan. 2008. Using an individual-based model to examine the roles of habitat fragmentation and behavior on predator-prey relationships in seagrass landscapes. Landscape Ecology 23:75-89.

Kuebbing, S. E., L. Souza, and N. J. Sanders. 2014. Effects of co-occurring non-native invasive plant species on old-field succession. Forest Ecology and Management 324:196-204. 
Kuglerová, L., R. Jansson, R. A. Sponseller, H. Laudon, and B. Malm-Renöfält. 2014. Local and regional processes determine plant species richness in a river-network metacommunity. Ecology 96:140817224931000.

Logue, J. B., N. Mouquet, H. Peter, and H. Hillebrand. 2011. Empirical approaches to metacommunities: a review and comparison with theory. Trends in Ecology \& Evolution 26:482-91.

Loughnan, D., and B. Gilbert. 2017. Trait-mediated community assembly: distinguishing the signatures of biotic and abiotic filters. Oikos 126:1112-1122.

Muneepeerakul, R., E. Bertuzzo, H. J. Lynch, W. F. Fagan, A. Rinaldo, and I. RodriguezIturbe. 2008. Neutral metacommunity models predict fish diversity patterns in Mississippi-Missouri basin. Nature 453:220-222.

Mutshinda, C. M., and R. B. O'Hara. 2011. Integrating the niche and neutral perspectives on community structure and dynamics. Oecologia 166:241-251.

Petchey, O. L., and K. J. Gaston. 2006. Functional diversity: Back to basics and looking forward. Ecology Letters 9:741-758.

Reshi, Z., I. Rashid, A. A. Khuroo, and B. A. Wafai. 2008. Effect of invasion by Centaurea iberica on community assembly of a mountain grassland of Kashmir Himalaya, India. Tropical Ecology 49:147-156.

Richter-Boix, A., N. Garriga, A. Montori, M. Franch, O. San Sebastián, D. Villero, and G. a. Llorente. 2013. Effects of the non-native amphibian species Discoglossus pictus on the recipient amphibian community: niche overlap, competition and community organization. Biological Invasions 15:799-815.

Sanders, N. J., N. J. Gotelli, N. E. Heller, and D. M. Gordon. 2003. Community disassembly by an invasive species. Proceedings of the National Academy of Sciences of the United States of America 100:2474-7.

Stone, L., and A. Roberts. 1990. The checkerboard score and species distributions. Oecologia 85:74-79.

Ulrich, W., and N. J. Gotelli. 2013. Pattern detection in null model analysis. Oikos 122:2-18.

Violle, C., M. L. Navas, D. Vile, E. Kazakou, C. Fortunel, I. Hummel, and E. Garnier. 2007. Let the concept of trait be functional! Oikos 116:882-892.

Winegardner, A. K., B. K. Jones, I. S. Y. Ng, T. Siqueira, and K. Cottenie. 2012. The terminology of metacommunity ecology. Trends in Ecology \& Evolution 27:2534. 


\section{APPENDICES}

Appendix 1 Total number of each taxa caught in all solution holes combined in each year. Asterisk denotes non-native status.

\begin{tabular}{|c|c|c|c|}
\hline Species & Year 1 & Year 2 & Year 3 \\
\hline Ameiurus natalis & 333 & 16 & 0 \\
\hline Belonesox belizanus* & 35 & 12 & 29 \\
\hline Cichlasoma bimaculatum* & 74 & 8 & 2 \\
\hline Parachromis managuensis* & 1 & 0 & 1 \\
\hline Mayaheros urophthalmus* & 10 & 4 & 0 \\
\hline Clarias batrachus* & 26 & 19 & 21 \\
\hline Fundulus chrysotus & 15 & 65 & 40 \\
\hline Fundulus confluentus & 174 & 78 & 38 \\
\hline Fundulus grandis & 3 & 0 & 0 \\
\hline Fundulus seminolis & 3 & 0 & 0 \\
\hline Gambusia holbrooki & 343 & 684 & 973 \\
\hline Hemichromis letourneuxi* & 363 & 363 & 305 \\
\hline Heterandria formosa & 20 & 4 & 69 \\
\hline Hoplosternum littorale* & 0 & 0 & 2 \\
\hline Jordanella floridae & 10 & 203 & 21 \\
\hline Lepomis gulosus & 42 & 9 & 20 \\
\hline Lepomis macrochirus & 0 & 1 & 0 \\
\hline Lepomis marginatus & 30 & 42 & 34 \\
\hline Lepomis punctatus & 42 & 14 & 1 \\
\hline Lucania goodei & 4 & 2 & 7 \\
\hline Macrognathus siamensis* & 0 & 4 & 0 \\
\hline Monopterus albus* & 2 & 7 & 13 \\
\hline Poecilia latipinna & 22 & 122 & 64 \\
\hline Annual totals & 1552 & 1657 & 1640 \\
\hline
\end{tabular}


Appendix 2 Trait values and references for each species for all traits derived by literature review. Primary literature was used whenever possible. Secondary and gray literature were used only when no superior source was available.

\begin{tabular}{|c|c|c|c|}
\hline Trait & Species & Value & Reference \\
\hline \multicolumn{4}{|c|}{ Colonization tendency } \\
\hline (2) & $\begin{array}{l}\text { Amerius natilis } \\
\text { Belonesox belizanus } \\
\text { Cichlasoma bimaculatum } \\
\text { Clarias batrachus } \\
\text { Fundulus chrysotus } \\
\text { Fundulus confluentus } \\
\text { Fundulus grandis } \\
\text { Fundulus seminolis } \\
\text { Gambusia holbrookii } \\
\text { Hemichromis letourneuxi } \\
\text { Heterandria formosa } \\
\text { Hoplosternum littorale } \\
\text { Jordanella floridae } \\
\text { Lepomis gulosus } \\
\text { Lepomis machrochirus } \\
\text { Lepomis marginatus } \\
\text { Lepomis punctatus } \\
\text { Lucania goodei } \\
\text { Macrognathis siamensis } \\
\text { Mayaheros urophthalmus } \\
\text { Monopterus albus } \\
\text { Parachromis managuensis } \\
\text { Poecillia latininna }\end{array}$ & $\begin{array}{l}7.36 \\
3.90 \\
4.88 \\
3.67 \\
3.22 \\
1.19 \\
2.21 \\
2.21 \\
1.04 \\
8.17 \\
1.94 \\
3.67 \\
1.59 \\
6.43 \\
5.80 \\
1.86 \\
4.20 \\
5.69 \\
4.00 \\
7.08 \\
2.00 \\
8.00 \\
377\end{array}$ & $\begin{array}{l}\text { (Loftus et al. 2005) } \\
\text { (Loftus et al. 2005) } \\
\text { (Loftus et al. 2005) } \\
\text { (Loftus et al. 2005) } \\
\text { (Loftus et al. 2005) } \\
\text { (Loftus et al. 2005) } \\
\text { (Loftus et al. 2005) } \\
\text { (Loftus et al. 2005) } \\
\text { (Loftus et al. 2005) } \\
\text { (Loftus et al. 2005) } \\
\text { (Loftus et al. 2005) } \\
\text { (Loftus et al. 2005) } \\
\text { (Loftus et al. 2005) } \\
\text { (Loftus et al. 2005) } \\
\text { (Loftus et al. 2005) } \\
\text { (Loftus et al. 2005) } \\
\text { (Loftus et al. 2005) } \\
\text { (Loftus et al. 2005) } \\
\text { (Loftus et al. 2005) } \\
\text { (Loftus et al. 2005) } \\
\text { (Loftus et al. 2005) } \\
\text { (Loftus et al. 2005) } \\
\text { (Loftus et al 2005) }\end{array}$ \\
\hline \multicolumn{4}{|l|}{ Parental care } \\
\hline & Amerius natilis & 1 & (Frimpong and Angermeier 2009) \\
\hline
\end{tabular}




\begin{tabular}{|c|c|}
\hline & $\begin{array}{l}\text { Belonesox belizanus } \\
\text { Cichlasoma bimaculatum } \\
\text { Clarias batrachus } \\
\text { Fundulus chrysotus } \\
\text { Fundulus confluentus } \\
\text { Fundulus grandis } \\
\text { Fundulus seminolis } \\
\text { Gambusia holbrookii } \\
\text { Hemichromis letourneuxi } \\
\text { Heterandria formosa } \\
\text { Hoplosternum littorale } \\
\text { Jordanella floridae } \\
\text { Lepomis gulosus } \\
\text { Lepomis machrochirus } \\
\text { Lepomis marginatus } \\
\text { Lepomis punctatus } \\
\text { Lucania goodei } \\
\text { Macrognathis siamensis } \\
\text { Mayaheros urophthalmus } \\
\text { Monopterus albus } \\
\text { Parachromis managuensis } \\
\text { Poecillia latipinna }\end{array}$ \\
\hline \multirow{2}{*}{ Relative fecundity } & \\
\hline & $\begin{array}{l}\text { Ameiurus natalis } \\
\text { Belonesox belizanus } \\
\text { Cichlasoma bimaculatum } \\
\text { Parachromis managuensis } \\
\text { Mayaheros urophthalmus } \\
\text { Clarias batrachus } \\
\text { Fundulus chrysotus }\end{array}$ \\
\hline
\end{tabular}

3 (Frimpong and Angermeier 2009)

2 (Frimpong and Angermeier 2009)

1 (Frimpong and Angermeier 2009)

3 (Frimpong and Angermeier 2009)

3 (Frimpong and Angermeier 2009)

3 (Frimpong and Angermeier 2009)

3 (Frimpong and Angermeier 2009)

3 (Frimpong and Angermeier 2009)

2 (Frimpong and Angermeier 2009)

3 (Frimpong and Angermeier 2009)

3 (Frimpong and Angermeier 2009)

3 (Frimpong and Angermeier 2009)

1 (Frimpong and Angermeier 2009)

1 (Frimpong and Angermeier 2009)

1 (Frimpong and Angermeier 2009)

1 (Frimpong and Angermeier 2009)

3 (Frimpong and Angermeier 2009)

3 (Frimpong and Angermeier 2009)

2 (Frimpong and Angermeier 2009)

1 (Frimpong and Angermeier 2009)

2 (Frimpong and Angermeier 2009)

3 (Frimpong and Angermeier 2009)

$3 \quad$ (Froese and Pauly 2017)

$1 \quad$ (Froese and Pauly 2017)

3 (Mérona and Vigouroux 2012)

$4 \quad$ (Froese and Pauly 2017)

3 (Mérona and Vigouroux 2012)

$4 \quad$ (Froese and Pauly 2017)

$2 \quad$ (Froese and Pauly 2017) 


\begin{tabular}{|c|c|c|c|}
\hline & $\begin{array}{l}\text { Fundulus confluentus } \\
\text { Fundulus grandis } \\
\text { Fundulus seminolis } \\
\text { Gambusia holbrooki } \\
\text { Hemichromis letourneuxi } \\
\text { Heterandria formosa } \\
\text { Hoplosternum littorale } \\
\text { Jordanella floridae } \\
\text { Lepomis gulosus } \\
\text { Lepomis macrochirus } \\
\text { Lepomis marginatus } \\
\text { Lepomis punctatus } \\
\text { Lucania goodei } \\
\text { Macrognathus siamensis } \\
\text { Monopterus albus } \\
\text { Poecilia latipinna }\end{array}$ & $\begin{array}{l}2 \\
2 \\
2 \\
2 \\
2 \\
1 \\
3 \\
1 \\
4 \\
4 \\
4 \\
4 \\
2 \\
2 \\
3 \\
2\end{array}$ & $\begin{array}{l}\text { (Froese and Pauly 2017) } \\
\text { (Froese and Pauly 2017) } \\
\text { (Froese and Pauly 2017) } \\
\text { (Froese and Pauly 2017) } \\
\text { (Froese and Pauly 2017) } \\
\text { (Froese and Pauly 2017) } \\
\text { (Froese and Pauly 2017) } \\
\text { (Froese and Pauly 2017) } \\
\text { (Cooke and Phillip 2009) } \\
\text { (Coyle et al. 1993) } \\
\text { (Cooke and Phillip 2009) } \\
\text { (Cooke and Phillip 2009) } \\
\text { (Froese and Pauly 2017) } \\
\text { (Froese and Pauly 2017) } \\
\text { (Froese and Pauly 2017) } \\
\text { (Froese and Pauly 2017) }\end{array}$ \\
\hline Trophic level & $\begin{array}{l}\text { Ameiurus natalis } \\
\text { Belonesox belizanus } \\
\text { Cichlasoma bimaculatum } \\
\text { Parachromis managuensis } \\
\text { Mayaheros urophthalmus } \\
\text { Clarias batrachus } \\
\text { Fundulus chrysotus } \\
\text { Fundulus confluentus } \\
\text { Fundulus grandis } \\
\text { Fundulus seminolis } \\
\text { Gambusia holbrooki } \\
\text { Hemichromis letourneuxi } \\
\text { Heterandria formosa }\end{array}$ & $\begin{array}{l}3.3 \\
2.9 \\
3.6 \\
4.0 \\
3.9 \\
3.4 \\
3.2 \\
3.2 \\
3.4 \\
3.3 \\
3.1 \\
3.0 \\
2.7\end{array}$ & $\begin{array}{l}\text { (Froese and Pauly 2017) } \\
\text { (Froese and Pauly 2017) } \\
\text { (Froese and Pauly 2017) } \\
\text { (Froese and Pauly 2017) } \\
\text { (Froese and Pauly 2017) } \\
\text { (Froese and Pauly 2017) } \\
\text { (Froese and Pauly 2017) } \\
\text { (Froese and Pauly 2017) } \\
\text { (Froese and Pauly 2017) } \\
\text { (Froese and Pauly 2017) } \\
\text { (Froese and Pauly 2017) } \\
\text { (Froese and Pauly 2017) } \\
\text { (Froese and Pauly 2017) }\end{array}$ \\
\hline
\end{tabular}


Hoplosternum littorale Jordanella floridae

Lepomis gulosus

Lepomis macrochirus

Lepomis marginatus

Lepomis punctatus

Lucania goodei

Macrognathus siamensis

Monopterus albus

Poecilia latipinna
$2.7 \quad$ (Froese and Pauly 2017)

$2.9 \quad$ (Froese and Pauly 2017)

$3.4 \quad$ (Froese and Pauly 2017)

3.2 (Froese and Pauly 2017)

3.3 (Froese and Pauly 2017)

3.4 (Froese and Pauly 2017)

3.2 (Froese and Pauly 2017)

3.3 (Froese and Pauly 2017)

2.9 (Froese and Pauly 2017)

$2.0 \quad$ (Froese and Pauly 2017) 
Appendix 3 Overview, Details and Design (ODD) for the model used in chapter 3.

OVERVIEW

Purpose

The primary purpose of this model was to demonstrate one mechanism by which intraspecific variability of individual personalities, in this case sociability, can influence key metapopulation parameters at multiple scales, via colonization mediation, during reassembly, and how this interacts with dispersal window length.

This model addressed the primary question: Can sociability structure a metapopulation in space and time?

Specifically, it was designed to evaluate the hypotheses in Table 7.

Entities, state variables and scales

\section{Entities:}

This model is designed to simulate an ephemeral floodplain system where pools are distributed along a landscape which is seasonally connected to a single source population. This model had two entities: fish (turtles) and patches.

\section{State variables:}

Fish: Each fish had one state variable of sociability, which placed them in to one of four categories based on the range of their sociability scores: social, asocial, normally distributed, or neutral (a no personality control) which was selected by the user before initialization. All personality scores were drawn randomly from a beta distribution and bound to greater than 0.5 for social, less than 0.5 for asocial. This sociability score 
determined an individual's preferred conspecific density, which they sought to achieve, by

$$
\text { Preferred density = sociability score } * \text { maximum target density }
$$

where the acceptable local density range is set by

$$
\text { Preferred density } * 0.75<\text { local density }<\text { Preferred density } * 1.25
$$

They were able to move a maximum of $3,000 \mathrm{~m}$ in a single day (tick), which has been estimated to be a reasonable maximum linear dispersal distance for Gambusia holbrooki, a common small-bodied poeciliid fish which is a congener of the most commonly studied fish in sociability studies, Gambusia affinis (Cote et al., 2011), in the Everglades (J Gatto unpublished data). Fish were also characterized by their discrete location and a "hang out" probability which reduces by $10 \%$ each day the fish was in a pool that did not contain an acceptable local density and is dependent on their individual sociability. When queried, each fish reported their local density and the total distance traveled during the run.

Patches: Patches had one categorical state variable of depth, which in this model was either 0 or -1 (an arbitrary negative value). When depth is less than 0 a patch is considered viable, henceforth called pools. When it is not, then fish are able to cross the patch, meta-system matrix, but will not consider staying there. At the end of the run, any fish not in a patch with depth less than 0 died.

Spatial scale: This model used a generalized form of the Rocky Glades region of the Everglades ecosystem as a model ephemeral floodplain with a single source (Figure 19). 
All fish start with an $\mathrm{x}$ coordinate less than 5 and a random y coordinate, to represent starting in the source area. The world itself is bound as a box, and consists of $200 * 100$ regular square patches each representing $100 \mathrm{~m}$ of the model system. Therefore, when scaled to reality this model simulated a $20,000 * 10,000 \mathrm{~m}$ marsh with the source at the western edge of the system. The real marsh is approximately $20 \mathrm{~km}$ wide and previous work has suggested that the primary source of colonists to this area are from the western Shark River Slough. While the Rocky Glades themselves are taller than $10 \mathrm{~km}$, it is reasonable to assume that few fish exhibit the rheotaxis necessary to move too distantly North, while the southern edge can be used to represent the Main Park Road which likely serves as a dispersal barrier for most fishes. 


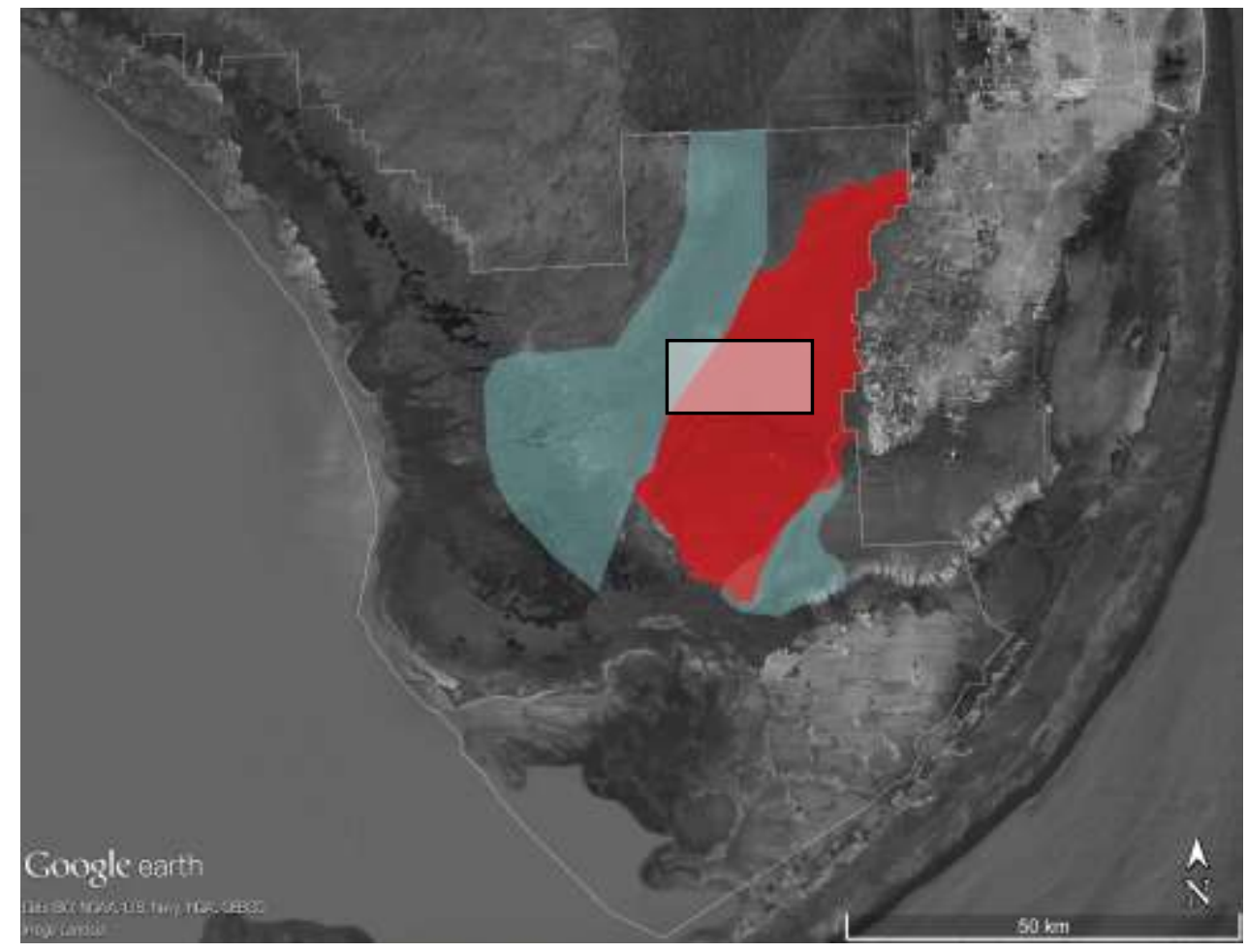

Figure 19 Map of Everglades national park (outlined in white) with the model system, the Rocky Glades, shown in red and the longest hydroperiod regions (Shark River Slough, west, and Taylor Slough east) shown in blue. Previous work suggests that Shark River Slough is the primary source community for fishes entering the Rocky Glades. Main Park Road, shown in black likely inhibits most southerly dispersal. The shaded black box approximates the area simulated in this model.

\section{PROCESS, OVERVIEW AND SCHEDULING}

When the model was initialized, pools were generated in a fixed arrangement, the coordinates of which were generated once by randomly placing 50 pools in the marsh. All pools were assigned a depth of -1 . No environmental gradients were imposed in this model. While this detracts from the reality of the model system, additional complexity would distract from the purpose of this first model. 1000 fish were generated with one of four sociability beta-distributions: social, asocial, normal or neutral (Figure 20), in the 
source area using the parameters found in Table 9. A beta distribution was chosen as it is bound between 0 and 1, and the two input parameters allow for skewed sociability distributions.

Table 9 Parameters used to generate random beta distributions from which sociability scores were drawn for the population. Note that neutral populations had no personality.

\begin{tabular}{l|ll} 
Population & $\alpha$ & $\mathrm{B}$ \\
\hline \hline Neutral & - & - \\
Social & 10 & 2 \\
Normal & 2 & 2 \\
Asocial & 2 & 10
\end{tabular}



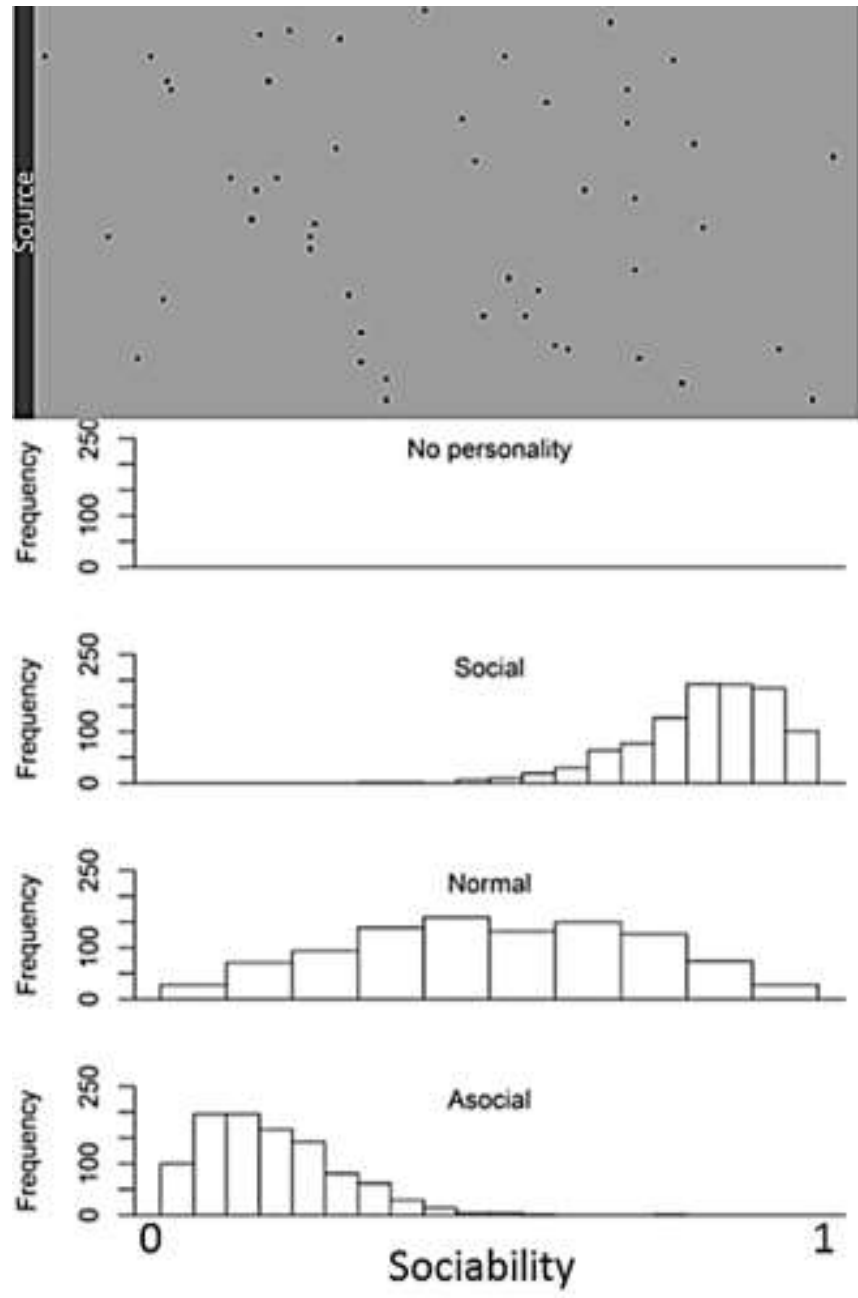

Figure 20 The top panel shows the model landscape with black patches representing pools, the dark western bar shows the source area and the gray area is the dispersal matrix. Example distributions of sociability for each of the populations which contain intraspecific variability.

On each tick, day, fish moved in the bottom-up ranked order of their sociability scores, in accordance with the hypothesized mechanism put forth by Cote et al. (2010). Movement was comprised of two sequential processes: pool searching and conspecific evaluation. If a pool was determined to be unsatisfactory, then a sub-procedure of the conspecific evaluation determined (with $10 \%$ daily reductions in probability) if the fish would remain or leave. 
Pool searching: Every fish was required to find a pool before it could make any other decisions. Fish did this by first checking if the patch it was on, or those within their maximum search radius $(0.25 *$ the maximum daily linear distance they can move), had a depth less than 0. If so, then they centered themselves on that pool and evaluated the conspecific density (except neutral fish, which simply stopped at the pool and emigration was decided randomly with $50 \%$ probability each day). If they started the day in a pool, then they observed the surrounding area. If there was a pool nearby they would go there and evaluate the conspecific density. If no pools were nearby, then they began a circular search procedure. If they had found a pool recently, but it lacked an acceptable density, the fish would use a tight search procedure. However, if too long passed without finding a new pool then the fish used a broader search pattern. When they found a pool, they evaluated the conspecific density. A key feature of this search protocol is that the fish remembered the last pool it evaluated and would not settle in to it again until it found a different pool. This prevented the fish from getting 'stuck' continually returning to and re-evaluating a single pool.

Conspecific density evaluation: A fish decided if it should stay in a pool by first evaluating the conspecific density, considering any value between $\pm 0.25 *$ Preferred density as acceptable. If the density was acceptable, then the fish stayed where it was and set the probability of remaining to maximum. If the pool was unacceptable then the fish decided daily, with a daily $10 \%$ reduction in probability, if they should stay to wait for conditions to improve. The initial value of the staying probability was calculated as the maximum allowable wait time (five days) * their individual sociability scores such that asocial fishes had a higher probability of leaving sooner than social fishes. If a fish 
decided to abandon the pool, it noted the location of the pool and on the following day it would begin the pool search procedure anew. If it re-encountered that same pool before finding a new one then the pool was ignored; however, the fish's memory only extended to the most recently evaluated pool.

\section{DESIGN CONCEPTS}

Basic principles: Metapopulation structure emerges from the dispersal of propagules among patches embedded in a low-quality matrix (Hanski and Gilpin 1991). The reason and rate at which these propagules disperse (Gotelli 1991), the pathways they use (Baguette and Van Dyck 2007, Altermatt et al. 2011), and their use of environmental information (Proulx et al. 2013) as it relates to immigration and emigration have dominated the metapopulation discussion. Typically, these individual propagules are considered functional equivalents within a metapopulation. However, recent works have demonstrated that intraspecific trait variation can influence emergent metapopulation structure through dispersal mediation (e.g., Hawkes, 2009; Sutherland et al., 2014). Of the traits influencing dispersal, personality-type (PT) is now recognized as a particularly important behavioral trait mediating metapopulation structure (Conrad et al. 2011, Spiegel et al. 2017).

A PT, also referred to as behavioral-type, is the consistent response of individuals to given stimuli, relative to conspecifics, regardless of environmental context (Sih et al. 2004, 2012, Conrad et al. 2011, Wolf and Weissing 2012). Variation in PT has been demonstrated to influence key features of metapopulation dynamics, such as propagule dispersal tendencies (Duckworth and Badyaev 2007, Cote et al. 2010a, Myles-Gonzalez 
et al. 2015), dispersal speed (Maes et al. 2013), dispersal distances (Cote et al. 2010b), competitive abilities (Groen et al. 2012, Capelle et al. 2015), physiological states (MylesGonzalez et al. 2015), parental abilities (Duckworth and Badyaev 2007), and colonization behaviors (Duckworth 2008, Groen et al. 2012). To influence metapopulation structure through dispersal, a single PT needs to, at minimum, affect both the spatial (e.g., distance) and temporal (e.g., speed) components of dispersal, at ecologically-relevant scales. Typically, this is considered by way of the personality dependent dispersal (PDD) concept, which relies on the idea that an individual's personality is going to be a primary determinant of their net dispersal behavior. Most often PDD is studied as a function of boldness or life-history related personality traits. Work to date has shown that the spatiotemporal distribution of animals can be influenced by their boldness and aggression, with fitness consequences and related energetic tradeoffs, such that more bold and aggressive individuals tend to travel first and furthest. Sociability, the propensity of an individual to associate with conspecifics (Cote and Clobert 2007), has also been suggested to affect both of these aspects of dispersal by mediating emigration and immigration probabilities, as well as dispersal distances (Cote et al., 2010a; 2010b). However, it has received far less experimental attention than other traits.

The potential for sociability to influence metapopulation structure stems from density-dependent individual decisions influenced by patch conditions. As first conceptualized by Cote et al. (2010b), asocial individuals or those that prefer low conspecific densities, disperse away from high density source patches in search of preferable conditions. In doing so, the patch may be sufficiently depleted as to encourage emigration of social individuals in search of conspecifics. Multiple iterations of this result 
in a metapopulation being structured in both space and time, with the emergent structure depending on the population's sociability and the length of the dispersal-window (Cote et al. 2010a). Some evidence exists for this, at small spatial scales. Cote et al (2010a) demonstrated a negative relationship between sociability, and individual dispersal distances in a fish mesocosm. Similarly, in a reptile macrocosm, dispersal from low density patches was attributed to higher sociality, and visa-versa (Cote and Clobert 2007). However, there is still a lack of information regarding how this translates to ecologically relevant spatial scales (10s-100s of $\mathrm{km})$, and how it interacts with time.

This knowledge gap is particularly pressing because, while many habitats are temporally stable with functionally unlimited dispersal-windows, dispersal-window lengths in ephemeral landscapes are often tied to climatic patterns via hydrology (Lindenmayer and Hobbs 2007). As the global climate shifts, many ephemeral landscapes may experience changes to the drivers of their dispersal-windows, resulting in currently not understood changes to the spatiotemporal structures of metapopulations. To understand these effects, we need to understand how changes in dispersal-windows influence temporally-dependent dispersal mechanisms, such as sociability-dependent dispersal (SDD). To begin filling this need, and to evaluate the effects of SDD at ecologically relevant spatiotemporal scales, we used a simulation approach to test and refine hypotheses of metapopulation structuring, at multiple scales (individual, local and regional), which can be directly evaluated in future field-based studies.

For this simulation, our goal was to build an understanding of observable SDD patterns in ephemeral metapopulations. To do this, we built a behavioral individual-based 
model (IBM), parameterized with information from an existing ephemeral wetland; short hydroperiod wetlands in the Everglades. Using this IBM, we experimentally manipulated the sociability of individuals (fishes) and dispersal-windows (relative to a no personality, neutral, control), to examine the effects of SDD on the dispersal distances of individuals, the density of individuals within patches, and the proportion of the landscape colonized (see Table 1 for detailed hypotheses). We also examined the interacting effects of sociability and varying dispersal windows (long vs. short) on these three variables. Per results of the model, we refine these hypotheses and suggest how each could be tested with a long-term field study aimed at understanding the role of SDD in real-world metapopulation structuring, and how this will interact with shifting climatic regimes to alter contemporary patterns.

Emergence: This model demonstrated how spatiotemporal patterns of metapopulation structure can emerge from individual variation in personality. Specifically, it showed a relationship between dispersal distance and individual sociability, a lack of association between landscape occupation and population sociability, and a relationship between mean population sociability and distance from the source.

Adaptation: At each time step, each individual decided whether or not to move based on the depth of their current patch, and if in a pool then the decision was based on their own sociability as it related to local and regional conspecific densities over time.

Objectives: Agents had only a sociability-based objective to optimize local conspecific density by abandoning found pools which did not contain an acceptable conspecific density. However, to account for the possibility of an unacceptable pool becoming 
acceptable, the fish waited for a short time before abandoning the pool to search for a new one. The length of time they will was dependent on their individual sociability, with asocials waiting the least amount of time, and the probability of remaining in an unsuitable pool decreases by $10 \%$ each day.

Learning: The only learning fish were capable of was the ability to remember the last pool they evaluated by refusing to spend time evaluating/settling in to that pool, and to keep track of how long it had been since they settled in to an unacceptable pool as well as how long they spend dispersing after abandoning a pool. They forgot the pool after another was found. No prior knowledge of the system was inherent at the start of the run.

Sensing: Each individual fish had total knowledge of their maximum search radius, which was $25 \%$ of the maximum linear distance it could move. This was assumed to be the area a fish could intensively search in a single day; however, future works should evaluate this assumption.

Interaction: The only interaction between fish was mediated through pool density.

Stochasticity: When no specific direction was determined by objective seeking, movement direction and distance were determined using random number generators under various constraints. Individual sociability was also drawn randomly from a beta distribution, except for the neutral (no personality) control populations.

Collectives: The formation of population collectives emerges from individual fish's decisions regarding settlement and emigration, as part of their sociability-based objective. Observation: To evaluate if the model was operating properly, the model output: 
- The percentage of fish which survived.

- The percentage of survivors which successfully attained their target conspecific density.

- Mean, median, modes and standard deviation of the density of occupied pools.

- Mean, median, modes and standard deviation of the target density of fish.

- Raw density of all pools over space.

- Mean total distance traveled by all surviving fish.

Additionally, for better visualization of a single agents actions and verification of model performance, an option was included via toggle switch to shrinks all fish except one random fish which was then inspected, watched, asked to draw its path and highlight its total search radius each day.

To demonstrate that individual personalities can increase the spatial structuring of a metapopulation, the model output: the mean density of occupied pools and their associated $\mathrm{x}$ coordinate, the total distance traveled by each individual, and the sociability score of all agents paired with their $\mathrm{x}$ and $\mathrm{y}$ coordinates on the Cartesian plane. These values were compared between all four sociability distributions and two dispersal window lengths.

\section{DETAILS}

Initialization: The model was initialized with pools arranged in fixed arrangement with a corner origin (Figure 20). This western 5 columns were the source area, within which 1000 fish were randomly distributed. Individual fish receive a sociability score from one of four distributions, depending on the treatment being tested (Figure 20, Table 9). The 
maximum daily traversable distance was set to 30 patches, which represented $3 \mathrm{~km}$ and has been found in recent studies to be a reasonable maximum potential daily movement limit for Gambusia holbrooki (J Gatto, unpublished data), the most common fish in the model system (Kobza et al. 2004, Kline et al. 2014).

Input data: The landscape required input of a depth matrix, which was generated by randomly placing 50 pools in the matrix. This allowed for a random distribution of pools in the landscape, while controlling for any effect of pool location stochasticity on the model. No other aspects of the model required input data.

Sub-models: A complete flow diagram of all sub-models and decision trees is provided in Figure 21.

Control_pool_search: If a neutral (control) population was called, this procedure told the population to first make note of where they were with reference to where they have been in the past. If a fish started the day in a pool, it determined if it should stay or leave by generating a random number between -1 and 101 . If the number generated was greater than 50, it stopped, if not, it left the pool. If a fish started outside a pool it first evaluated if the local depth was greater than any of the other patches in the searchable radius, and if any of those other patches are pools. If they were, then the fish moved to one of the patches in the searchable radius with the minimum depth of the area and stopped. If the local patch and surrounding patches were not pools, then it engaged in the new_pool_search procedure.

New_pool_search: If the time since the last new pool was found was less than $10 \%$ of the total run time, then the fish turned to the right at a random real angle less than $181^{\circ}$. If 
not, then the fish turned right at a random real angle less than $361^{\circ}$. After turning the fish moved at a random real distance less than the maximum distance a single fish can move in a single day.

Pool_search: For all non-neutral distributions, this procedure told the population to first make note of where they were with reference to where they had been in the recent past, and if they were in a pool then it told them to decide if they should stay using the should_I_hang_out procedure. If the fish was not in a pool it looked to see if there was one nearby, if so the it went there. If not, then it ran new_pool_search.

Should_I_hang_out: This procedure decided if a fish found the pool acceptable. In this context, acceptable was defined as having a local density within $25 \%$ of the individual's target density (sociability * maximum target density). If the pool was acceptable, the fish stayed. If not, then it randomly decided if it should stay or not. The maximum probability of staying in a pool was determined by the global MAX_HANG_OUT_TIME * SOCIABILITY, with a daily $10 \%$ decrease. This counter was compared to a randomly drawn real number. If the randomly drawn number was greater than the current value of the counter, the fish abandoned the patch on the following day. $M A X \_H A N G \_O U T \_T I M E$ was set to five days, as a sensitivity analysis indicated the model was sensitive to values below, but not above five days. 


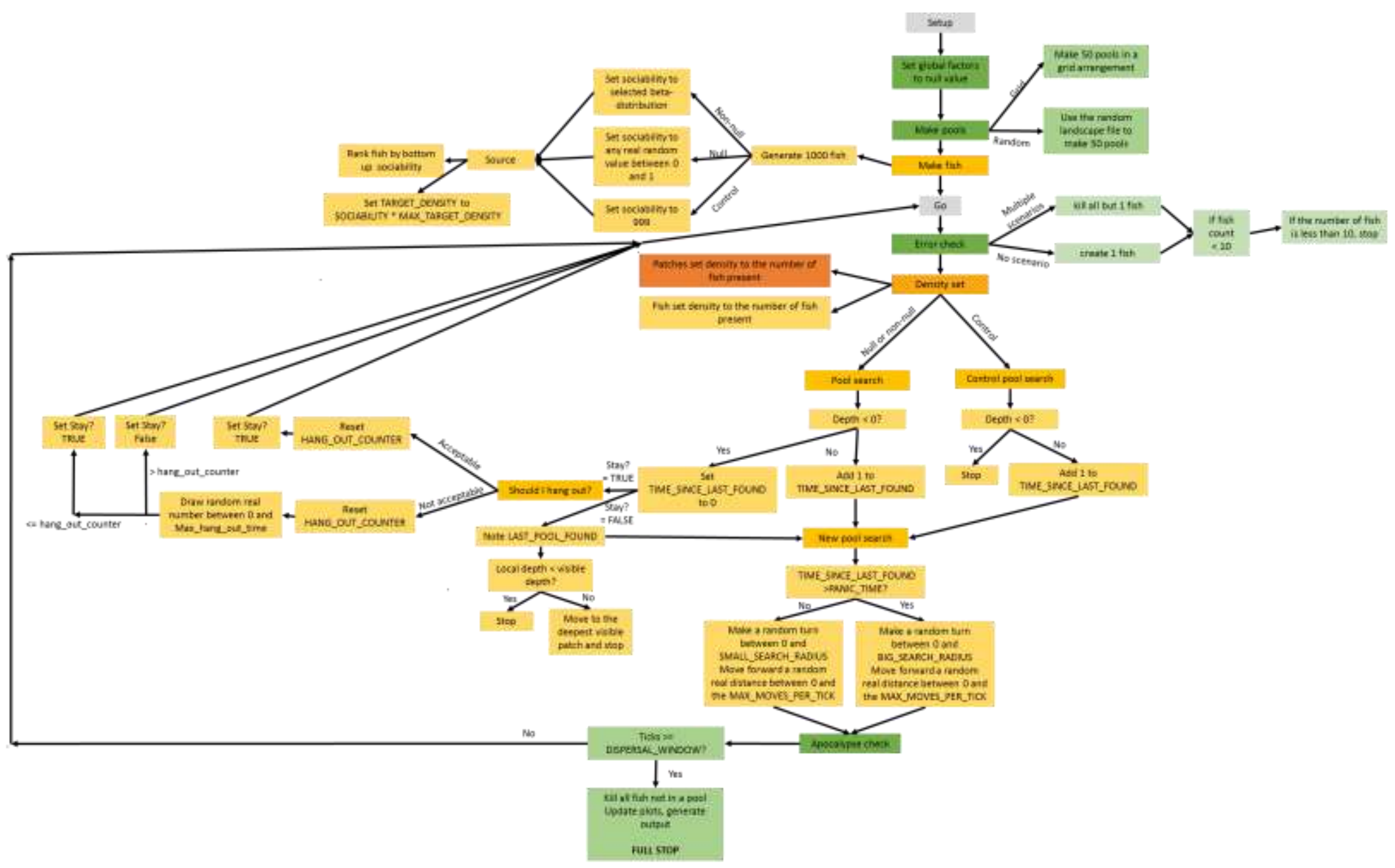

Figure 21 Conceptual flow diagram of the model. Grey represents user interface buttons, green shows initialization procedures, orange shows patch processes yellow represents fish (turtle) processes. Lighter colors indicate features of the preceding process. Words in all capitals are model parameters. 


\section{REFERENCES}

Cadotte, M.W., 2007. Competition-Colonization Trade-offs and Disturbance Effects at Multiple Scales. Ecology 88, 823-829.

Conrad, J.L., Weinersmith, K.L., Brodin, T., Saltz, J.B., Sih, A., 2011. Behavioural syndromes in fishes: a review with implications for ecology and fisheries management. J. Fish Biol. 78, 395-435. doi:10.1111/j.1095-8649.2010.02874.x

Cote, J., Clobert, J., Brodin, T., Fogarty, S., Sih, A., 2010. Personality-dependent dispersal: characterization, ontogeny and consequences for spatially structured populations. Philos. Trans. R. Soc. Lond. B. Biol. Sci. 365, 4065-76. doi:10.1098/rstb.2010.0176

Cote, J., Fogarty, S., Brodin, T., Weinersmith, K., Sih, A., 2011. Personality-dependent dispersal in the invasive mosquitofish: group composition matters. Proc. R. Soc. Biol. Sci. 278, 1670-8. doi:10.1098/rspb.2010.1892

Cote, J., Fogarty, S., Weinersmith, K., Brodin, T., Sih, A., 2010. Personality traits and dispersal tendency in the invasive mosquitofish (Gambusia affinis). Proc. R. Soc. Biol. Sci. 277, 1571-9. doi:10.1098/rspb.2009.2128

Duckworth, R. a., 2006. Aggressive behaviour affects selection on morphology by influencing settlement patterns in a passerine bird. Proc. Biol. Sci. 273, 1789-95. doi:10.1098/rspb.2006.3517

Duckworth, R. a., Badyaev, A. V, 2007. Coupling of dispersal and aggression facilitates the rapid range expansion of a passerine bird. Proc. Natl. Acad. Sci. U. S. A. 104, 15017-22. doi:10.1073/pnas.0706174104

Heino, J., Nokela, T., Soininen, J., Tolkkinen, M., Virtanen, L., Virtanen, R., 2015. Elements of metacommunity structure and community- environment relationships in stream organisms. Freshw. Biol. 60, 973-988. doi:10.1111/fwb.12556

Holyoak, M., Liebold, M.A., Holt, R.D., 2005. Metacommunities.

Kadowaki, K., Leschen, R. a. B., Beggs, J.R., 2011. Competition-colonization dynamics of spore-feeding beetles on the long-lived bracket fungi Ganoderma in New Zealand native forest. Oikos 120, 776-786. doi:10.1111/j.16000706.2011.19302.x

Kline, J. L. et al. 2014. Recent Fish Introductions Into Everglades National Park: An Unforeseen Consequence of Water Management? - Wetlands 34: 175-187.

Kobza, R.M., Trexler, J.C., Loftus, W.F., Perry, S.A., 2004. Community structure of fishes inhabiting aquatic refuges in a threatened Karst wetland and its 
implications for ecosystem management. Biol. Conserv. 116, 153-165. doi:10.1016/S0006-3207(03)00186-1

Meldrum, G.E., 2012. Interactive effects of dispersal rate and disturbance synchrony on microarthropod diversity at multiple spatial scales: resuce effects do not increase regional richness. The University of British Colombia.

Myles-Gonzalez, E., Burness, G., Yavno, S., Rooke, A., Fox, M.G., 2015. To boldly go where no goby has gone before: boldness, dispersal tendency, and metabolism at the invasion front. Behav. Ecol. In Press. doi:10.1093/beheco/arv050

Pintor, L.M., Sih, A., Bauer, M.L., 2008. Differences in aggression, activity and boldness between native and introduced populations of an invasive crayfish. Oikos 117, 1629-1636. doi:10.1111/j.1600-0706.2008.16578.x

Sih, A., Cote, J., Evans, M., Fogarty, S., Pruitt, J., 2012. Ecological implications of behavioural syndromes. Ecol. Lett. 15, 278-89. doi:10.1111/j.14610248.2011.01731.x

Truhlar, A.M., Aldridge, D.C., 2014. Differences in behavioural traits between two potentially invasive amphipods, Dikerogammarus villosus and Gammarus pulex. Biol. Invasions 1569-1579. doi:10.1007/s10530-014-0816-9

Wey, T.W., Spiegel, O., MOntiglio, P., Mabry, K.E., 2015. Natal dispersal in a social landscape: Considering individual behavioral phenotypes and social environment in dispersal ecology. Curr. Zool. 61, 543-556. 
VITA

JESSE R. BLANCHARD

2009

B.Sc. Marine biology

Florida Institute of Technology

Melbourne, FL

2010

B.Sc. Aquaculture

Florida Institute of Technology

Melbourne, FL

2010

OPS Biologist I

Florida Fish and Wildlife Institute

Melbourne, FL

2011

Teaching Assistant

Florida Institute of Technology

Melbourne, FL

2012

M.Sc. Marine biology

Florida Institute of Technology

Melbourne, FL

2012

Adjunct Professor

Eastern Florida State College

Palm Bay, FL

2012-2018

Teaching Assistant

Florida International University

Miami, FL

2012-2013

Vice President- Florida American

Fisheries Society Student Section

2013-2014

President- Ecological Society of

America Physiological Ecology

Student Section

2018

Doctoral Candidate

Florida International University

Miami, FL 


\section{PUBLICATIONS AND PRESENTATIONS}

Rehage, J. S., J. R. Blanchard, R. E. Boucek, J. J. Lorenz, and M. Robinson. 2016.

Knocking back invasions: variable resistance and resilience to multiple cold spells in native vs nonnative fishes. Ecosphere 7:1-13.

Rehage, J. S., and J. R. Blanchard. 2016. What Can We Expect from Climate Change for Species Invasions? Fisheries 41:405-407.

2018. “Trait-based metacommunity assembly: what traits matter when?” Blanchard, J.R., J.S. Rehage. FIU Earth and Environment Graduate Research Symposium.

2017. "Individual personalities can structure metapopulations in both space and time: implications for invasion management." Blanchard, J.R. Annual meeting of F.I.S.H.

2017. "Knocking back invasions: variable resistance and resilience to multiple cold spells in native and nonnative fishes." Blanchard, J.R., J.S. Rehage, M. Robinson, J.J. Lorenz. Annual meeting of the American Fisheries Society.

2017. "Fish in marl prairies- Disturbance severity, invasions, traits and emergent community structure.” Blanchard, J.R., J.S. Rehage. Greater Everglades Ecosystem Restoration conference.

2017. "Searching for the missing variance: individual personalities structuring dispersal limited metapopulations.” Blanchard, J.R., R.O. Santos, J.S.Rehage. FIU Earth and Environment Graduate Symposium.

2016. "Ephemeral metacommunity reassembly: how do functional traits influence assembly?" Blanchard, J.R., Rehage, J.S. annual meeting of the Ecological Society of America

2016. "Knocking back invasions: variable resistance and resilience to multiple cold spells in native vs. nonnative fishes.” Rehage,J.S., Blanchard, J.R., Boucek, R.B. SFL Non-native Fish Chat

2016. "What drives ephemeral metacommunity assembly?” Blanchard, J.R., J.S. Rehage. FIU Earth and Environment Graduate Symposium.

2016. Investigating the influence of behavioral types and nonnative species on ephemal metacommunity assembly. Blanchard, J.R. Proposal defense.

2014. Rocky Glades Studies: invasive influence on metacommunity assembly, native behavior and parasite assemblages. Blanchard, J.R., V. Trujillo, C. Beck, J. Rehage. SFL Non-native Fish Chat 